\title{
Heat balance analysis of annealing and galvanneal furnace in continuous galvanizing lines
}

\author{
Senthil Kumar Sundaramoorthy \\ West Virginia University
}

Follow this and additional works at: https://researchrepository.wvu.edu/etd

\section{Recommended Citation}

Sundaramoorthy, Senthil Kumar, "Heat balance analysis of annealing and galvanneal furnace in continuous galvanizing lines" (2010). Graduate Theses, Dissertations, and Problem Reports. 4661. https://researchrepository.wvu.edu/etd/4661

This Thesis is protected by copyright and/or related rights. It has been brought to you by the The Research Repository @ WVU with permission from the rights-holder(s). You are free to use this Thesis in any way that is permitted by the copyright and related rights legislation that applies to your use. For other uses you must obtain permission from the rights-holder(s) directly, unless additional rights are indicated by a Creative Commons license in the record and/ or on the work itself. This Thesis has been accepted for inclusion in WVU Graduate Theses, Dissertations, and Problem Reports collection by an authorized administrator of The Research Repository @ WVU. For more information, please contact researchrepository@mail.wvu.edu. 


\title{
HEAT BALANCE ANALYSIS OF ANNEALING AND GALVANNEAL FURNACE IN CONTINUOUS GALVANIZING LINES
}

\author{
Senthil Kumar Sundaramoorthy
}

\author{
Thesis submitted to the \\ College of Engineering and Mineral Resources \\ at West Virginia University \\ in partial fulfillment of the requirements \\ for the degree of
}

\author{
Master of Science \\ in \\ Industrial Engineering \\ Bhaskaran Gopalakrishnan, Ph.D., Chair \\ Robert Creese, Ph.D. \\ Xingbo Liu, Ph.D. \\ Frank Goodwin, Ph.D.
}
Department of Industrial and Management Systems Engineering
Morgantown, West Virginia
2010
Keywords: Heat Balance, Continuous Galvanizing, Energy Consumption, Heat Losses, Galvanizing Parameters.

Copyright 2010 Senthil K. Sundaramoorthy 


\section{ABSTRACT \\ Heat Balance Analysis of Annealing and Galvanneal Furnace in Continuous Galvanizing Lines}

\section{Senthil Kumar Sundaramoorthy}

Galvanizing facilities are highly energy intensive operation with electrical and fuel energy representing a significant share of their total energy usage. Furnaces are extensively used in galvanizing process. Production process expertise along with the energy conservation practices can play a significant role in proper usage of energy at galvanizing facilities. Therefore, benchmarking galvanizing energy consumption and understanding the specific energy consumption by various elements are critical. E-GEPDSS (Enhanced Galvanizing Energy Profiler Decision Support System) was built to identify this specific energy consumption by using heat balance analysis. The use of E-GEPDSS does not hinder the production process and the user may run the model for different set of operating conditions and observe the results. The results obtained from the analysis will help the user to make energy enhancing decisions.

This research involved the analysis of galvanizing operations focusing on the furnace side of energy consumption. The furnace heat balance was built and applied using the data collected from a host company during the plant visit. Sensitivity analysis were done to study the impact of changing process and product parameters on the total heat loss from the system.

From the energy analysis conducted for the furnace equipment at the host facility, it was found that the useful heat absorbed by the product is only $50 \%$ of the heat supplied to the furnace and rest of heat dissipates as losses. Heat losses from surfaces, walls, water cooling and stack are significant. Heat loss due to opening and phase change heat loss seem not to be significant. Emissivity, dimensions of the furnace, temperature of the zones, thermal conductivity of insulation materials and the strip temperature at the entry and exit of each zone have significant impact on the total heat loss. In the future, the model will be applied extensively to more galvanizing lines in order to help the galvanizers to have a better understanding about the energy consumption while producing their product. 


\section{Acknowledgement}

I would like to wholeheartedly thank my advisor, Dr. B. Gopalakrishnan, for his continued support, guidance, and encouragement during my entire course of graduate studies at WVU and during the conduct of this research work.

I would also like to thank my research committee members, Dr. Robert Creese and Dr. Xingbo Liu for their constant advice and support and for providing me a scientific perspective to the analytical approach used in this research.

I would like to extend my special thanks to Dr. Frank Goodwin, and Galvanized Auto body Partnership members who made it possible to collect the invaluable data required for this research.

I would also like to thank Mr. Michel Dubois for his suggestions and feedback on the heat balance concepts.

Above all, I wish to thank God, my loving parents, my sister and all my friends for their constant support and blessings and enabling my success and happiness in all my pursuits and endeavors in life.

Senthil Kumar Sundaramoorthy 


\section{TABLE OF CONTENTS}

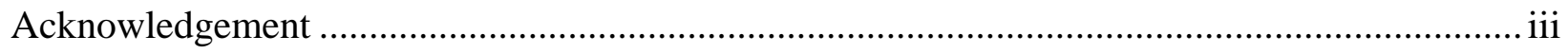

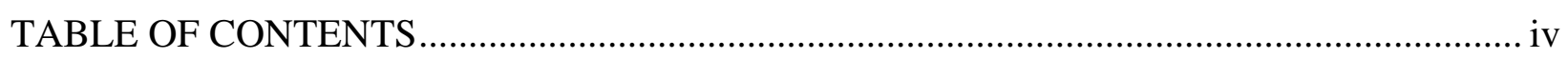

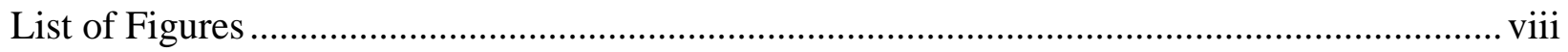

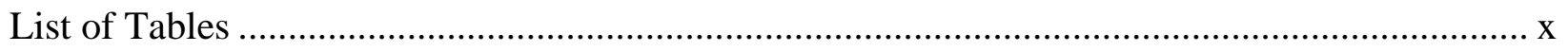

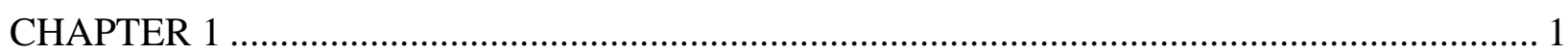

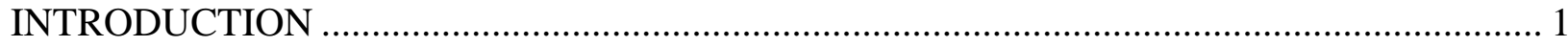

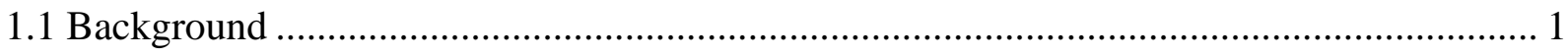

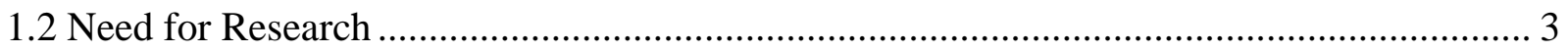

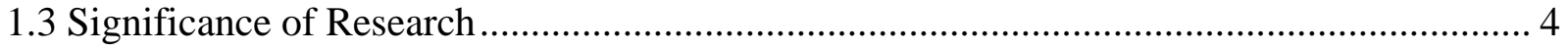

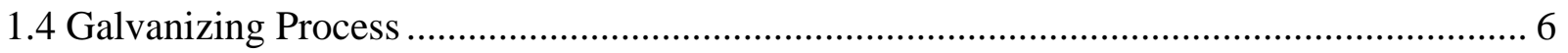

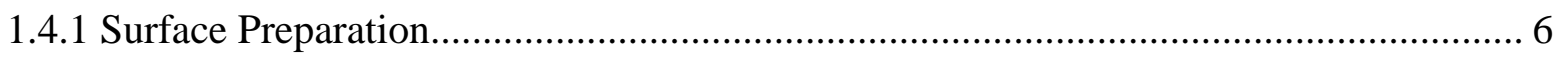

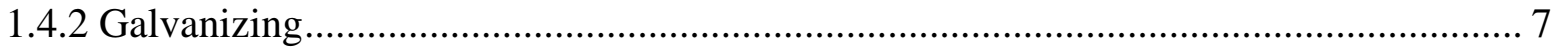

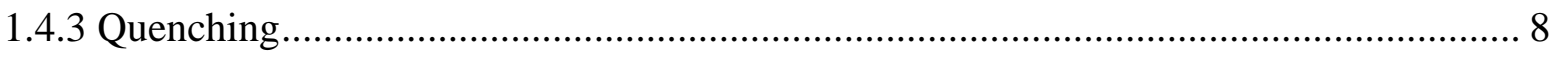

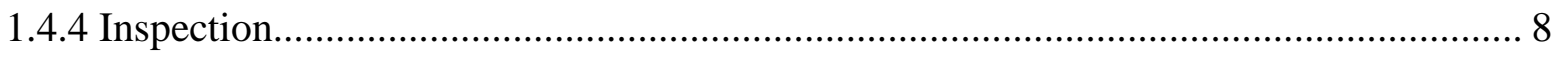

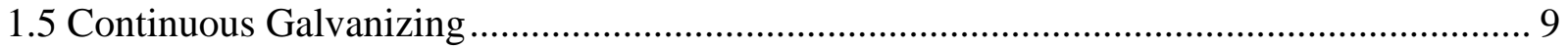

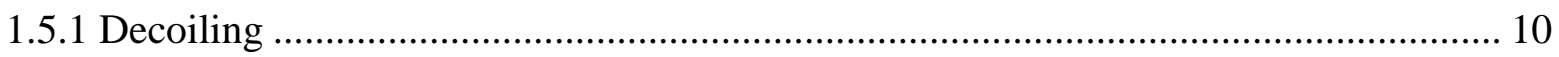

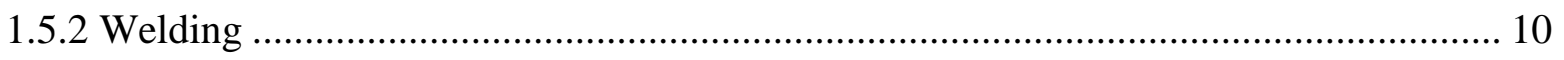

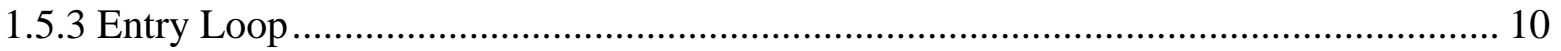

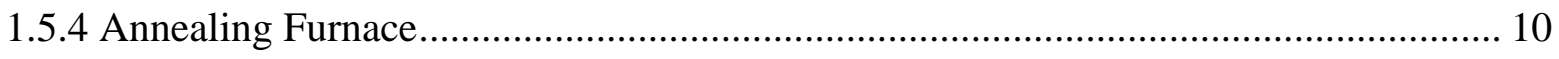

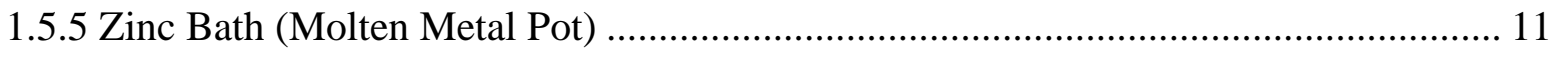

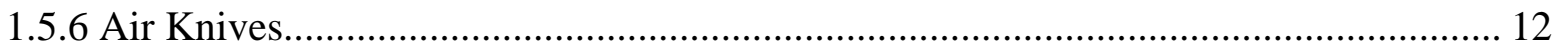

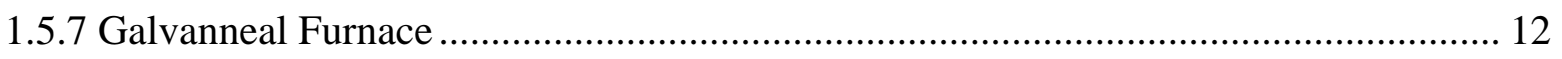

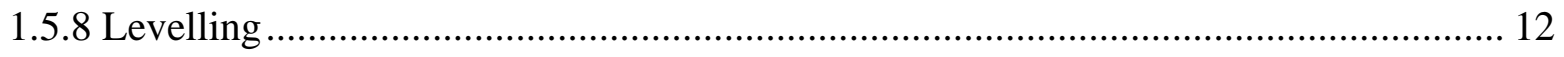

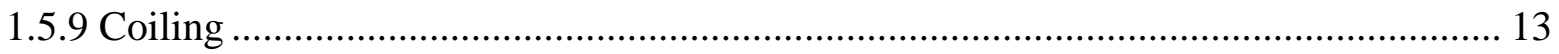

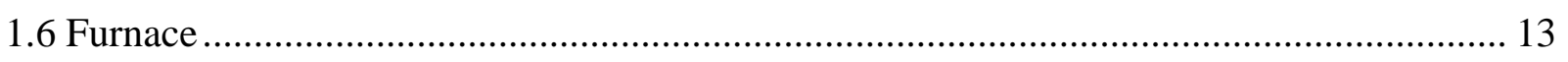

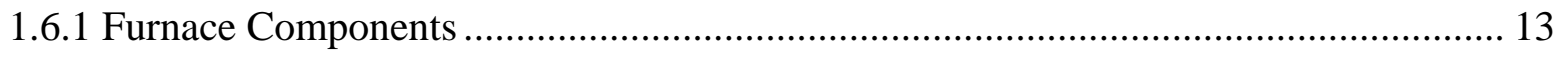

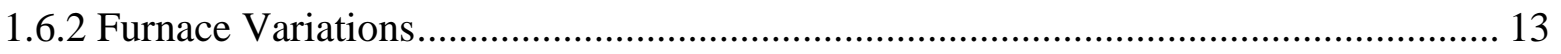

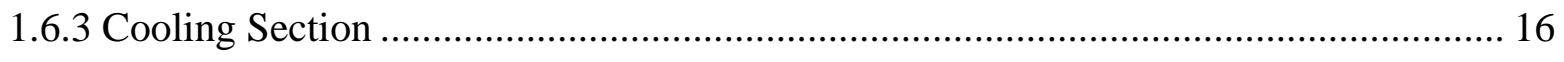

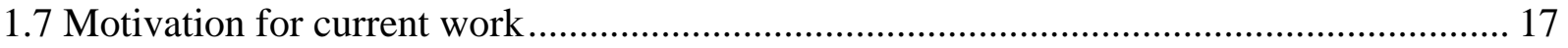


1.7.1 Galvanizing Energy Profiler Decision Support System (GEPDSS)........................ 17

1.7.2 Enhanced Galvanizing Profiler Decision Support System (E-GEPDSS).................. 18

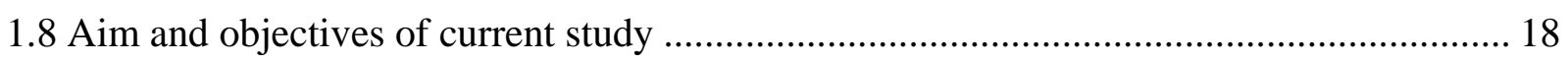

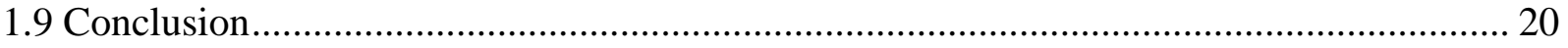

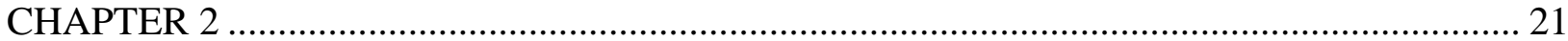

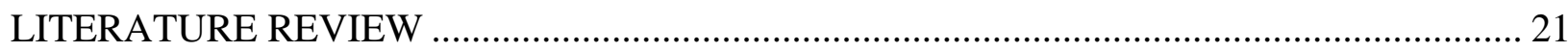

2.1 Energy Usage and Conservation Measures in Steel Industries ...................................... 21

2.2 Mathematical models and programming in integrated steel industries............................. 22

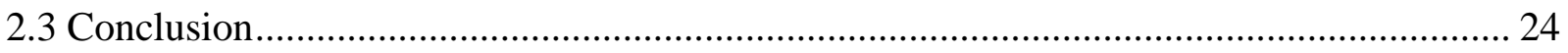

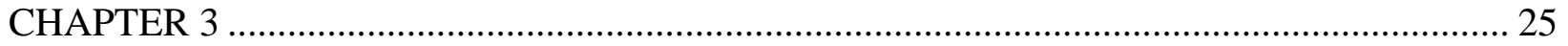

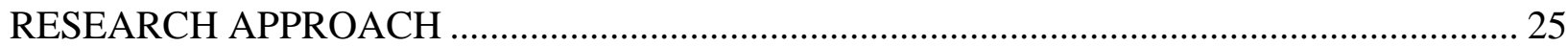

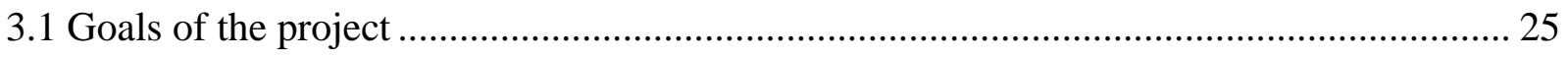

3.2 Studying the galvanizing process (Plant Visits and Data collection)............................. 25

3.2.1 Plant Visits and Data Collection.................................................................... 25

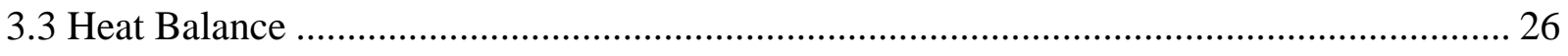

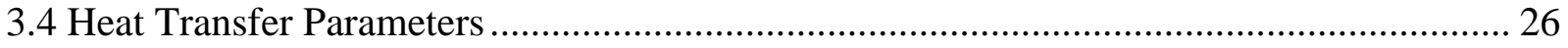

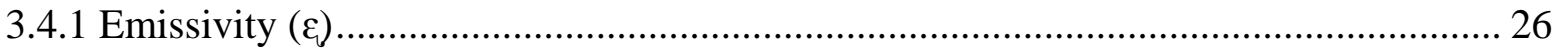

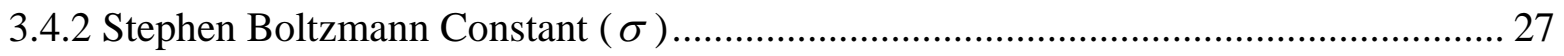

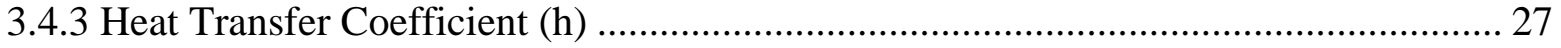

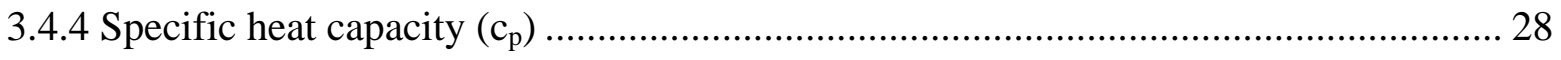

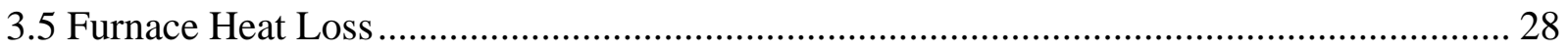

3.5.1. Heat Balance Fundamentals ............................................................................. 29

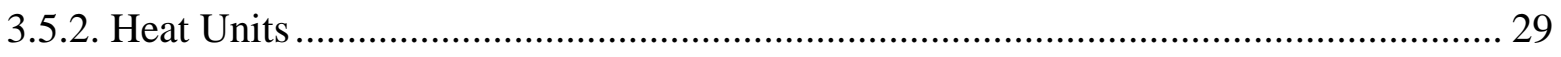

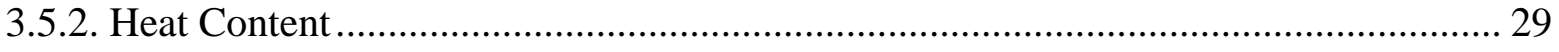

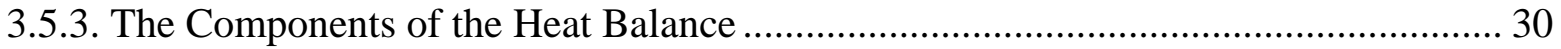

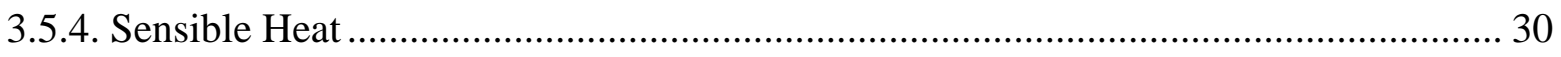

3.5.5 Heat of Formation and Decomposition ........................................................ 31

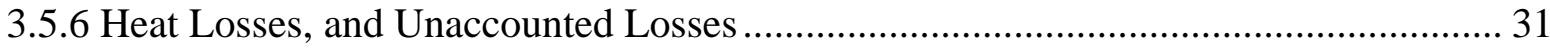

3.5.7. Heat Conducted Through the Walls - (Conduction)........................................... 32

3.5.8 Heat Loss Through other Surfaces (Fins, Burner walls and other typical surfaces emitting heat) - (Radiation \& Convection) .......................................................... 33 


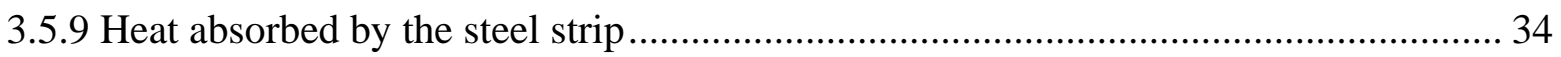

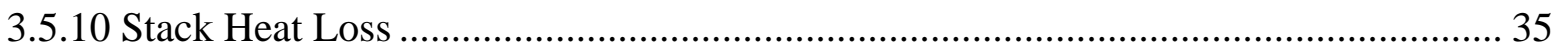

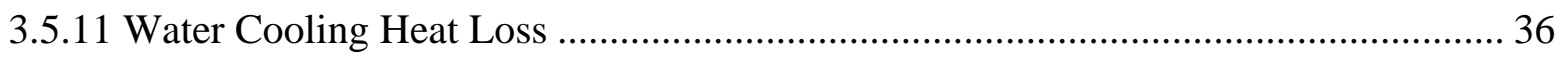

3.5.12 Opening Loss (Radiation) - Opening to accommodate steel strip entry..................... 36

3.5.13 Phase Change Heat Loss........................................................................................... 37

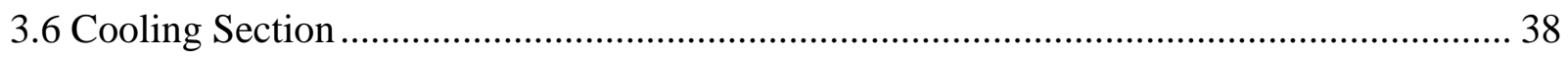

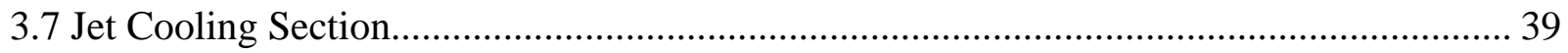

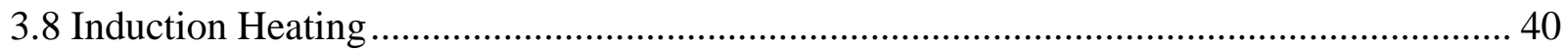

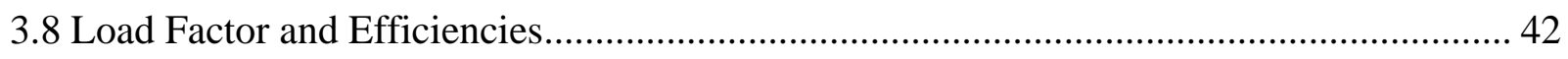

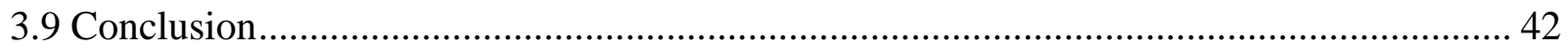

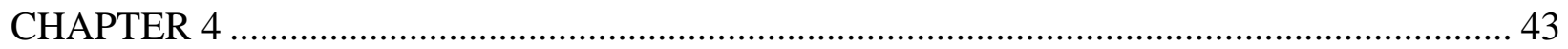

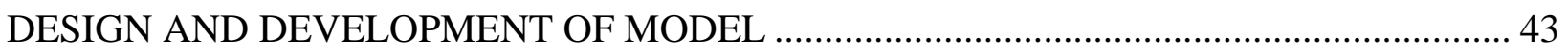

4.1 Purpose of Modeling ........................................................................................................ 43

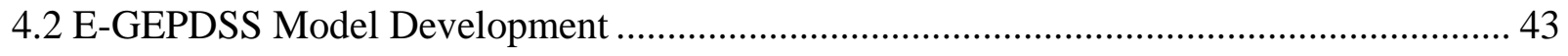

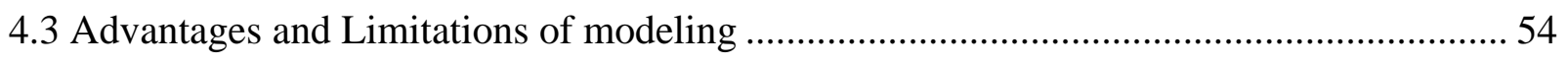

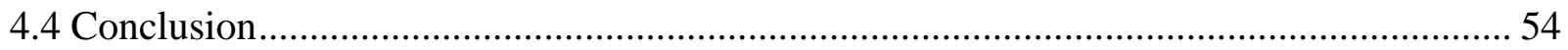

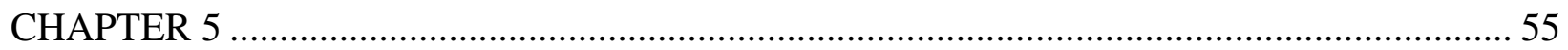

MODEL EXECUTION, ANALYSIS AND RESULTS ....................................................... 55

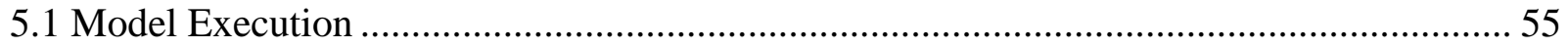

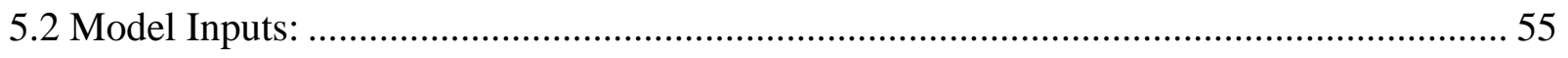

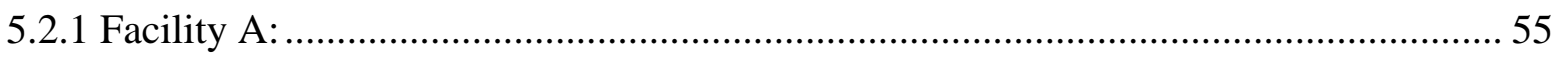

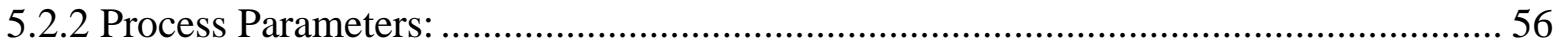

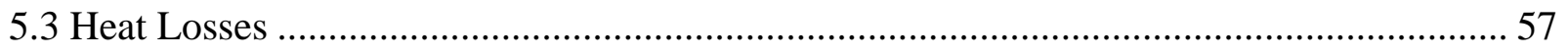

5.3.1 Heat Conducted Through the Walls ........................................................................ 57

5.3.2. Heat Loss Through other Surfaces (Fins, Burner walls and other typical surfaces

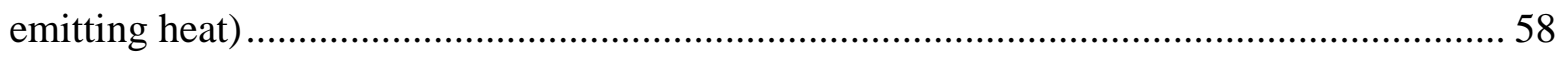

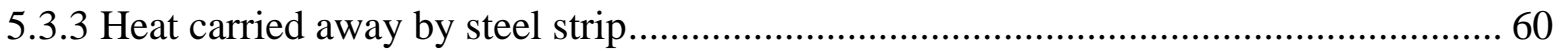

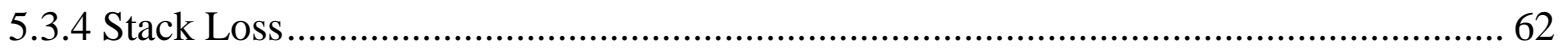

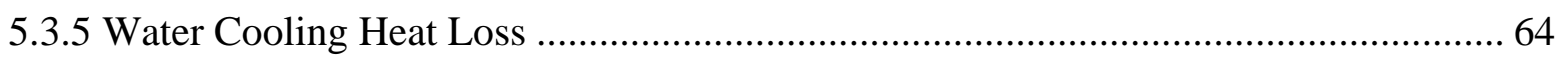

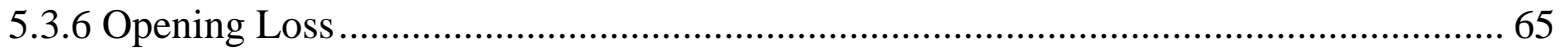

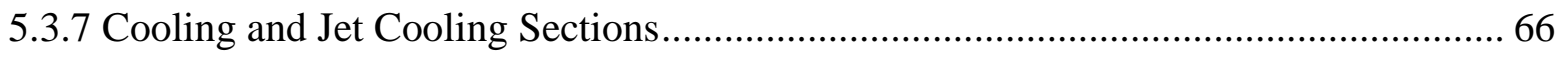




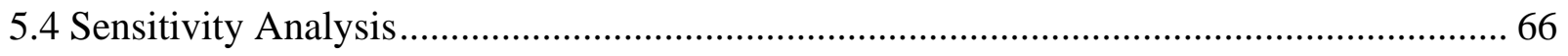

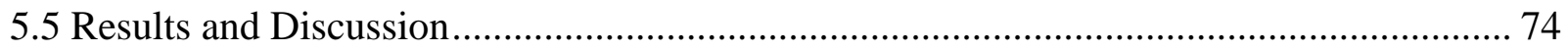

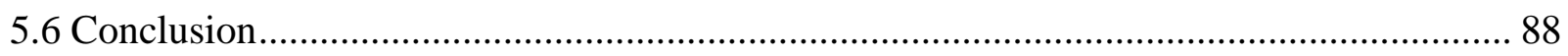

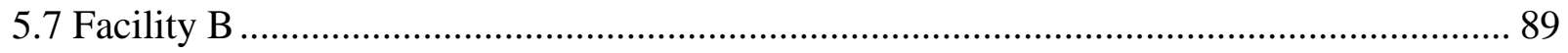

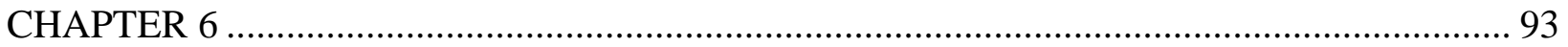

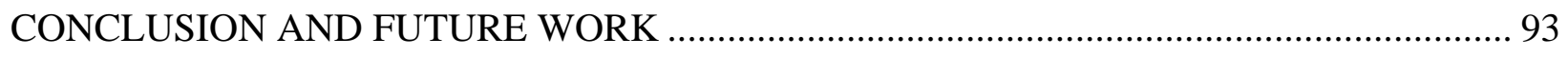

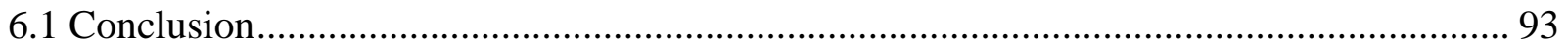

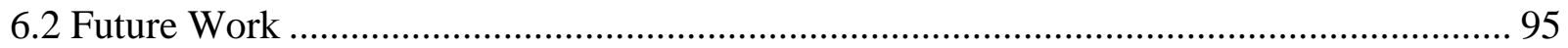

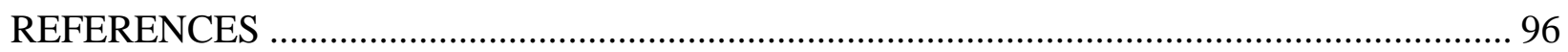




\section{List of Figures}

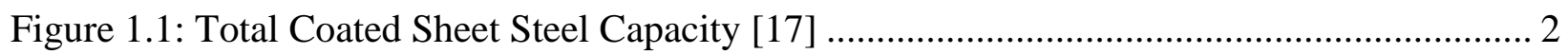

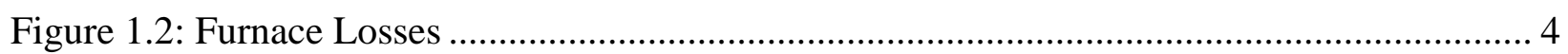

Figure 1.3: Continuous Galvanizing Line for the Coating of Steel Sheet [24]............................. 9

Figure 1.4: Schematic of Direct Fired Furnace [11] ............................................................... 14

Figure 1.5: Schematic of Traditional Radiant Tube Burner Section [12] .................................... 15

Figure 1.6: Energy Expenditures in the Steel Industry [4] ..................................................... 17

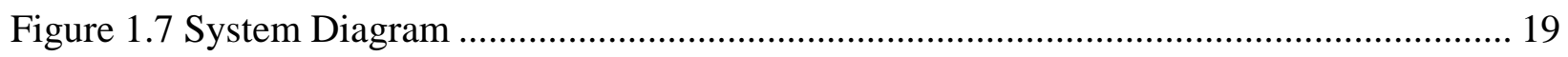

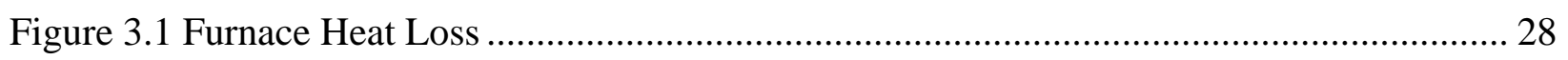

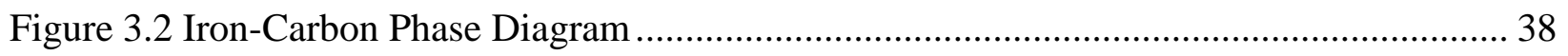

Figure 4.1 Mass Balance of Reactants and Products of Combustion .......................................... 44

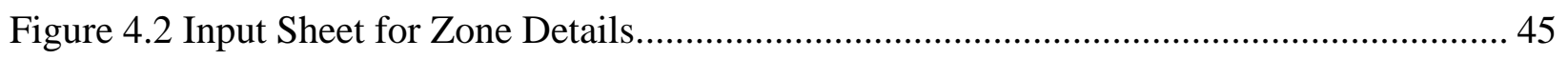

Figure 4.3 Input Sheet for entering Area of Heat Emitting Surfaces.......................................... 46

Figure 4.4 Input Sheet for Stack Analysis ................................................................................... 46

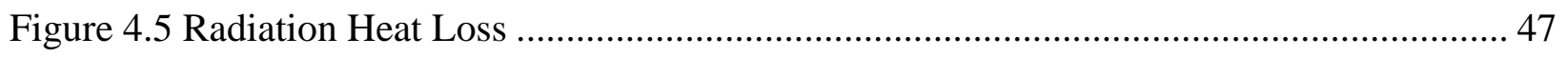

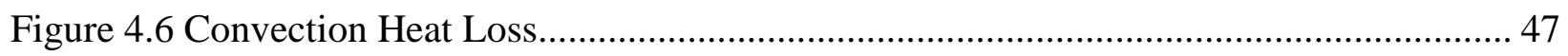

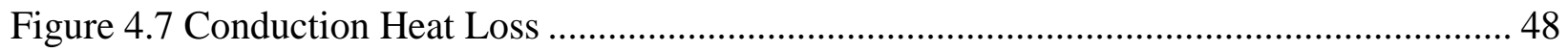

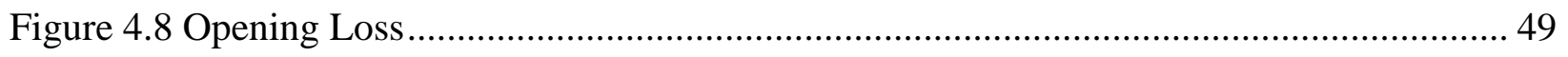

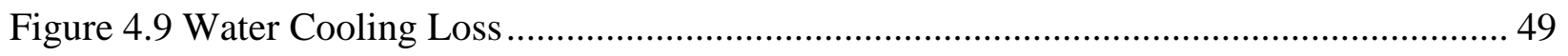

Figure 4.10 Phase Change Heat Loss .................................................................................... 49

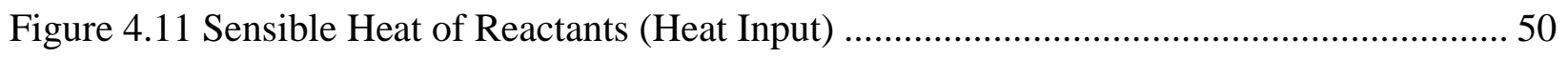

Figure 4.12 Sensible Heat of Products (Heat Output) ................................................................ 51

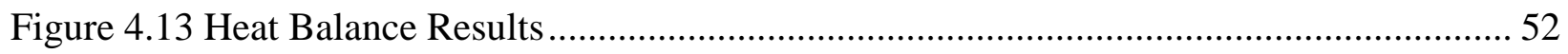

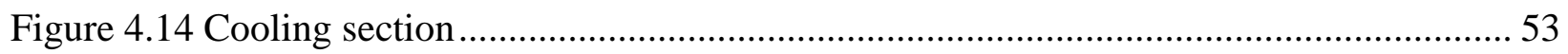

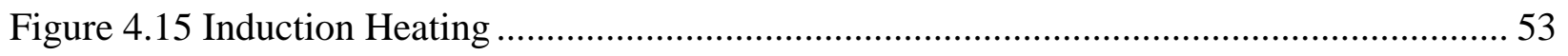

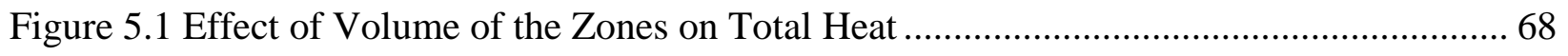

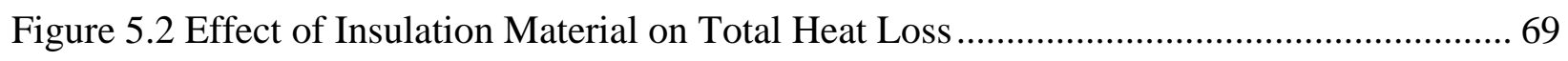

Figure 5.3 Effect of Line Speed on Total Heat Loss ................................................................. 70

Figure 5.4 Effect of Steel Strip Gage on Total Heat Loss ....................................................... 71

Figure 5.5 Effect of Strip Density on Total Heat Loss .............................................................. 72 
Figure 5.6 Effect of Average Furnace Temperature on Total Heat Loss................................. 73

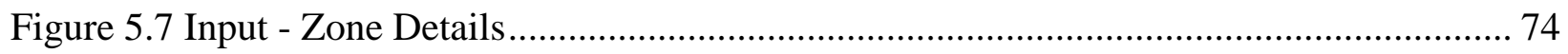

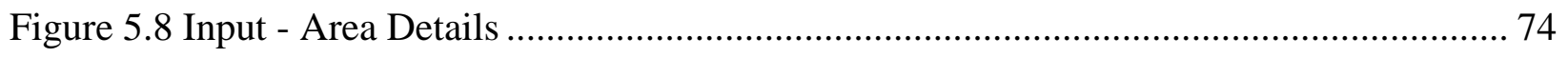

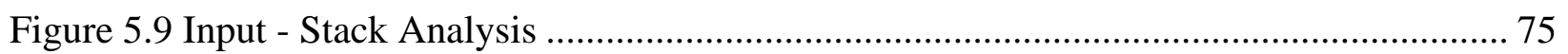

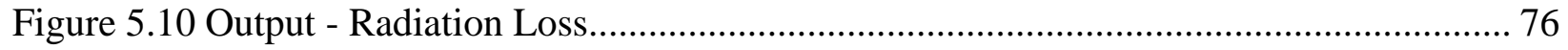

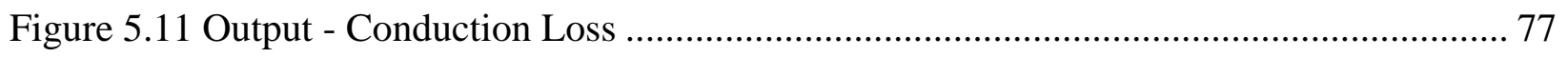

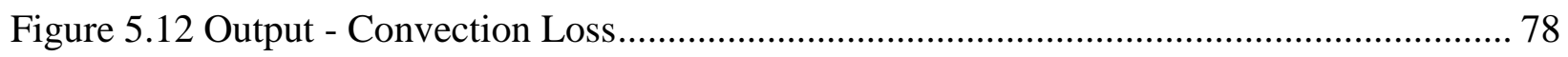

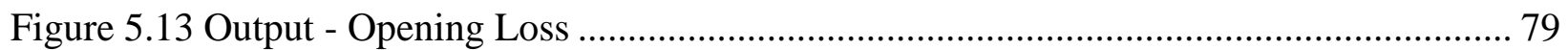

Figure 5.14 Output - Water Cooling Loss ..................................................................... 79

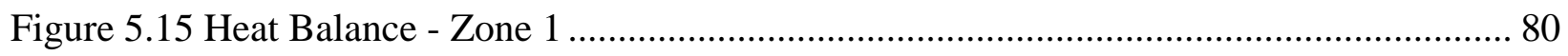

Figure 5.16 Heat Balance - Zone 2 ......................................................................... 81

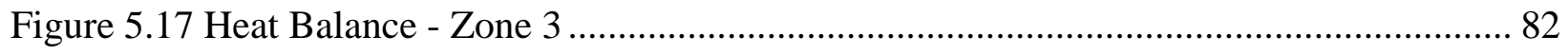

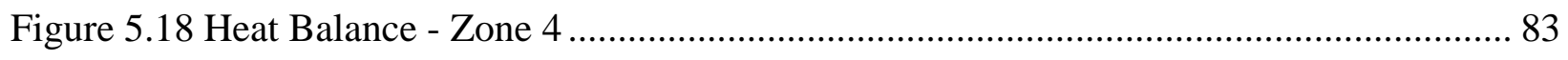

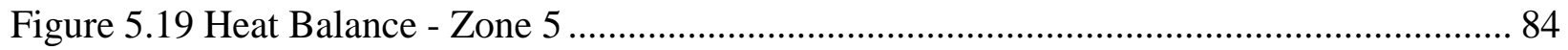

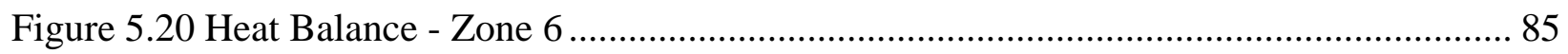

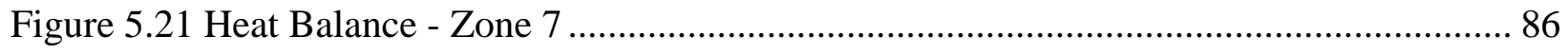

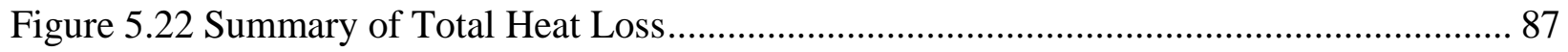

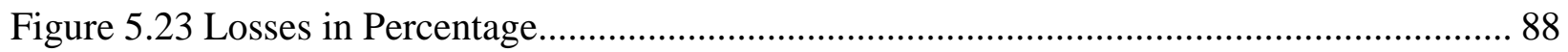

Figure 5.24 Product and Process Parameters ................................................................... 89

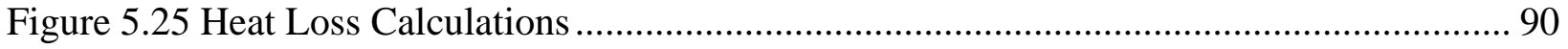

Figure 5.26 Heat Loss Calculations (Cont)................................................................ 91

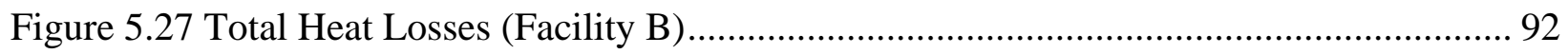




\section{List of Tables}

Table 1.1: U.S. Net Shipment of Steel Mill Products [16] .................................................. 2

Table 1.2: Product and Process Parameters .............................................................................. 3

Table 1.3: Product and Process Parameters for Two Products .................................................. 5

Table 3.1 Major Components of Heat balance ..................................................................... 30

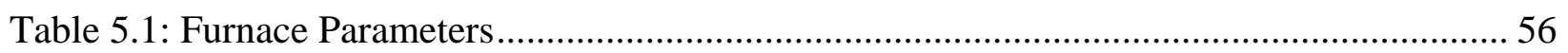

Table 5.2: Conduction Heat Loss.................................................................................... 57

Table 5.3: Radiation Heat Loss.......................................................................................... 59

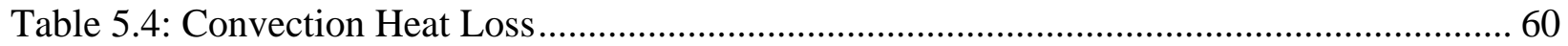

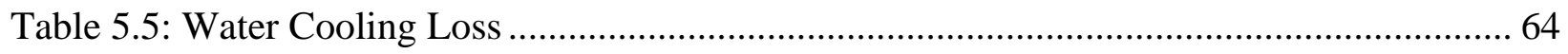

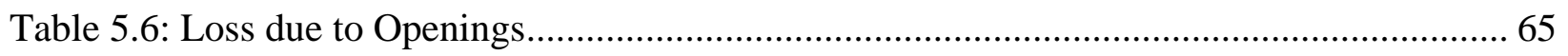

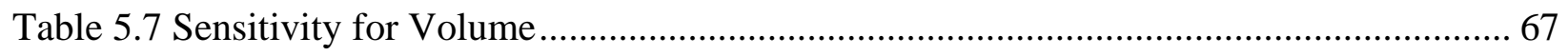

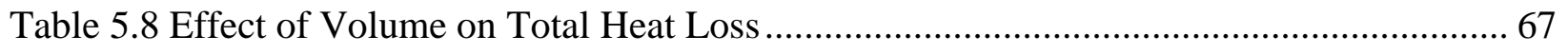

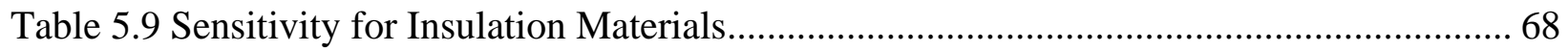

Table 5.10 Effect of Insulation Material on Total Heat Loss ............................................... 68

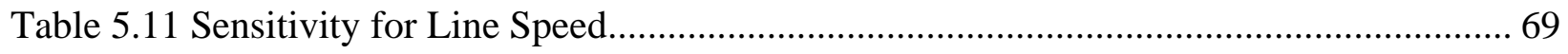

Table 5.12 Effect of Line Speed on Total Heat Loss .......................................................... 70

Table 5.13 Sensitivity for Strip Gage ...................................................................... 70

Table 5.14 Effect of Strip Gage on Total Heat Loss......................................................... 71

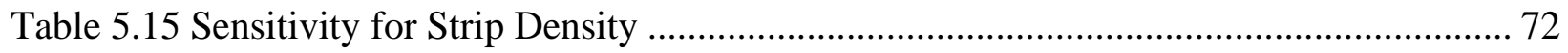

Table 5.16 Effect of Strip Density on Total Heat Loss...................................................... 72

Table 5.17 Sensitivity for Furnace Temperature …......................................................... 73

Table 5.18 Effect of Average Zone Temperature on Total Heat Loss.................................... 73 


\section{CHAPTER 1}

\section{INTRODUCTION}

\subsection{Background}

The steel industry accounts for around 3\% of total US energy [1], [3]. The steel industry is among the largest energy consumers in the manufacturing sector. Steel is a very hard, durable metal and it must be heated to high temperatures to manufacture it which consumes significant amount of energy.

There are about 40 galvanizing lines in the United States currently operating [2]. They produce galvanized steel by passing the sheet into the furnace operated at very high temperatures and then pulling it over a roller that is submerged in molten zinc, zinc alloy or aluminum alloy bath.

Although highly competitive, galvanized steel is profitable for the steel industry [2]. The coat acts as an anticorrosive component thus increasing the service life of steel. Galvanizing is found in almost every major application and industry where iron or mild steel is used. The utilities, chemical process, pulp and paper, automotive, and transportation industries historically have made extensive use of galvanizing for corrosion control.

Table 1.1 summarizes the net shipment of various steel products for the year 2000 and 2001 [16]. It can be observed that galvanized steel manufactured with the hot dip process in year 2000 and 2001 accounts for 14,872,000 and 14,293,000 tons respectively. This ranks the production of galvanized sheet steel to be second highest in the steel industry and thus explains the huge demand for galvanized steel products in the US market.

According to the data compiled by the International lead and zinc research organization, the total capacity of the total coated sheet steel has been steadily increasing from 1975 - 2000 [17]. Figure 1.1 shows the total coated sheet steel in million metric tons [17]. The coated sheet offers a unique combination of properties unmatched by any other material. Some of the properties include high strength, formability, light weight. corrosion resistance, aesthetics, recyclability, and low cost. 
Table 1.1: U.S. Net Shipment of Steel Mill Products [16]

(Thousands of Net Tons)

\begin{tabular}{|l|r|r|r|}
\hline Steel Products & \multicolumn{1}{|c|}{2001} & \multicolumn{1}{|c|}{2000} & \% Change (00-01) \\
\hline Sheets & 18,287 & 19,770 & $(7.5)$ \\
$\quad$ Hot-rolled & 12,404 & 14,847 & $(16.5)$ \\
Cold-rolled & & & \\
\hline Sheets and Strip & 14,293 & 14,872 & $(3.8)$ \\
$\quad$ Galvanized hot-dipped & 3,012 & 3,496 & $(13.8)$ \\
Galvanized electrolytic & 1,902 & 2,138 & $(11.0)$ \\
All other metallic-coated & 481 & 529 & $(20.6)$ \\
Electrical & & & $(25.6)$ \\
\hline Strip & 690 & 869 & $(9.3)$ \\
$\quad$ Hot-rolled & 1,683 & 2,262 & 109,050 \\
$\quad$ Cold-rolled & 98,940 & & \\
\hline Total & & & \\
\hline
\end{tabular}

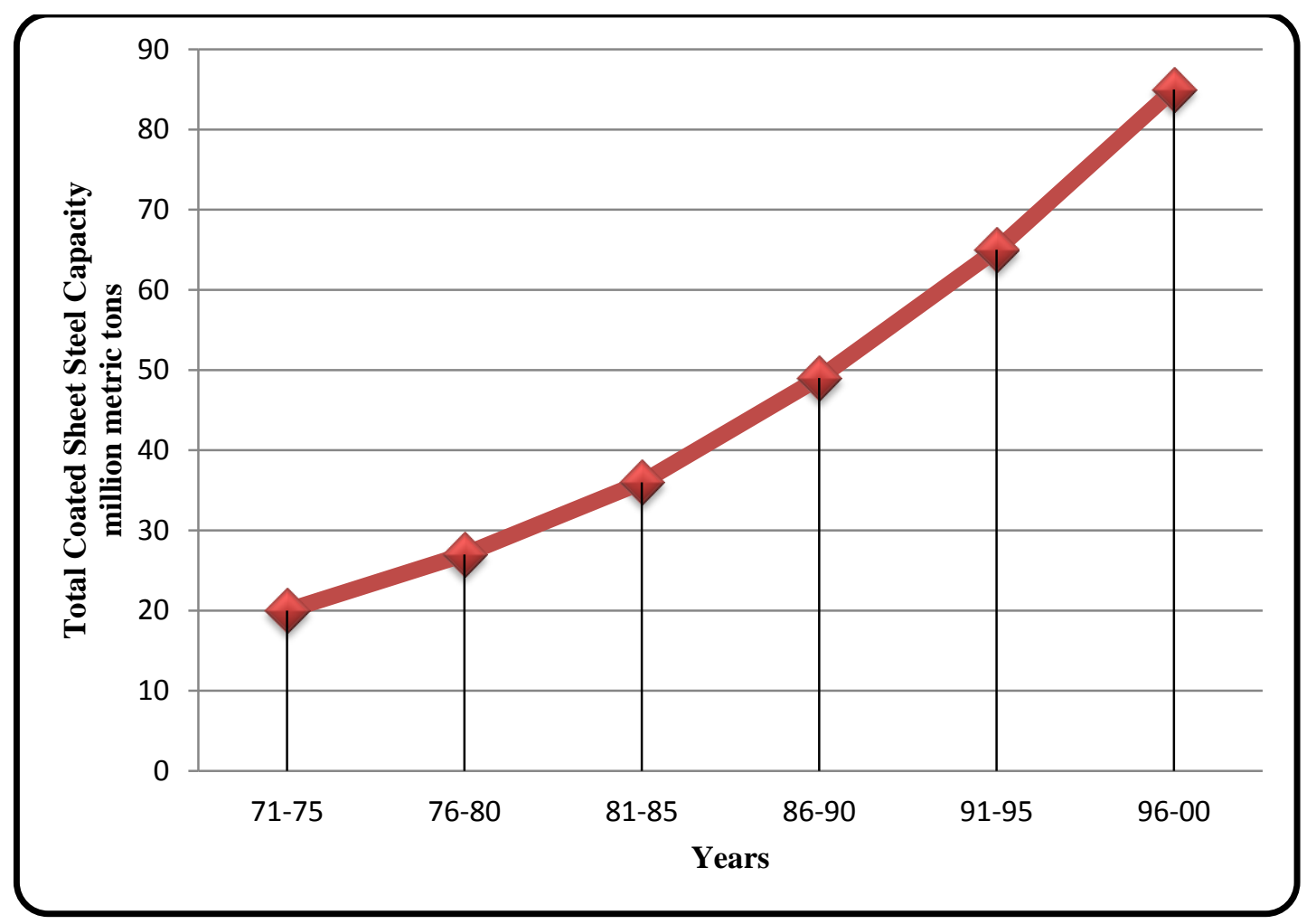

Figure 1.1: Total Coated Sheet Steel Capacity [17] 


\subsection{Need for Research}

The continuous galvanizing process is the coating of sheet steel with zinc. This coating involves significant amount of energy. Not all the energy used in galvanizing is converted into useful heat (Useful heat is the amount of heat that is being transferred to the steel strip during its movement inside the furnace), rest of heat dissipates as losses. The energy used varies with product types as the process parameters also vary. Therefore, it is difficult for galvanizers to maintain a constant thermal cycle in their process. The product and process parameters that highly influence energy consumption in a galvanizing line is shown in Table 1.2.

Table 1.2: Product and Process Parameters

\begin{tabular}{|c|c|c|}
\hline S.No & Product Parameters* & Process Parameters* $^{*}$ \\
\hline 1 & Steel strip width & Line speed \\
\hline 2 & Steel strip thickness (Gauge) & Furnace zone temperatures \\
\hline
\end{tabular}

*The parameters that will be referred further in the document

For example, the amount of energy consumed and losses involved while galvanizing a steel strip with 0.0028 feet ( 0.00086 meters) thickness, 5 feet (1.524 meters) wide, with a line speed of 450 feet $/ \mathrm{min}(138 \mathrm{~m} / \mathrm{min})$ at $1700^{\circ} \mathrm{F}\left(927^{\circ} \mathrm{C}\right)$ furnace temperature differs from a steel strip with 0.0042 feet ( 0.00128 meters) thickness, 4 feet ( 1.22 meters) wide, line speed $400 \mathrm{feet} / \mathrm{min}$ (122 $\mathrm{m} / \mathrm{min})$ at $2200^{\circ} \mathrm{F}\left(1204^{\circ} \mathrm{C}\right)$. Research efforts can quantify this energy consumed based on products and process parameters.

The energy provided to the furnace is being absorbed by various elements of the furnace. It is difficult for galvanizers to identify this energy that is transferred, though they know the total amount of energy supplied to the furnace. By knowing the amount of energy transferred or the percentage of heat going into different elements of the furnace, the galvanizers can identify the areas that need improvement to operate their furnace as efficient as possible.

This situation in galvanizing industry can be enhanced by a model which can i) render the difference in energy consumption for changing product and process parameters ii) calculate the amount of heat going into various elements of the furnace. A heat balance approach can fulfill these requirements. 


\subsection{Significance of Research}

Numerous studies [34] on energy consumption by various galvanizing lines have been studied in the past. But relatively very few studies have been performed to study the detailed energy consumption by the various zones in the furnaces and cooling sections of the galvanizing lines using heat balance analysis. These studies are needed as there is always a continuous demand from galvanizers to run their furnace efficiently.

Heat balance analysis is capable of differentiating the heat supplied to the furnace as useful heat and the heat lost in the process. It identifies the amount of heat going into various elements of the furnace. The losses concerned with the furnace are shown in Figure 1.2.

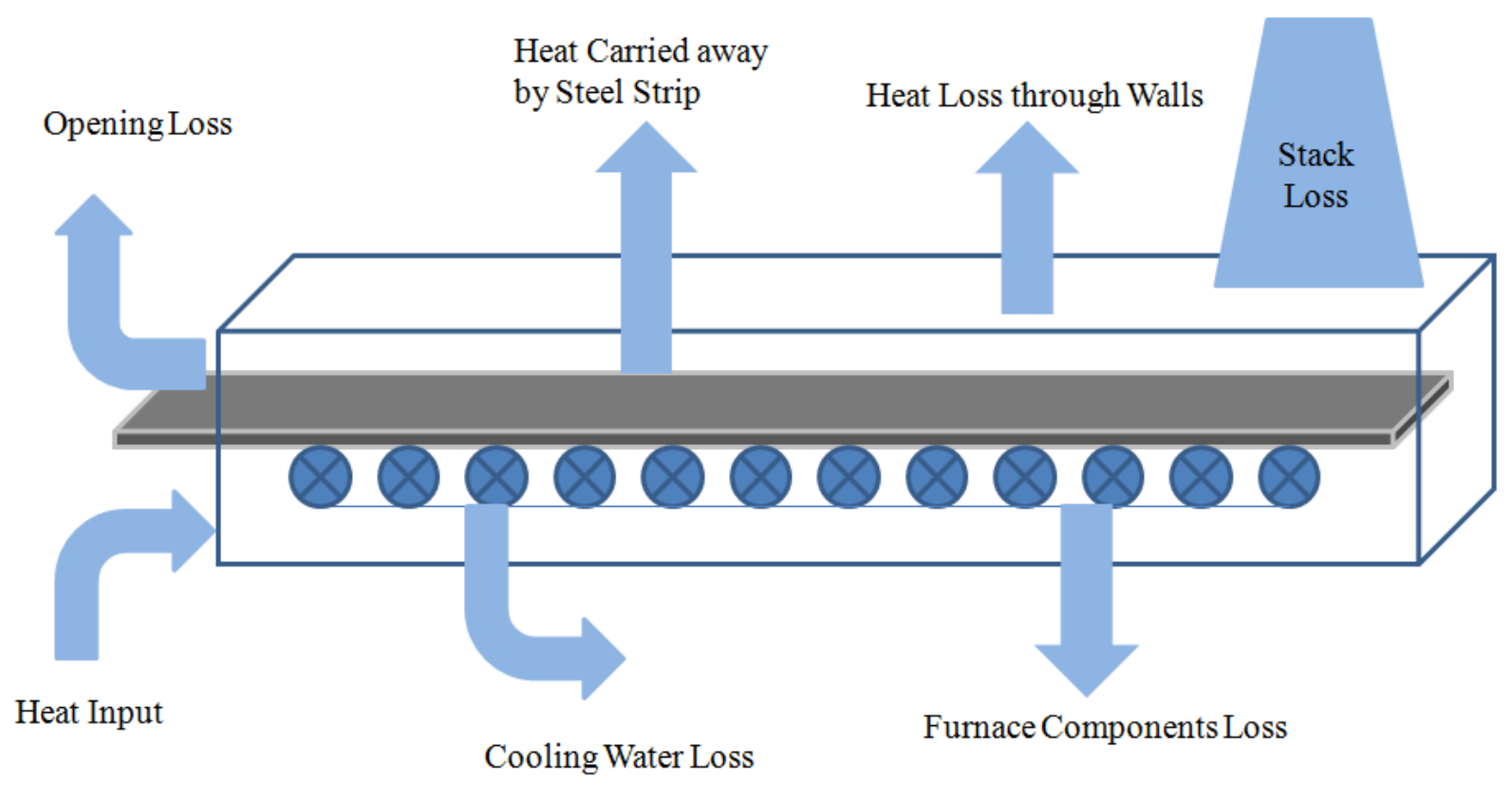

Figure 1.2: Furnace Losses

The losses considered are highly important as far as heat balance is concerned. It is assumed that the total heat input to the furnace is dissipated as useful heat and losses as shown in the formula below. Heat input and losses vary according to the product under production.

$$
\begin{aligned}
Q_{\text {Input }} & =Q_{\text {SteelStrip }}+Q_{\text {WallLosses }}+Q_{\text {StackLoss }}+Q_{\text {CoolingWarLoss }}+Q_{\text {ProtectionGioLoss }}+Q_{\text {OpeningLos }} \\
& =\text { Gas combustion energy (amount of gas \& combustion of gas) }
\end{aligned}
$$


For an example, the difference of heat or energy consumption for two products with different product and process parameters are shown below.

Table 1.4: Product and Process Parameters for Two Products

\begin{tabular}{|c|l|l|}
\hline S.No & \multicolumn{1}{|c|}{ Product A } & \multicolumn{1}{c|}{ Product B } \\
\hline 1 & Steel strip width $-4.3 \mathrm{ft}$ & Steel strip width $-4.8 \mathrm{ft}$ \\
\hline 2 & Steel strip thickness (Gauge) $-0.0021 \mathrm{ft}$ & Steel strip thickness (Gauge) $-0.0024 \mathrm{ft}$ \\
\hline 3 & Line speed $-423 \mathrm{ft} / \mathrm{min}$ & Line speed $-405 \mathrm{ft} / \mathrm{min}$ \\
\hline 4 & Furnace zone temperatures $-1650^{\circ} \mathrm{F}$ & Furnace zone temperatures $-1750^{\circ} \mathrm{F}$ \\
\hline
\end{tabular}

Heat Input: Product A - NG input - 35,600 $\mathrm{ft}^{3} / \mathrm{hr}$, Air - 372,353 $\mathrm{ft}^{3} / \mathrm{hr}$

: Product B - NG input - 40,000 $\mathrm{ft}^{3} / \mathrm{hr}$, Air - 432,500 $\mathrm{ft}^{3} / \mathrm{hr}^{2}$

\section{Product A:}

Heat carried away by steel strip - $\quad$ 17.57 MMBtu/hr

Wall losses $\quad$ - $\quad 8.2 \mathrm{MMBtu} / \mathrm{hr}$

Stack loss $\quad$ - $\quad 6.8 \mathrm{MMBtu} / \mathrm{hr}$

Cooling water loss $\quad$ - $\quad 1.7 \mathrm{MMBtu} / \mathrm{hr}$

Opening Loss $\quad$ - $\quad 0.0027 \mathrm{MMBtu} / \mathrm{hr}$

Unaccounted loss $\quad$ - $\quad 0.82 \mathrm{MMBtu} / \mathrm{hr}$

Total Heat $\quad$ - $\quad 35 \mathrm{MMBtu} / \mathrm{hr}$

\section{Product B:}

Heat carried away by steel strip - $\quad 19.25 \mathrm{MMBtu} / \mathrm{hr}$

Wall losses $\quad$ - $\quad 9.2 \mathrm{MMBtu} / \mathrm{hr}$

Stack loss $\quad$ - $\quad 7.2 \mathrm{MMBtu} / \mathrm{hr}$

Cooling water loss $\quad$ - $\quad 2 \mathrm{MMBtu} / \mathrm{hr}$

Opening Loss $\quad$ - $\quad 0.0055 \mathrm{MMBtu} / \mathrm{hr}$

Unaccounted loss $\quad$ - $\quad 1.5 \mathrm{MMBtu} / \mathrm{hr}$

Total Heat $\quad$ - $\quad 40 \mathrm{MMBtu} / \mathrm{hr}$

The coating process is performed in the same furnace for varying process and product parameters that are tabulated above. 
As shown above, heat balance identifies the amount of heat going into different elements of the furnace. It is also evident that comparing the products by cost incurred and on energy basis is possible by utilizing this approach.

The approach also helps the galvanizers to do what if analysis and in decision making. It helps them to compare between current and modified conditions. From the example above, product A has significant amount of heat escaping through the stack which can be reduced by controlled combustion. Thus an area for improvement has been identified. Oxygen percentage in the stack is one of the criteria that influence the heat going through the stack. The galvanizers can work on the improvement by replacing the burners with oxy-fuel burners or by adjusting the air-fuel ratio. After making the necessary changes in their process, the galvanizers can input the new values in the model and get the results for modified conditions.

A detailed description of galvanizing is discussed in section 1.4.

\subsection{Galvanizing Process}

The galvanizing process consists of four basic elements:

- Surface Preparation

- Galvanizing

- Quenching

- Inspection

\subsubsection{Surface Preparation}

Surface preparation is the critical step in the application of any coating. In most cases where a coating fails before the end of its expected service life, it is due to incorrect or inadequate surface preparation [28]. The surface preparation step in the galvanizing process has its own built-in means of quality control in that zinc will not react with a steel surface that is not perfectly clean. Any failures or inadequacies in surface preparation will be immediately apparent when the steel is withdrawn from the molten zinc because the unclean areas will remain uncoated [28].

On-site painting or other field-applied systems of corrosion protection may involve the use of different subcontractors and/or work groups to prepare the surface and apply the coating. This 
can result in problems in coordinating activities, leading to costly and time-consuming delays, errors, and disputes concerning responsibility and financial liability. Surface preparation for galvanizing typically consists of three steps: caustic cleaning, acid pickling, and fluxing [28].

\subsubsection{Caustic Cleaning}

A hot alkali solution often is used to remove organic contaminants such as dirt, paint markings, grease, and oil from the metal surface. Epoxies, vinyl, asphalt, or welding slag must be removed before galvanizing by grit blasting, sand blasting, or other mechanical means [28].

\subsubsection{Acid Pickling}

Scale and rust normally are removed from the steel surface by pickling in a dilute solution of hot sulfuric acid or ambient temperature hydrochloric acid [28].

\subsubsection{Fluxing}

Fluxing is the final surface preparation step in the galvanizing process. Fluxing removes oxides and prevents further oxides from forming on the surface of the metal prior to galvanizing and promotes bonding of the zinc to the steel or iron surface. The method for applying the flux depends upon whether the particular galvanizing plant uses the wet or dry galvanizing process [28].

In the dry galvanizing process, the steel or iron materials are dipped or pre-fluxed in an aqueous solution of zinc ammonium chloride. The material is then thoroughly dried prior to immersion in molten zinc. In the wet galvanizing process, a blanket of liquid zinc ammonium chloride is floated on top of the molten zinc. The iron or steel being galvanized passes through the flux on its way into the molten zinc [28].

\subsubsection{Galvanizing}

In this step, the material is completely immersed in a bath consisting of mostly pure molten zinc. The bath temperature is maintained at about $850^{\circ} \mathrm{F}\left(454^{\circ} \mathrm{C}\right)[28]$. 
Products are immersed in the bath long enough to reach bath temperature. The products are withdrawn slowly from the galvanizing bath and the excess zinc is removed by blowing air at a certain pressure with the help of air knife [28].

The chemical reactions that result in the formation and structure of the galvanized coating continue after the products are withdrawn from the bath as long as these products are near the bath temperature. The products are cooled in either water or ambient air immediately after withdrawal from the bath and the chemical reaction stops after cooling [28].

\subsubsection{Quenching}

This process solidifies the zinc coating to ensure easy handling. It also arrests the alloying reaction in the case of reactive steels, which continues well below the melting temperature of zinc. The quench water normally contains a passivating chemical, which retards the formation of white rust (wet storage stain) until such time as when the freshly applied reactive zinc surface has developed a stable and protective basic zinc carbonate film [6].

There are two methods of galvanizing, hot dip galvanizing and continuous galvanizing. In hot dip galvanizing, ferrous components that are to be galvanized are held by an overhead crane and dipped sequentially in tanks containing various liquids for surface preparation before dipping them in to the final molten zinc bath. Hot dip galvanizing is done to steel products like rods, channels, small and medium size machine components, steel plates, bolts, nuts and many more, which can be hanged firmly with help of wires [6].

Continuous galvanizing on the other hand consists of galvanizing sheet steel products of various gauges. The sheet steel strip is fed continuously from a payoff reel and passes through a number of sections, and gets coated with $\mathrm{Zn} / \mathrm{Zn}$ alloy before getting coiled up again. This process runs uninterrupted for weeks; hence it is called continuous galvanizing. The modern continuous galvanizing process was invented by Sendzimir over a half century ago [5].

\subsubsection{Inspection}

The two properties of the galvanized coating that are closely scrutinized after galvanizing are coating thickness and coating appearance. The coating thickness is controlled by adjusting the 
pressure in the air knives. A variety of simple physical and laboratory tests may be performed to determine thickness, uniformity, adherence, and appearance [28].

Detailed description of different sections of continuous galvanizing line is discussed in the following sections.

\subsection{Continuous Galvanizing}

Figure 1.3 [24] shows a real picture of a continuous galvanizing line.

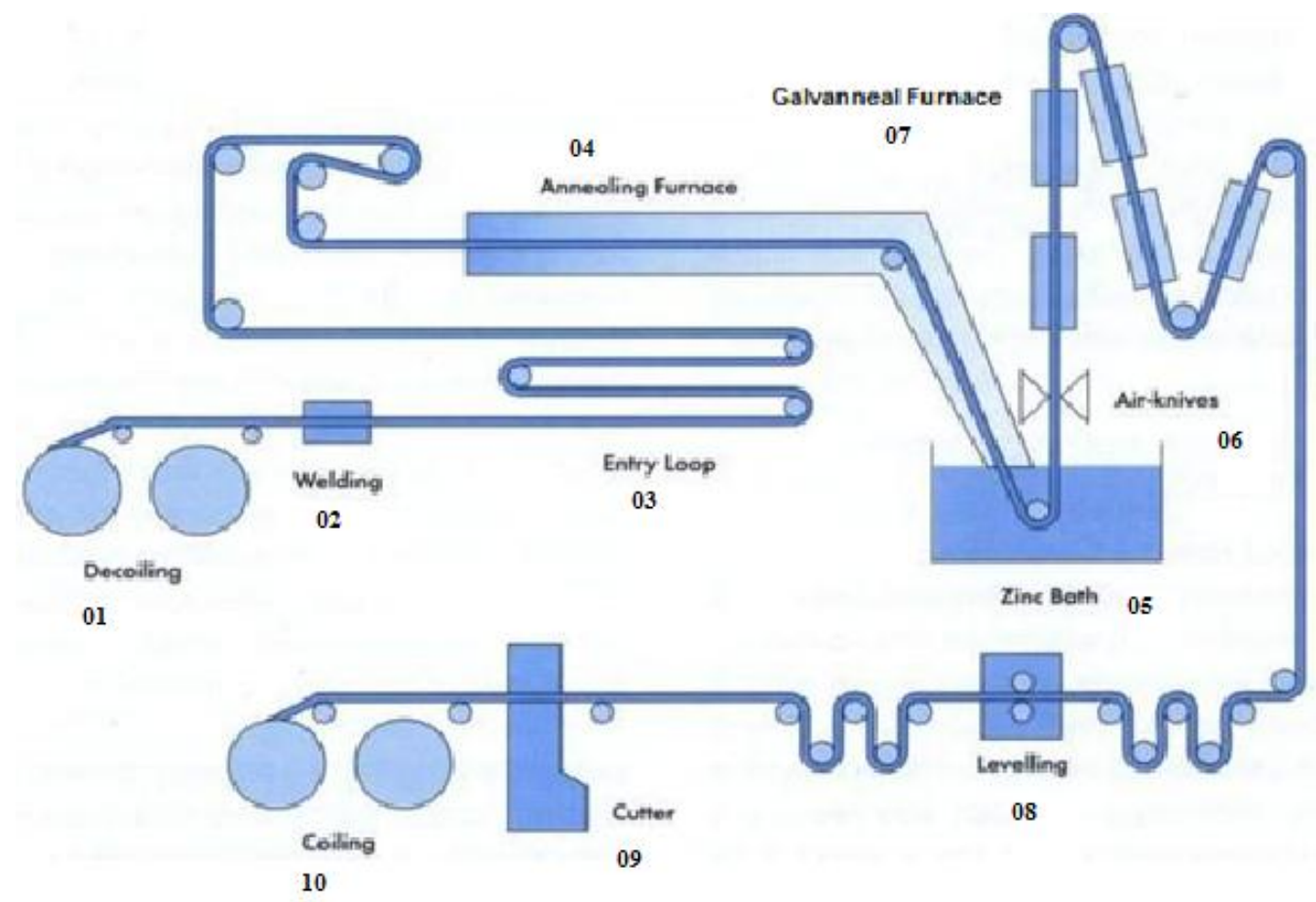

Figure 1.3: Continuous Galvanizing Line for the Coating of Steel Sheet [24]

$\begin{array}{llll}01 & \text { Decoiling } & 06 & \text { Air Knives } \\ 02 & \text { Welding } & 07 & \text { Galvanneal Furnace } \\ 03 & \text { Entry Loop Car } & 08 & \text { Levelling } \\ 04 & \text { Annealing Furnace } & 09 & \text { Cutter } \\ 05 & \text { Zinc Bath } & 10 & \text { Coiling }\end{array}$

The equipment listed above consumes either electricity or natural gas. The main electricity consuming devices are large motors used in these equipment and resistance or induction coils used for pre-melt and main zinc pot. In case of natural gas the largest consumers are the 
annealing and the galvanneal furnaces. A brief description of the process and the equipment it transfers through is explained in the following sections.

\subsubsection{Decoiling}

This is the initial phase of the galvanizing line where uncoated steel sheets are loaded. There are typically two decoilers [6]. When one roll is about to end, the trailing end of that roll is welded to the leading end of the second roll. Then, as the second roll is unwound a new roll is kept ready in place of the first roll for discharge. This helps to keep the process continuous.

\subsubsection{Welding}

The trailing end of the exhausting decoiler roll is welded to the leading end of the new roll with the help of the seam welder [6]. During this time, the line is fed through the accumulated steel sheet from the entry loop.

\subsubsection{Entry Loop}

The entry loop car is situated at the entry end and serves the purpose of maintaining the continuity of the process when there is a change in the decoiler rolls. It covers for the time lag caused by the seam welder. The loop car consists of series of rolls in a zigzag fashion through which the steel sheet travels. The steel sheet inventory is stored in the accumulator by increasing the distance between the consecutive rolls. Whenever the accumulator is unloading, the rolls start coming closer, thus releasing the steel sheet passing through them. The loop car is capable of storing steel sheets of length up to 1000 feet [6].

\subsubsection{Annealing Furnace}

Annealing is a process of heating a material to high temperatures and then cooling it to induce softness in that material. The annealing furnace usually has 4 sections: 1) pre heat section, 2) non-oxidizing section, 3) heating section, and 4) jet cooling (controlled cooling) section [6]. The annealing furnace is the largest natural gas consuming equipment in the galvanizing facility. The different sections are discussed in detail;

a) Pre-heat section: This section generally comprise of burners firing directly on the strip in order to remove impurities that may be present on the surface of the strip. 
b) Non-Oxidizing section: The non-oxidizing section of the annealing furnace heats the strip in a deoxidizing atmosphere. The set point temperature in this section is between $2000^{\circ} \mathrm{F}$ to 2450 ${ }^{\circ} \mathrm{F}$, and varies according to the type of steel. The furnace atmosphere mostly consists of a gas mixture of $15 \%$ hydrogen and $85 \%$ nitrogen [29]. The nitrogen is used to maintain a positive pressure inside the furnace and hydrogen atmosphere to prevent oxidation on the strip surface.

c) Heating section: The heating section usually has a set point of $1500^{\circ} \mathrm{F}$ to $2200^{\circ} \mathrm{F}$. Again, it varies for different types of steels. The heating section of the furnace helps to maintain the strip temperature in the deoxidizing atmosphere [6].

d) Controlled cooling (Jet cooling) section: The controlled cooling section of the furnace use water-cooled heat exchangers and fans to consistently lower the temperature of the steel. Steel sheet cools in the jet cooling section to approximately $860^{\circ} \mathrm{F}$ [6]. The controlled cooling section is sometimes provided with electric heating elements in case, it is required to raise the temperature of the strip.

\subsubsection{Zinc Bath (Molten Metal Pot)}

The galvanizing line typically comprises of two pots, pre-melt pot and the main pot [6]. The zinc and other alloy metals are mixed in proper compositions in the pre-melt pot after which it is transferred to the main pot with the help of channels. The snout which is a mode of transfer for the steel strip from the furnace to the pot is immersed inside the main pot. The main pot also has the sink and stabilizing rolls submerged in it, and over which the steel sheet from the snout is passed. The pre-melt pot and the main pot contents are heated by heating elements like inductors and natural gas burners. The heating method varies for different companies.

A typical galvanizing bath inside the main pot is maintained in a temperature around $842^{\circ} \mathrm{F}$ to $878^{\circ} \mathrm{F}\left(450^{\circ} \mathrm{C}\right.$ to $\left.470^{\circ} \mathrm{C}\right)$ [6]. The temperature varies according to the product being produced. Continuous galvanizing baths usually contains a small amount of $\mathrm{Al}$, frequently less than $0.3 \%$, to extenuate the reaction between the molten $\mathrm{Zn}$ alloy and coated steel.

The $\mathrm{Al}$ content in the bath can be as high as $55 \%$ if super corrosion coating is required but it is usually maintained less than $1 \%$ for optimum level. After more than a decade of intensive research and development, the optimum $\mathrm{Al}$ content of a coating bath can now be defined based 
on the product and pot specifics: around $0.136 \%$ for galvanneal, $0.18 \%$ for galvanized for the construction market, and $0.25 \%$ for automotive exposed applications [7]. The bath inside the pot is maintained in a molten state even during downtime (when there is no production).

\subsubsection{Air Knives}

The steel strip is passed in between the air knives after the coating process in the zinc pot. Air knives are used to blow out excess coating from the steel strip [6]. The thickness of coating is performed according to the specifications by adjusting the pressure in the air knives.

\subsubsection{Galvanneal Furnace}

The galvannealing process is slightly different from the galvanizing process. The variation in the production process is that, to produce a galvanneal coating, the strip coming out of the coating bath is further heated by passing it through a furnace. By heating to approximately 1000 to $1050^{\circ} \mathrm{F}\left(538\right.$ to $\left.565^{\circ} \mathrm{C}\right)$ and holding the strip at this temperature for a specific amount of time, the zinc coating alloys with iron by diffusion between the molten zinc and iron from the steel strip. The result is that the final product has a coating that is an alloy of approximately $90 \%$ zinc and $10 \%$ iron [9]. The final iron concentration depends on the heating cycle since diffusion is a function of the time/temperature cycle.

Galvanneal furnace is not a necessity in all galvanizing facilities. It may not be present in the facilities where galvanneal products are not produced. Galvanneal is used in the automotive industry because of its improved manufacturing performance in models which use lighter and stronger grades of steel. The advantage of galvanneal coating is improved spot-weld ability and improved coating adhesion.

\subsubsection{Levelling}

Finally, the finished hot-dip coated sheet can be temper rolled continuously in the exit section of every plant and tension levelled. This way quality with high surface requirements and flatness can be produced. Before being wound into coils ready for shipping, the surface is chemically passivated or oiled to protect the steel strip against temporary corrosion and friction oxidation. 


\subsubsection{Coiling}

As a final process the steel strip is oiled, rewound and coiled to be shipped. The coiling system winds the out coming strip from the processes. This is the final set-up in a galvanizing line [6].

\subsection{Furnace}

The galvanizing line comprises of various components out of which the furnace and pot are two major energy consumers. This project focuses on the opportunities for energy saving in the furnace section. The components of furnace are listed as follows.

\subsubsection{Furnace Components}

A hot dip coating line has two furnaces, one is the annealing furnace where the steel strip is heated to high temperatures and cooled before coating and second is galvanneal furnace where the steel strip enters after zinc bath coating. Both the furnaces are maintained within the temperature range of $1400^{\circ} \mathrm{F}$ to $2200^{\circ} \mathrm{F}\left(760^{\circ} \mathrm{C}\right.$ to $\left.1204^{\circ} \mathrm{C}\right)$ depending on the products produced.

Annealing furnace is usually divided into four sections: 1) pre- heating section, 2) heating section, 3) holding section, and 4) cooling section. The steel sheet enters through pre-heating section at beginning of furnace and then passes through heating section where the temperature is maintained at a high level. The steel sheet, before it exits to cooling section, is passed through holding section where the temperature is comparatively lower than the heating sections. Finally the strip enters the cooling sections or the jet cooling sections where the strip is cooled to the pot bath temperature. The strip is introduced inside the bath with the help of a snout. A reducing atmosphere of hydrogen, nitrogen gas is maintained in the furnace up to the snout. The galvanneal furnace has the same features as the annealing furnace except that cooling section is not present in the galvanneal furnace.

\subsubsection{Furnace Variations}

Furnaces used in galvanizing facilities vary in characteristics based on products produced and technology utilized. The furnaces used may have radiant tube sections, direct fired sections or induction coils. In the radiant tube section the strip is heated by the heat radiated from the radiant tubes inside the furnace. The direct fired furnace is also called as direct combustion furnace 
where the flame is directly introduced to the furnace zone. Induction heating is mostly used in the galvanneal furnace in which heating of the strip is achieved by passing it in between high alternating magnetic fields.

\subsubsection{Direct Fired Furnace}

Direct fired furnaces are unique components in the production process of coated steels. These furnaces are designed to provide a uniform heating environment for the steel strip prior to the coating operation [10]. High velocity burners are mounted along both sides of the furnaces in a staggered pattern that produces excellent temperature uniformity as shown in Figure 1.4 [11].

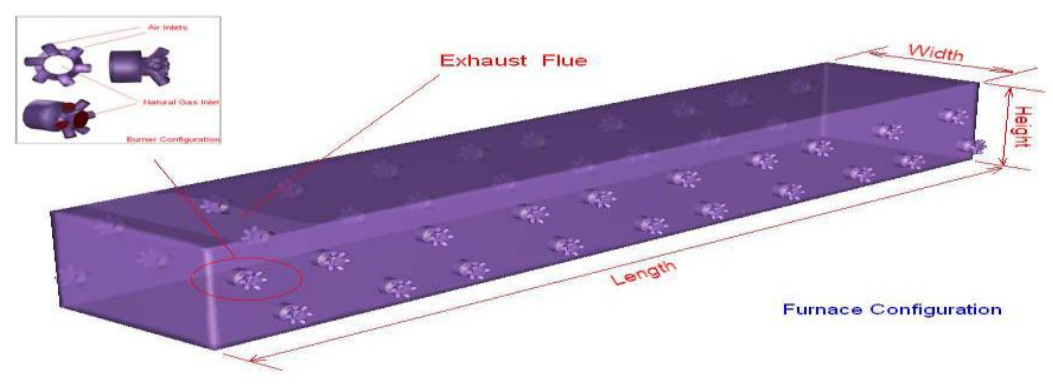

Figure 1.4: Schematic of Direct Fired Furnace [11]

Natural gas enters the burner along the central axis while air is injected into the stream tangentially. In this way, a swirl is induced to improve the mixing of the fuel and air in preparation for combustion. The steel strip enters the direct fired furnace at room temperature from one end of the furnace and moves steadily to the other end's exit while being heated. It is a continuous process with a new strip welded to the tail end of the previous strip.

\subsubsection{Radiant Tube Furnace}

Radiant tube furnaces are operated with a reducing atmosphere and are heated by natural gas fired radiant tubes. The heating of strip is almost totally accomplished by radiation. The steel strip passes between a row of burner tubes above the strip and below the strips. These burner tubes are fired to specified temperatures depending upon the facility. Heat is radiated from these tubes and is absorbed by the strip. Some heating is also achieved by radiation from the furnace walls after the furnace has been operating for a period of time. The rate or the time to heat the strip in this furnace depends upon the tube temperature. The higher the tube temperature, faster rate of heating. A schematic of traditional radiant tube burner section is shown in Figure 1.5 [12]. 


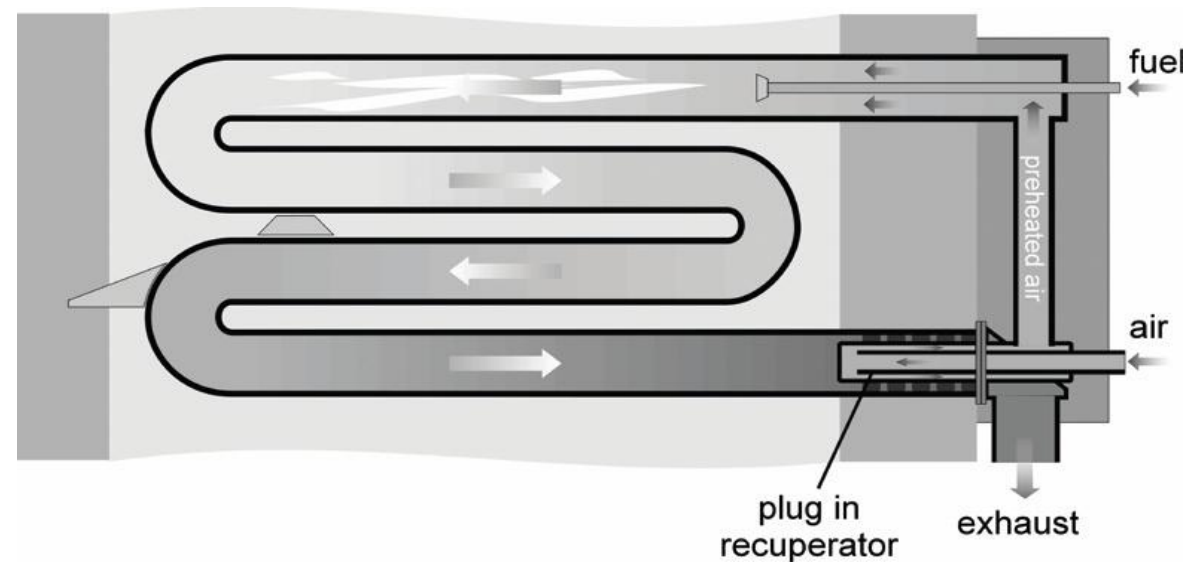

Figure 1.5: Schematic of Traditional Radiant Tube Burner Section [12]

As seen in Figure 1.5, combustion takes place at one end of the burner section and flue gas escapes through the other end. The combustion air is preheated by the flue gas with the help of plug in recuperator. The transfer of heat to the strip in radiant tube furnace is not uniform unlike direct fired furnace in which combustion takes place in a large chamber where heat can be transferred at the same time to the entire stock. Non uniform or steady composition of the combustion gases, alternating reducing and oxidizing atmosphere, is harmful to metal radiant Tubes and very hot gas pockets provoke high NOx formation in case of radiant tube furnaces [13].

\subsubsection{Induction Furnace}

Induction heating concept is widely used in galvanneal furnace than in annealing furnace [14]. The purpose of galvanneal furnace is to provide an iron-zinc alloy to the strip which is known as "galvanneal product". The temperature at which proper alloying occurs lies between $1000^{\circ} \mathrm{F}$ to $1050^{\circ} \mathrm{F}\left(538^{\circ} \mathrm{C}\right.$ to $\left.565^{\circ} \mathrm{C}\right)$. In order to get a high quality galvanneal product, it is important to control the temperature of the strip within this range and then to cool it.

The reason for using an induction furnace upon conventional gas-fired and radiant tube heating is because induction heating is more efficient than the other two. In case of conventional gas-fired heating it is difficult to control the strip temperature and cooling it rapidly. Further, the exhaust gases inhibit the rapid cooling of the strip. Similarly in case of radiant heating, to penetrate the zinc coating (which is highly reflective), the strip must dwell a fairly long time in the furnace, which can lead to temperature control problems [14]. 
The basic principle of induction heating is quite simple. Alternating current is passed through a solenoid coil; a magnetic field is produced that varies with the amount of current. The field is concentrated inside the coil. The steel strip passes inside the coil, eddy currents will be induced inside the strip and flow in a direction opposite to the current flow in the coil. Heating is caused by electrical resistance to the eddy currents induced in the strip.

In any type of heating section, the time it takes for the strip to reach a given temperature is very critical. The factors that influence these criteria are;

1. The mass or volume being heated. This is a direct function of gauge and width. For the same gauge of strip it takes longer to heat wider strip than narrower strip, and in the same manner for the same widths it takes longer to heat heavier gauge than lighter gauge to the same temperature [15].

2. Emissivity of the strip: A smooth, highly reflective strip surface will reflect rather than absorb the heat, therefore taking longer to heat than a duller, less reflective strip. This strip characteristics is generally directly proportional to the surface roughness; a rough finish being less reflective [15].

\subsubsection{Cooling Section}

The strip enters into the cooling section where it loses heat. Cooling takes place either by radiation or convection heat transfer [15]. Radiation cooling is the reverse of the method used to bring the strip up to temperature. The strip passes between rows of cooling tubes through which room temperature air is constantly being drawn. The strip radiates its heat to these tubes. This method results in relatively slow cooling rates. In convection cooling cold atmosphere furnace gas is blown over the surface of the hot strip. The furnace atmosphere gas is drawn through a heat exchanger where the gas is cooled down considerably. This cold gas is then put back into the furnace so that it blows directly on the strip. Rapid cooling rates can be attained using this method. 


\subsection{Motivation for current work}

The continuous galvanizing process is an energy intensive process in the steel industry. Figure 1.6 below shows the different forms of energy used by the steel industries and their dollar values [4]. It is evident that the dollar values for electricity and natural gas are nearly half the total expenditure. Mostly natural gas and electricity are the two sources of energy being used by galvanizers in the furnace. Hence the analysis will be done considering electricity and natural gas.

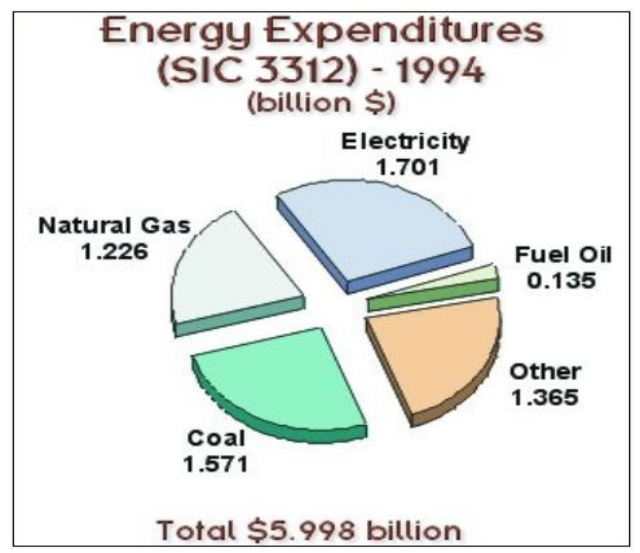

Figure 1.6: Energy Expenditures in the Steel Industry [4]

This study has investigated the performance of the furnace and cooling sections zone by zone with changing process and product parameters. It has also taken advantage of prior experimental and numerical work done on energy consumption by galvanizing lines (GEPDSS). Since the effect of energy consumption for changing product and process parameters have not been fully investigated experimentally or computationally, a generalized heat transfer approach has been used to investigate the sensitivity of galvanizing lines for changing product and process parameters.

\subsubsection{Galvanizing Energy Profiler Decision Support System (GEPDSS)}

GEPDSS is decision support system capable of investigating the effect of improved pot hardware and/or improved process equipment in continuous galvanizing lines. It performs an economic analysis on energy efficiency measures resulting from improved pot hardware or any other process related equipment in a continuous galvanizing line. It can also validate the energy savings in a continuous galvanizing line. 
This decision support enables static simulation of production, rejection and energy consumption. It allows the user to do sensitivity analysis and evaluate economic benefits of adopting new hardware materials, to analyze the impact of energy saved if they implement any energy savings and efficiency improvement technique on their equipments. The GEPDSS caters to the production and energy consumption for up to three different processes. To summarize, GEPDSS can simulate a scenario to identify the magnitude of energy and cost benefits that can be obtained as a result of any energy savings measures implemented.

\subsubsection{Enhanced Galvanizing Profiler Decision Support System (E-GEPDSS)}

A need for an enhancement of the successful GEPDSS has been identified. The enhanced system provides heat balance calculations. This allows users to perform "what if" analysis to find the effect of varying product and process parameters on energy consumption along the galvanizing line. The enhanced system (or E-GEPDSS) focuses mainly on heat balance of the galvanizing furnace, galvanneal furnace, and the zinc pot as these are the three major components in galvanizing. The utilization of GEPDSS and E-GEPDSS provides the industrial user with flexible tools to determine energy related cost savings due to production of varying product grades.

\subsection{Aim and objectives of current study}

The objective of E-GEPDSS is to explore the potential of saving energy in galvanizing lines by utilizing heat balance analysis. A large amount of data is collected in industries for generating a database. This raw data must be converted into meaningful information and must be presented in a proper format to generate knowledge about the system. This information and knowledge will help the companies to analyze their system as well as carry out sensitivity analysis for the system. The objective of this research is to convert such raw data into knowledge. The aim of this research is to design and develop a computer based model for the galvanizing line in the steel industry with the help of collected data, validate the model and evaluate the usefulness of the model in making decisions to enhance the performance of the galvanizing line. 


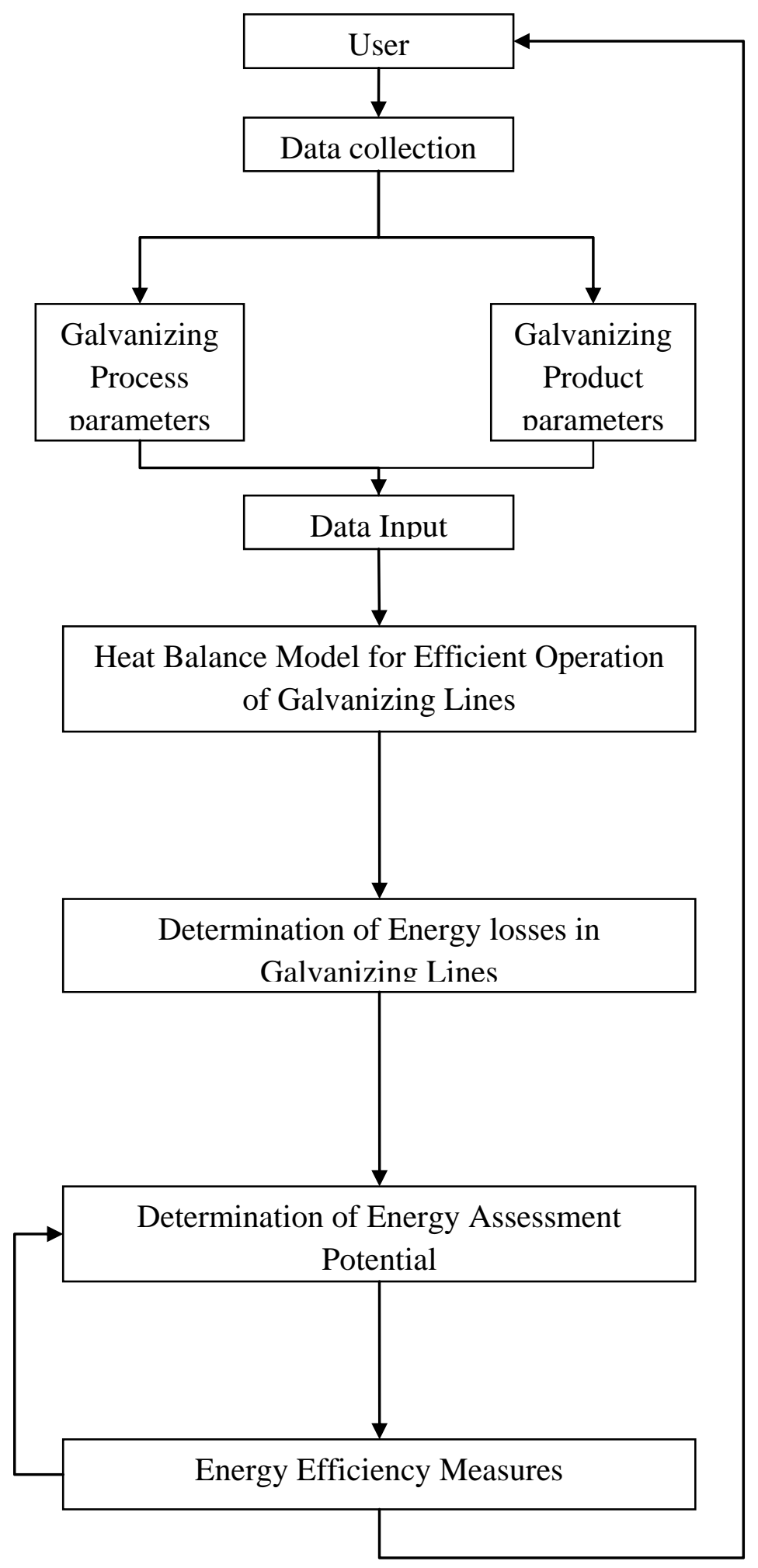

Figure 1.7 System Diagram 
The specific objectives of this research are listed as follows:

1. Develop an interactive model to estimate the energy consumed for changing product and process parameters.

2. Enable sensitivity analysis using the model to identify the key parameters sensitive to energy.

3. Validate the model using data collected during plant visits.

\subsection{Conclusion}

The galvanizing industry at present faces considerable loss of energy as a result of being inefficient in their production process. The impact of having a heat balance model used to differentiate the heat losses from useful heat is discussed in section 1.3. The proposed model is expected to analyze and provide results in terms of energy savings obtained as a result of any modification to the existing process. 


\section{CHAPTER 2}

\section{LITERATURE REVIEW}

\subsection{Energy Usage and Conservation Measures in Steel Industries}

The United States Steel Industries has taken numerous measures over the past decades to reduce its energy consumption. A study conducted on energy use: historical perspective and future opportunities in the Steel Industry [18] explained the historical reduction in energy consumption and how it offered guidance for future. A comparison is made between current average energy consumption and with those of good practices. It had proposed new technologies available for various processes in steelmaking to further reduce energy consumption per ton. It had also proposed how overall average energy consumption could be reduced by further restructuring of industries. Overall, this study had given a thorough in sight of the energy usage, concept of good practices and how further savings will accrue through new technologies.

Steel production is not only crucial in United States but all over the world. The productivity of steel in India had declined largely over the past due to the protective policy of the price and distribution of iron and steel and inefficiency in the public sector that is integrated with steel plants, It is difficult to continue these trends in future where energy use is in concern. A study on India's Iron and Steel industry [19] by Katja Schumacher and Jayant Sathaye explains the opportunities on productivity, energy efficiency and carbon emissions in iron and steel industry. They examined the current changes in structure and energy efficiency in the steel sector and concluded that, with the liberalization of the iron and steel sector, the industry is rapidly moving towards the world's best technology, which will result in fewer carbon emissions, improved productivity and more efficient energy use in existing and future plants. This report presents energy saving potentials by comparing specific energy consumption in Indian iron and steel plants with that of energy consumption in plants using the world's best technology. The report in addition focuses on categories for energy efficiency improvement including the improvement in input factors, from technology conversion and retrofitting as well as from recycling and waste heat recovery. It also states how the implementation initiatives towards energy efficiency is being hindered by barriers both of general and process nature occurring at the macro and micro 
level of the economy. Finally, carbon dioxide emissions and mitigation potentials accepting energy efficiency measures had been calculated.

Not only is energy critical for steel industries but for metal casting industries. The metal casting industry is one of the most energy intensive manufacturing sectors with the melting process accounting for over half of its energy consumption [20]. Although the consumption of energy in the melting process has been a substantial concern in foundry operations, the industry continues to use melting technologies with low energy efficiencies. A report has been generated by BCS Corporation [20] to explore the concepts of breakthrough technologies in melting metals that may drastically reduce the energy consumption. This study accomplishes its purpose by analyzing current and emerging melting technologies and discussing the barriers to scale up issues and research needed to advance these technologies. It provides the potential for improving melting efficiency, lowering metal transfer heat loss and reducing scrap and improving yield. Some of the recommendations include optimizing melting and heat treating operations; cover the furnace and maintain refractories; and install radiant panels in crucible furnaces. The report also provides information about the current condition of the furnaces used and how energy reduction can be implemented by centering on retrofit improvements for existing furnaces. Although, the report focuses on metal melting applications, the melting technologies and developments discussed in this report are applicable to all furnaces and molten material processes, including primary aluminum, secondary aluminum, glass, iron and steel, and other industries.

\subsection{Mathematical models and programming in integrated steel industries}

An algorithm was developed by Yoshitani, N and Hasegawa, A (Model-based control of strip temperature for the heating furnace in continuous annealing) [21] for cases where some knowledge on parameter variability can be obtained in advance. In this model a simplified mathematical model is derived from the first principles. The model parameters are recursively estimated with an algorithm called recursive parameter estimation with a vector-type variable forgetting factor (REVVF) where the control system of strip temperature presented is hierarchical. The upper level is called "optimal preview control", which performs preset control. It previews the approaching setup change, such as the change in strip size or reference temperature, and optimizes the line speed and the strip temperature trajectory. The lower level is called "temperature tracking control", which performs closed-loop control using the above 
trajectory as the control target. At this level, the generalized pole-placement self-tuning control was first employed; and later, the generalized predictive self-tuning control was introduced. These control methods were applied with some practical modifications and with the REVVF mentioned above. The control has been working successfully in several real plants.

Bin Zhang, Zhigang Chen, Liyun Xu, Jingcheng Wang, Jianmin Zhang, Huihe Shao worked on a model for controlling a reheating furnace [22]. The model consists of three sub-models, automatic combustion control model (ACC), dynamic model of combustion process, and control loops model. ACC model calculates the set points of furnace temperature such that the slabs in the furnace can be heated to discharging temperature. Dynamic model describes the behavior of fumace under the state of rolling line and fuel flux provided by control loop model. Control loop model, or distributed control system model (DCS) control the fuel flux of each zone according to set points of furnace temperature and state of furnace. This model can be used to develop new energy-saving techniques, or to realize quality optimization.

S. G. Blakey and S. B. M. Beck [23] came up with a dimensionless equation-demonstrating method for improving furnace efficiency. In their analysis they showed that the current method of burner turndown to reduce energy consumption will affect the thermal efficiency of the furnace especially at low levels of capacity utilization. The research targeted on energy consumption of natural gas fired galvanizing bath furnace. Their approach was the first one, using specific energy consumption from the demand and supply point of view, to describe thermal efficiency. The equations developed are used to compare furnaces of different design and fuel types [23]. However, the equations do not take any other equipment present on a galvanizing line into account.

A research team from West Virginia University and International Lead Zinc and Research Organization (ILZRO) had focused on developing decision support software called Galvanizing Energy Profiler Decision Support System (GEPDSS) that takes into account all the major energy consuming equipment in a typical hot dip continuous line. This DSS allows the user to model their galvanizing line in Excel ${ }^{\mathrm{TM}}$ based software. The DSS maintains track of the current production and energy consumption for up to three different processes. It can simulate a scenario to identify the magnitude of benefits that can be obtained as a result of any energy savings measures implemented [6]. 
US-DOE Process Heating Assessment and Survey Tool (PHAST ${ }^{\mathrm{TM}}$ ) [9] from Industrial Heating Equipment Association provides data for energy lost as a result of improperly or un-insulated surfaces and calculate efficiency based on air fuel ratio and heat balances for process heating equipment, respectively.

\subsection{Conclusion}

This literature review gives an idea about the work carried out in the area of energy conservation in steel industry and the measures taken towards reducing the energy cost and optimizing the utility resources in steel industry. It can be seen that a lot of research had been carried out in the area of energy conservation in the steel manufacturing process. New technology and use of mathematical models for optimization had helped the iron and steel manufacturing process to be energy efficient.

There is no source available at present to compute the amount of energy consumed by a continuous galvanizing line when switching between different product grades and process parameters. The model developed through this research could be used for sensitivity analysis and process enhancement decisions. Thus, research in this area will be of immense help to the steel industry for analyzing and improving their energy efficiency. 


\section{CHAPTER 3}

\section{RESEARCH APPROACH}

\subsection{Goals of the project}

The research objectives of the project are listed below.

- Studying the Galvanizing line parameters by plant visits.

- Heat balance of annealing and galvanneal furnace.

- Development of software (E-GEPDSS) to enable sensitivity analysis from heat balance model.

- Validation of heat balance model with the data collected during plant visits.

\subsection{Studying the galvanizing process (Plant Visits and Data collection)}

A detailed study of the continuous galvanizing line was achieved by visiting lead galvanizing facilities. A detailed list of the furnace components and parameters were noted and studied. Discussion with the plant personnel helped in collecting accurate data on the furnace components and process parameters. A preliminary model consisting of different losses with the furnace was developed using all the data collected from the visits, and by reviewing heat transfer concepts.

The presentation of this preliminary model in the Galvanizers Association Meeting held in Baltimore, St Louis and Louisville helped in refining the model. The feedback from the meeting was taken into account and the model is being developed further in the galvanizer's point of view. Additional visits to the facilities were conducted to ensure the accuracy of the data used for the trial analysis. Several literature reviews helped the model being developed successfully. An Excel ${ }^{\circledR}$ model with heat balance equations formulating heat losses and sensitivity analysis was developed.

\subsubsection{Plant Visits and Data Collection}

Plant visits play an important role in this project. The model needs a real life data on the galvanizing lines for accuracy and these plant visits helped in the improvement of this project. The plant visited was US Steel Fairless Works, Fairless Hills, PA. Two trips were made to the plant to collect sufficient data for the model. Initial trip was made to gain knowledge on the 
galvanizing lines and also to collect data for the preliminary model. The second visit was to ensure the accuracy of the data used for trial analysis. During this visits the data collected were further refined and several observations and measurements were performed on the furnace section. Measurements on the galvanizing line are impossible without suitable instruments therefore a set of instrument kit was also taken to the plant. Some of the instruments needed for the measurements are Thermal Camera (helps to see variations in temperature), Temperature Gun (used for measuring temperatures of an object without contact), Combustion Stack Gas Analyzer. In addition to this, data was also collected from computers controlling the galvanizing line. The computer controlled system provided data for different temperatures maintained in different zones, strip temperature at the entry and exit of the zones and the flow readings for hydrogen and nitrogen. The data and information collected from the facility and other sources were refined and simplified to obtain the most accurate information possible. These visits helped in populating the model with real time data.

\subsection{Heat Balance}

The objective of this research is to study the heat balance of the furnace. The input energy to the furnace is being absorbed by the steel strip that passes through the furnace which is otherwise called as useful heat. The rest of the available heat is dissipated as losses such as conduction through the walls, radiation and convection by the furnace surfaces, stack or flue gas loss, cooling water loss, protection gas loss and opening loss. The losses are discussed in detail in the section 3.5.

\subsection{Heat Transfer Parameters}

Several parameters were identified and selected for the study. The following subsections describe the importance of each parameter.

\subsubsection{Emissivity $(\varepsilon)$}

The emissivity of an object is a ratio of the reflected and absorbed energy at the same temperature. A true blackbody has an emissivity of 1.00 , so a ratio that is closer to 1.00 would indicate that the object is closer to being a blackbody and would retain the heat or energy that the 
object contains. Since the study is associated with the heat losses, emissivity plays an important role in radiation loss. The radiation loss was determined using equation 1 [26].

$$
Q=\varepsilon \sigma A\left(T_{f w}^{4}-T_{a}^{4}\right)
$$

The emissivity depends upon the material considered for study which is steel in this case. Based on the literature review the emissivity for steel is found to be in the range of $0.5-0.9$ [35].

\subsubsection{Stephen Boltzmann Constant $(\sigma)$}

The relationship between radiant energy and temperature for a black body radiator is referred to as Stephen-Boltzmann constant. It relates the total radiant energy $\left(\mathrm{Btu} / \mathrm{hr}-\mathrm{ft}^{2}\right)$ from the surface of the black body to its temperature T:

$$
F=\sigma A T^{4}
$$

Where, $\sigma$ is the Stephen-Boltzmann constant in equation 2 [26].

The radiating body to be investigated in this experiment is the walls of the furnace. The walls are not a perfect black body radiator instead it can be thought of as a grey body that emits some fraction of the black body radiation given by its emissivity, $\varepsilon_{\text {: }}$ The radiant flux is simply the heat dissipated per unit area. Thus the total radiated energy by the walls can be represented as shown in equation 3 [26].

$$
Q=8 \sigma A T^{4}
$$

\subsubsection{Heat Transfer Coefficient (h)}

Heat energy transferred between a surface and a moving fluid or atmosphere at different temperatures is referred as convection. In this case the furnace walls are the surface and the atmosphere acts as the moving fluid. The convective heat transfer considered here is natural or free convection. The heat transfer per unit surface through convection was first described by Newton and the relation is known as the Newton's Law of Cooling. The equation for convection can be expressed as formula 4 [27] shown below. 


$$
Q=h A \Delta T
$$

Where, $\mathrm{h}$ is the heat transfer coefficient $\left(\mathrm{Btu} / \mathrm{hr}-\mathrm{ft}^{2}{ }^{\circ} \mathrm{F}\right)$.

\subsubsection{Specific heat capacity $\left(c_{p}\right)$}

Specific heat is the amount of heat per unit mass required to raise the temperature by one degree Fahrenheit. The relationship between heat and temperature change is usually expressed in the form shown below in formula 5 [26] where, cp is specific heat.

$$
Q=m c_{p} \Delta T
$$

\subsection{Furnace Heat Loss}

The Figure 3.1 shows the schematic representation of the heat supply and losses in a furnace.

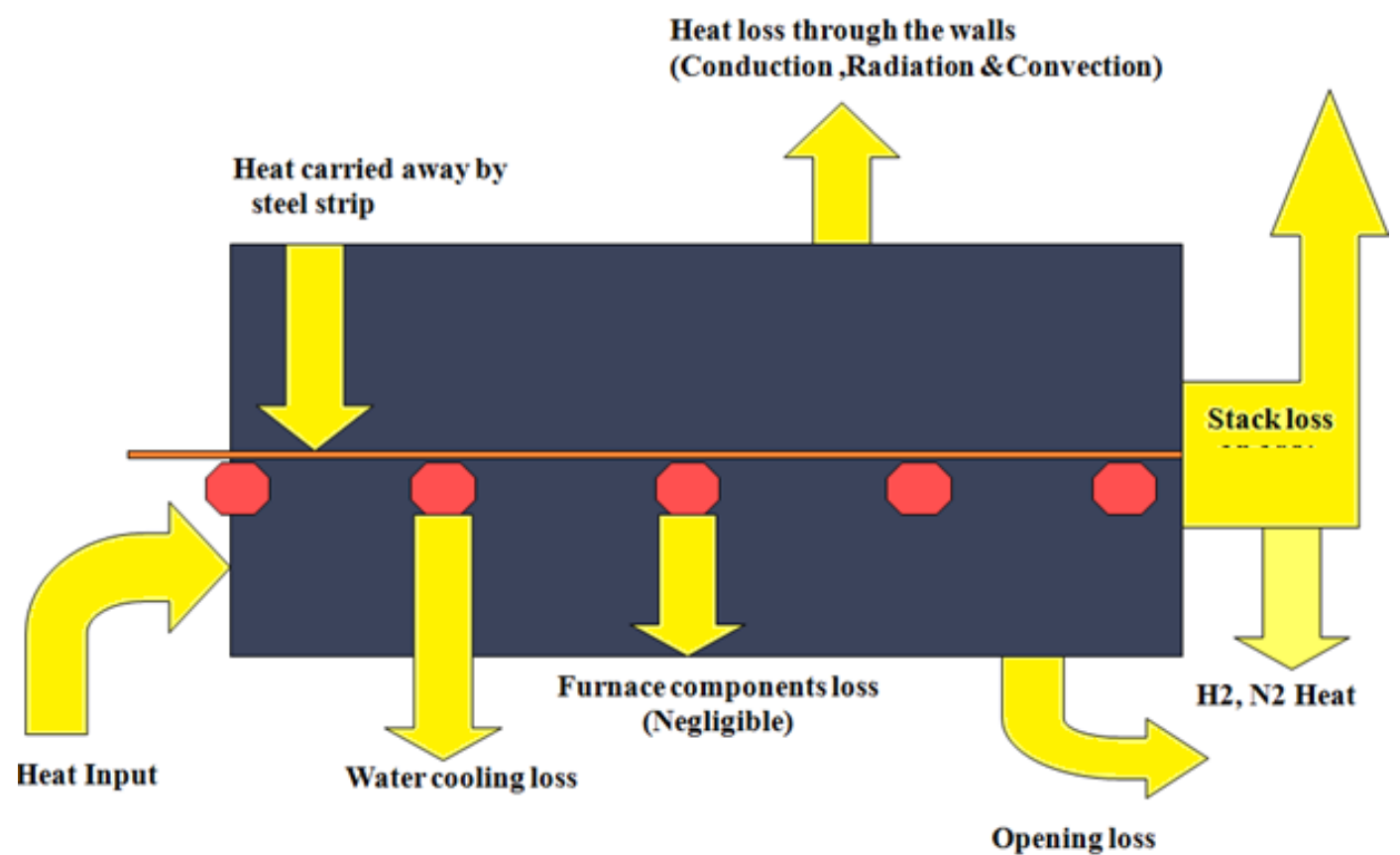

\section{Figure 3.1 Furnace Heat Loss}

The following sections detail the methods and results for heat loss through various furnace components. 


\subsubsection{Heat Balance Fundamentals}

The principle of the conservation of matter provides a simple, straightforward approach to setting up a materials balance. Similarly, the principle of energy conservation (also known as the First Law of Thermodynamics) provides a sound basis for setting up an energy balance. All that is essential is a knowledge of what enters and leaves the system; there is little or no need to consider the complexities and mechanisms of the process within the system [31].

\subsubsection{Heat Units}

The US unit for energy is the Btu (British thermal unit), but nearly all thermochemical and thermodynamic data are expressed in the units of calorie. The relationship among these units are:

$$
\begin{aligned}
& 1 \mathrm{Btu}=252 \mathrm{cal} \\
& 1 \mathrm{kcal}=\quad 3.97 \mathrm{Btu} \\
& 1 \mathrm{kcal}=\quad 1,000 \mathrm{cal}
\end{aligned}
$$

The calorie will be used for the heat input calculations in this model and then converted to Btu, since the calorie occurs most frequently in the thermodynamic tabulations. The calorie is defined as the amount of heat required to raise the temperature of one gram of water from 58 to $60^{\circ} \mathrm{F}$ (14.5 to $\left.15.5^{\circ} \mathrm{C}\right)$ [33].

\subsubsection{Heat Content}

The thermodynamic function of enthalpy is used to describe the heat content of a system. It is a state function, and since its absolute value is not known, it can be expressed only in terms of differences. The base temperature is taken as $77^{\circ} \mathrm{F}\left(298^{\circ} \mathrm{K}\right.$ or $\left.25^{\circ} \mathrm{C}\right)$ and the term HT - H77 represents the heat content above the base temperature. This heat is commonly called as the "sensible heat." The enthalpy function involves a constant pressure process. Enthalpy can be changed by temperature, by changes in state such as liquid to solid, by the formation of compounds from elements, and by the formation or dilution of solutions [33].

The units used to describe heat content are: calorie per gram-mole, kcal per gram-mole, Mcal per kilogram-mole, and Btu per pound mole. The conversions are given below: 


$$
\begin{array}{lll}
1000 \mathrm{cal} / \mathrm{gm}-\mathrm{mole} & = & 1 \mathrm{kcal} / \mathrm{gm}-\mathrm{mole} \\
1 \mathrm{Mcal} / \mathrm{kg}-\mathrm{mole} & = & 1000 \mathrm{kcal} / \mathrm{kg} \text {-mole } \\
1 \mathrm{Mcal} / \mathrm{kg}-\mathrm{mole} & = & 1800 \mathrm{Btu} / \mathrm{lb}-\mathrm{mole}
\end{array}
$$

\subsubsection{The Components of the Heat Balance}

The major components of the heat balance are: the sensible heat of reactants and products; the heats of formation of products and decomposition of reactants; the additional external energy supplied; and other energy losses from the system. The total heat inputs and outputs must be equal in a steady-state process in which there is no accumulation of energy. The unaccounted loss represents the heat which has not properly been accounted. The components of the heat balance are shown in table 3.1 [33].

\section{Table 3.1 Major Components of Heat balance}

\begin{tabular}{|c|l|l|}
\hline \multicolumn{1}{|c|}{ HEAT INPUT } & \multicolumn{1}{c|}{ HEAT OUTPUT } \\
\hline 1 & Sensible Heat of Reactants & Sensible Heat of Products \\
\hline 2 & $\begin{array}{l}\text { Heat of Formation of } \\
\text { Products }\end{array}$ & $\begin{array}{l}\text { Heat of Decomposition of } \\
\text { Reactants }\end{array}$ \\
\hline 3 & External Heat Supplied & Heat Evolved \\
\hline $3 \mathrm{a}$ & Electrical & Heat Losses \\
\hline $3 \mathrm{~b}$ & Unaccounted & Unaccounted \\
\hline
\end{tabular}

\subsubsection{Sensible Heat}

The sensible heat is the enthalpy increment above or below the reference temperature for the element under consideration. It includes the heat in all transformations, such as melting and vaporization. The variation of heat content with temperature is expressed adequately for most substances by the empirical relation [33]:

$$
\mathrm{H}_{\mathrm{T}}-\mathrm{H}_{\mathrm{TR}} \quad=\quad \mathrm{aT}+\mathrm{bT}^{2}+\mathrm{CT}^{-1}+\mathrm{d}
$$

T: Temperature point of interest $\left({ }^{\circ} \mathrm{K}\right)$

TR: Reference temperature $\left(298^{\circ} \mathrm{K}, 25^{\circ} \mathrm{C}, 77^{\circ} \mathrm{F}\right)$ 
In this equation, $\mathrm{H}_{\mathrm{T}}-\mathrm{H}_{\mathrm{TR}}$ is the increase in the heat content, as the substance is heated from the base temperature to the required temperature. Using equation (6) (32), the heat content above the base temperature is readily calculated from given values of a, b, c and d as long as no change in state of aggregation occurs between the reference temperature and desired temperature. The values for the constants for different metals and gases are given in the appendix. However, if the heat content is to be calculated for the same substance in a different state of aggregation, another equation with different values of $a, b, c$ and $d$ must be used.

\subsubsection{Heat of Formation and Decomposition}

When a chemical compound is formed from its elements, heat is either liberated or absorbed. If heat is liberated, the reaction is called as exothermic reaction, and the heat is produced in the system. If heat is absorbed, the reaction is called as endothermic reaction, and the heat is supplied to the system.

The heat of formation with the chemical change depends upon the nature of the reacting elements and the compound formed. The reacting elements are in their standard states, the pressure is maintained at $1 \mathrm{~atm}$, the reaction starts and ends at $25^{\circ} \mathrm{C}\left(77^{\circ} \mathrm{F}\right)$, and the compound formed is also in its standard state.

The decomposition of a compound into its constituent elements in their standard states is the reverse of that compound's formation; therefore, a compound's heat of decomposition is the negative of its formation [33].

\subsubsection{Heat Losses, and Unaccounted Losses}

Heat losses through the furnace walls can be estimated via the thermodynamic relations concerning conduction, convection, and radiation. Heat losses in water-cooled furnace rolls can be estimated from the flow rate and the temperature gain of the cooling water.

The heat balance determines the amount of energy and how the energy is used in the system. Due to inaccuracies in the measurement of the quantities charged, temperature of the gases, temperature of the walls, and area considered for losses, the totals for the input and output energy will not balance. The difference between the heat input and output is the unaccounted loss. 


\subsubsection{Heat Conducted Through the Walls - (Conduction)}

Conduction is heat transfer by means of molecular agitation within a material without any motion of the material as a whole. If one end of a metal is at a higher temperature, then energy will be transferred down the metal toward the colder end because the higher speed particles will collide with the slower particles with a net transfer of energy to the slower particles. In this case the higher temperature body is the inside walls of the furnace and the colder end is the outside walls of the furnace. The amount of heat transfer depends on the insulation of the furnace. The heat loss is less when there is more insulation. The heat conducted through the furnace wall can be calculated by using the formula [26] as follows:

\section{Calculation:}

$$
Q=A\left(T_{p}-T_{w}\right) /\left(\frac{t_{p}}{k_{p}}+\frac{t_{1}}{k_{1}}+\frac{t_{2}}{k_{2}}\right)
$$

Q: Heat loss through the walls by heat conduction (Btu/hr)

$\mathrm{t}_{\mathrm{p}}$ : Thickness of furnace wall material (ft)

$\mathrm{t}_{1}$ : Thickness of insulating material $1(\mathrm{ft})$

$\mathrm{t}_{2}$ : Thickness of insulating material $2(\mathrm{ft})$

$\mathrm{k}_{\mathrm{p}}$ : Thermal conductivity of furnace material $\left(\mathrm{Btu} / \mathrm{hr} . \mathrm{ft} .{ }^{\circ} \mathrm{F}\right)$

$\mathrm{k}_{1}$ : Thermal conductivity of insulating material 1 (Btu/hr.ft. $\left.{ }^{\circ} \mathrm{F}\right)$

$\mathrm{k}_{2}$ : Thermal conductivity of insulating material $2\left(\mathrm{Btu} / \mathrm{hr} . \mathrm{ft} .{ }^{\circ} \mathrm{F}\right)$

A: Area of furnace walls $\left(\mathrm{ft}^{2}\right)$

$\mathrm{T}_{\mathrm{p}}$ : Temperature inside the furnace $\left({ }^{\circ} \mathrm{F}\right)$

$\mathrm{T}_{\mathrm{w}}$ : Temperature at the outer surface of furnace walls $\left({ }^{\circ} \mathrm{F}\right)$ 


\subsubsection{Heat Loss Through other Surfaces (Fins, Burner walls and other typical surfaces emitting heat) - (Radiation \& Convection)}

\section{a) Radiation}

In this study, surfaces like beams, burner walls and other typical surfaces capable of emitting heat are energy emitting body and the atmosphere is the absorbing body. The relationship governing radiation from hot objects is called the Stephen-Boltzman law. Significant amount of heat is lost through these surfaces. The heat conducted through the surfaces is radiated and convected to the outside atmosphere.

Radiation heat energy loss is influenced by the temperatures maintained in the zone, insulation materials and the surface material. The emissivity of these surface materials is a critical factor in radiation. The radiation loss can be calculated using the formula [26] below.

\section{Calculation:}

$$
Q=\varepsilon B A\left(T_{s}^{4}-T_{a}^{4}\right)
$$

Q: Radiation heat loss from surfaces (Btu/hr)

$\varepsilon:$ Emissivity of the surfaces

B: Stephen Boltzmann constant $-0.1714\left(\mathrm{Btu} / \mathrm{h}-\mathrm{ft}^{2}-{ }^{\circ} \mathrm{R}^{4}\right)$

A: Area of other surfaces $\left(\mathrm{ft}^{2}\right)$

$\mathrm{T}_{\mathrm{s}}$ : Average surface temperature of other surfaces and burner walls $\left({ }^{\circ} \mathrm{R}\right)$

$\mathrm{T}_{\mathrm{a}}$ : Ambient temperature $\left({ }^{\mathrm{o}} \mathrm{R}\right)$

\section{b) Convection}

Convection is heat transfer by mass motion of a fluid such as air or water when the heated fluid is caused to move away from the source of heat, carrying energy with it. Convection above a hot surface occurs because hot air expands, becomes less dense, and rises. The heat transfer coefficient is an important factor to be considered in convective heat transfer. The heat transfer coefficient depends upon the type of fluid - gas or liquid, the flow properties such as velocity, 
flow and temperature dependent properties. The convection loss can be calculated using the formula [27] below.

Calculation:

$$
Q=h A\left(T_{z}-T_{a}\right)
$$

Q: Convection heat loss from other surfaces (Btu/hr)

h: Heat convection coefficient $\left(\mathrm{Btu} / \mathrm{hr} . \mathrm{ft}^{2}{ }^{\mathrm{o}} \mathrm{F}\right)$

A: Total other surface area $\left(\mathrm{ft}^{2}\right)$

$\mathrm{T}_{\mathrm{z}}$ : Surface temperature $\left({ }^{\circ} \mathrm{F}\right)$

\subsubsection{Heat absorbed by the steel strip}

Most of the heat is carried away by the steel strip passing through the furnace. This heat is called as the useful heat. The heat transfer mechanism depends on the type of furnace. In case of direct fired furnace, heat provided by the burners is conducted by the steel sheet unlike the radiant tube furnace where the steel sheet gains heat by the radiation from radiant tubes inside the furnace. Induction heating is applied usually in galvanneal furnace where the steel sheet is passed in between alternating magnetic field.

\section{Calculation}

$$
\mathrm{Q}=\text { Sensible heat } \mathrm{x} \text { Amount of Fe, C (in } \mathrm{kg} \cdot \mathrm{mol} / \mathrm{hr} \text { ) }
$$

Q: Heat carried away by the steel strip (Btu/hr)

$\mathrm{m}$ : Amount of Fe, C (lbs/hr)

where $\mathrm{m}=\mathrm{d} * \mathrm{~L} * \mathrm{t} * \mathrm{w} * 60$

$\mathrm{d}$ : Density of steel $\left(\mathrm{lb} / \mathrm{ft}^{3}\right)$

L: Line speed (ft/min)

$\mathrm{t}$ : thickness of the steel strip (ft) 
w: width of the steel strip (ft)

$$
\text { Amount of Fe, } \mathrm{C}=\frac{\mathrm{lbs}}{\mathrm{hr}} \mathrm{Fe}, \mathrm{C} \times \frac{1 \mathrm{lb} \mathrm{mol}}{55.85 \mathrm{lbs} F e, C} \times \frac{1 \mathrm{~kg}}{2.2 \mathrm{lbs}}=\frac{\mathrm{kg} \cdot \mathrm{mol}}{\mathrm{hr}} \mathrm{Fe}, \mathrm{C}
$$

Sensible heat of substance at $\mathrm{T}^{0} \mathrm{~K}: \mathrm{H}_{\mathrm{T}}-\mathrm{H}_{298}=\frac{\mathrm{aT}+\mathrm{bT}^{2}+\mathrm{cT}^{-1}+\mathrm{d}}{1000} \quad$ [31]

$\mathrm{H}_{\mathrm{T}}-\mathrm{H}_{298}$ is in Mcal/kg.mol

a, b, c, d: coefficients for $\mathrm{Fe}(\alpha) \& \mathrm{C}$ (graphite) (given in the Appendix)

$\mathrm{T}_{\text {exit }}$ : Temperature of the strip at the entry $\left({ }^{0} \mathrm{~K}\right)$

$\mathrm{T}_{\text {entry: }}$ Temperature of the strip at the exit $\left({ }^{0} \mathrm{~K}\right)$

\subsubsection{Stack Heat Loss}

During combustion, fuel remains unburnt and escapes through the stack carrying certain amount of heat. The generated flue gas during combustion has to be disposed off through the stack. This gas carries away significant amount of heat with it which is called stack heat loss. The composition is usually carbon dioxide, carbon monoxide, nitrogen and water vapor and excess oxygen if any. Carbon monoxide is usually unstable at high temperatures, therefore it is not considered as a combustion product in this study.

\section{$\underline{\text { Calculation }}$}

$$
\mathrm{Q}=\text { Sensible heat } \mathrm{x} \text { Amount of Combustion Products (in kg.mol/hr) }
$$

Q: Stack heat loss (Btu/hr)

$\mathrm{m}$ : Amount of combustion products going through the stack (kg.mol/hr)

where $\mathrm{m}=$ The amount observed by balancing the combustion equation

$$
\text { Amount of } \mathrm{Fe}, \mathrm{C}=\frac{\mathrm{lbs}}{\mathrm{hr}} \mathrm{Fe}, \mathrm{C} \times \frac{1 \mathrm{lb} \mathrm{mol}}{55.85 \mathrm{lbs} F e, C} \times \frac{1 \mathrm{~kg}}{2.2 \mathrm{lbs}}=\frac{\mathrm{kg} \cdot \mathrm{mol}}{\mathrm{hr}} \mathrm{Fe}, \mathrm{C}
$$

Sensible heat of substance at $\mathrm{T}^{0} \mathrm{~K}: \mathrm{H}_{\mathrm{T}}-\mathrm{H}_{298}=\frac{\mathrm{aT}+\mathrm{bT}^{2}+\mathrm{cT}^{-1}+\mathrm{d}}{1000}$ 
$\mathrm{H}_{\mathrm{T}}-\mathrm{H}_{298}$ is in $\mathrm{Mcal} / \mathrm{kg} . \mathrm{mol}$

a, b, c, d: coefficients for combustion products (given in the Appendix)

$\mathrm{H}_{\mathrm{T}}$ : Enthalpy of natural gas combustion products at stack temperature (Mcal/hr)

$\mathrm{H}_{298}$ : Enthalpy of natural gas combustion products at reference temperature (Mcal/hr)

\subsubsection{Water Cooling Heat Loss}

The steel sheet is passed through the furnace with the help of transfer rolls. These transfer rolls are made of steel which conducts certain amount of heat that is supplied by the furnace. These rolls remain in the furnace and are cooled by passing water through them. The water while passing through the rolls absorbs heat by conduction and exits at a temperature higher than the inlet temperature.

\section{Calculation}

$$
Q=m c\left(T_{\text {exit }}-T_{\text {entry }}\right)
$$

Q: Water cooling heat loss (Btu/hr)

$\mathrm{m}$ : flow of water (gallons/min)

c: specific heat capacity of water $\left(\mathrm{Btu} / \mathrm{lb}-{ }^{\circ} \mathrm{F}\right)$

$\mathrm{T}_{\text {exit: }}$ Exit temperature of water $\left({ }^{\circ} \mathrm{F}\right)$

$\mathrm{T}_{\text {entry: }}$ : Entry temperature of water $\left({ }^{\circ} \mathrm{F}\right)$

Conversion factor: Gallons to pounds of water: 1 gallon $=8.35 \mathrm{lbs}$

\subsubsection{Opening Loss (Radiation) - Opening to accommodate steel strip entry}

Furnaces and ovens operating at temperatures above $1,000^{\circ} \mathrm{F}$ have significant radiation losses. Hot surfaces radiate energy to nearby colder surfaces, and the rate of heat transfer increases with the fourth power of the surface's absolute temperature. Anywhere or anytime there is an opening in the furnace enclosure, heat is lost by radiation, often at a rapid rate. These openings include the furnace stack and doors left completely/partially open to accommodate charging or oversized work piece in the furnace. 


\section{Calculation}

$$
Q=\varepsilon B A\left(T_{s}^{4}-T_{a}^{4}\right)
$$

Q: Radiation heat loss from surfaces - average temperature at the opening (Btu/hr)

$\varepsilon:$ Emissivity of surfaces - furnace wall, steel strip

B: Stephen Boltzmann constant - $0.1714\left(\mathrm{Btu} / \mathrm{h}-\mathrm{ft}^{2}-{ }^{\circ} \mathrm{R}^{4}\right)$

A: Area of opening $\left(\mathrm{ft}^{2}\right)$

$\mathrm{T}_{\mathrm{s}}$ : Average surface temperature near the opening and the steel strip $\left({ }^{\mathrm{o}} \mathrm{R}\right)$

$\mathrm{T}_{\mathrm{a}}$ : Ambient temperature $\left({ }^{\mathrm{o}} \mathrm{R}\right)$

\subsubsection{Phase Change Heat Loss}

Phase change is the heat loss related to the change in the material structure of the steel strip when it is heated to high temperatures. Determination of heat losses due to phase change vary with product type. As the steel strip is annealed in the furnace, phase changes occur based upon product and process parameters. During such phase changes heat is either released (exothermic) or gained (endothermic).

The Figure 3.2 [30] represents the Iron-Carbon phase diagram for steel with different composition of carbon at different temperatures. Low carbon steels are the most commonly used galvanizing product and usually contains $0.03 \%$ of carbon. The initial phase is Ferrite $(\alpha)$ as shown in the figure. Phase change occurs at around $738^{\circ} \mathrm{C}\left(1360^{\circ} \mathrm{F}\right)$. At this point the steel has two phases, Ferrite and Austenite $(\alpha \& \gamma)$. There is not much of a phase change in this region. Complete phase change for a $0.03 \%$ carbon steel from ferrite to austenite occurs around $912^{\circ} \mathrm{C}$ $\left(1674^{\circ} \mathrm{F}\right)$. Therefore heat due to phase change is realized only above $912^{\circ} \mathrm{C}\left(1674^{\circ} \mathrm{F}\right)$. Since there is not much of heat involved in between $738^{\circ} \mathrm{C}\left(1360^{\circ} \mathrm{F}\right)$ and $912^{\circ} \mathrm{C}\left(1674^{\circ} \mathrm{F}\right)$, this loss can be considered negligible. For steels at high temperatures, the heat content can be calculated by calculating the difference in enthalpy. 


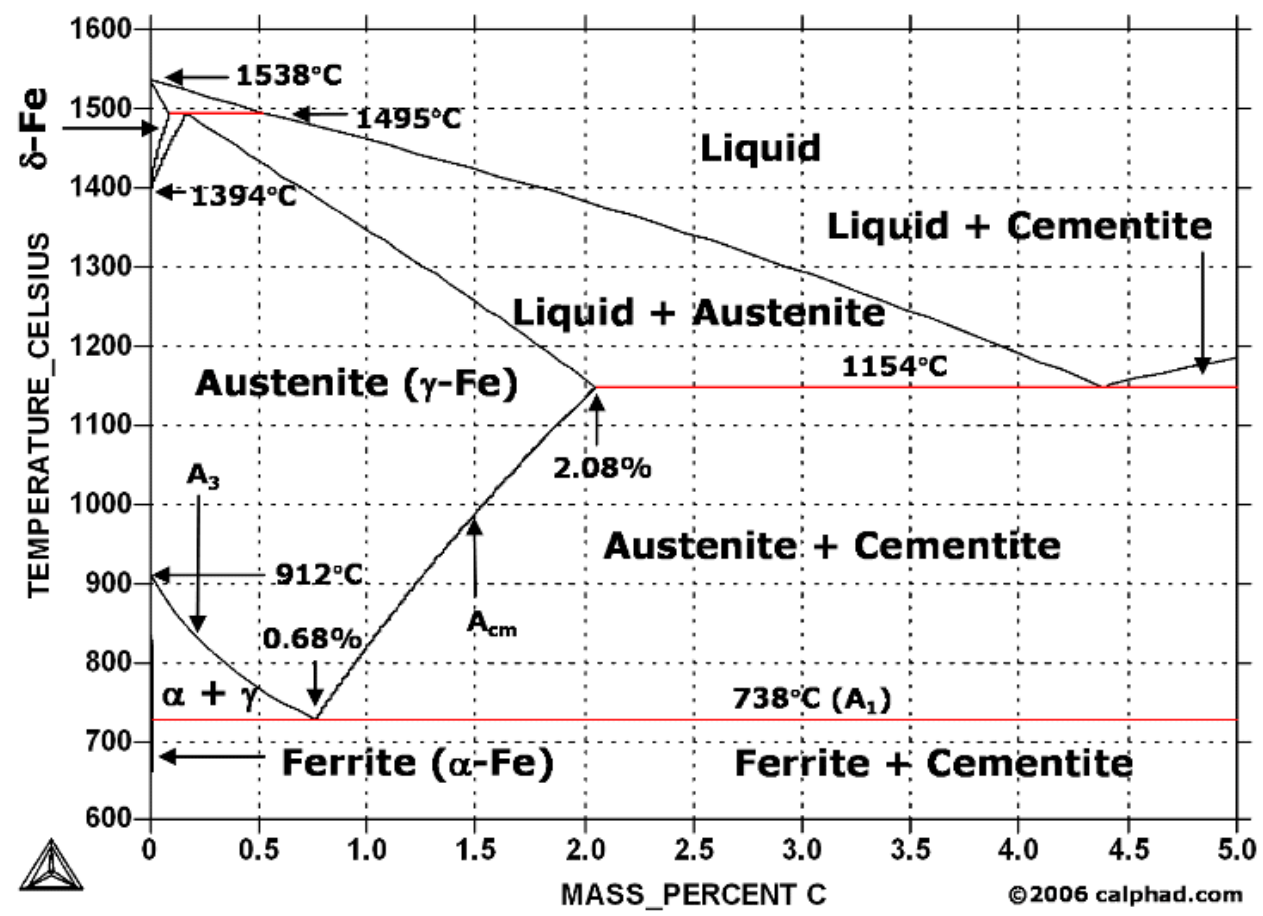

Figure 3.2 Iron-Carbon Phase Diagram

\subsection{Cooling Section}

In this section the steel strip loses certain amount of heat that it gained from the heating section. The steel strip is cooled either by radiation cooling or convection cooling which is done with the help of heat exchangers or with blowers. The amount of energy needed by the blowers to provide the cooling can be determined based on the extent of heat loss needed.

Calculation:

$$
Q=n m c\left(T_{\text {exit }}-T_{\text {entry }}\right)
$$

Q: Heat loss due to cooling section (Btu/hr)

$\mathrm{n}$ : number of cooling sections

$\mathrm{m}$ : amount of steel strip going through the Zinc bath per hour (lbs/hr)

where $\mathrm{m}=\mathrm{d}^{*} \mathrm{~L} * \mathrm{~A}$

$\mathrm{d}$ : density of steel $\left(\mathrm{lb} / \mathrm{ft}^{3}\right)$

L: line speed (ft/min) 
A: cutting area of steel strip $\left(\mathrm{ft}^{2}\right)$

where $\mathrm{A}=$ thickness*width

$\mathrm{T}_{\text {exit: }}$ Temperature of the strip at the entry $\left({ }^{\circ} \mathrm{F}\right)$

$\mathrm{T}_{\text {entry: }}$ Temperature of the strip at the exit $\left({ }^{\circ} \mathrm{F}\right)$

c: specific heat capacity of steel $\left(\mathrm{Btu} / \mathrm{lb}-{ }^{\circ} \mathrm{F}\right)$

\subsection{Jet Cooling Section}

In this section the steel strip will lose considerable amount of heat as compared to small amount lost in cooling section. Jet cooling section has higher cooling capacity than cooling sections to reduce temperature of steel strip approximately to pot temperature. Cooling takes place either by radiation or convection achieved by the means of heat exchangers or blowers. The amount of energy required by blowers to provide cooling can be determined based on the extent of heat loss needed.

\section{Calculation:}

$$
Q=n m c\left(T_{\text {exit }}-T_{\text {entry }}\right)
$$

Q: Heat loss due to cooling section (Btu/hr)

$\mathrm{n}$ : number of Jet cooling sections

m: amount of steel strip going through the Zinc bath per hour (in lbs/hr)

where $\mathrm{m}=\mathrm{d} * \mathrm{~L} * \mathrm{~A}$

$\mathrm{d}$ : density of steel $\left(\mathrm{lb} / \mathrm{ft}^{3}\right)$

L: line speed (ft/min)

A: cutting area of steel strip $\left(\mathrm{ft}^{2}\right)$

where $\mathrm{A}=$ thickness* width

$\mathrm{T}_{\text {exit: }}$ Temperature of the strip at the entry $\left({ }^{\circ} \mathrm{F}\right)$

$\mathrm{T}_{\text {entry }}$ : Temperature of the strip at the exit $\left({ }^{\circ} \mathrm{F}\right)$

c: specific heat capacity of steel $\left(\mathrm{Btu} / \mathrm{lb}-{ }^{\circ} \mathrm{F}\right)$ 


\subsection{Induction Heating}

Induction is a heating technique for electrical conductive materials (metals). It is frequently applied in several thermal processes such as melting and the heating of metals. Induction heating has the important characteristic that the heat is generated in the material to be heated itself. Because of this, induction has a number of advantages, such as a very good response and a good efficiency. The heating speeds are extremely high because of the high power density.

\section{Calculation:}

\section{Power Transfer:}

The load of an induction system is heated because of induced eddy currents. A simple formula can be used to find the amount of heat transferred inside the system.

Power Input $\quad: \quad \sqrt{3} \times V \times I \times \operatorname{Cos} \emptyset$

Where,

$\mathrm{V} \quad$ : line to line voltage

I : line current

$\operatorname{Cos} \varnothing \quad: \quad$ power factor

\section{Heat Stored:}

The effective heat stored inside the furnace depends upon the efficiency of induction. The efficiency of induction depends upon the type of frequency converters used.

The supplies can occur in different ways, depending on the frequency at which the system has to work.

Heat Stored : $\quad \sqrt{3} \times V \times I \times \operatorname{Cos} \emptyset \times \eta$

Where,

$\mathrm{V} \quad$ : line to line voltage 


$\begin{array}{lll}\text { I } & : & \text { line current } \\ \operatorname{Cos} \emptyset & : & \text { power factor } \\ \eta & : & \text { efficiency of induction }\end{array}$

\section{Water Cooling:}

The inductor consists of copper tube which is internally water cooled. The inductor is cooled continuously to keep the inductor from overheating and to provide long life to the inductors. The amount of heat transferred to the cooling water is the difference between the power input and heat stored.

Water Loss $\quad: \quad \sqrt{3} \times V \times I \times \operatorname{Cos} \emptyset-\sqrt{3} \times V \times I \times \operatorname{Cos} \emptyset \times \eta$

\section{Heat Carried away by Steel Strip}

Heat is stored inside the furnace. This heat that is stored will be transferred to the steel sheet passing through the furnace and to the walls of the furnace. Therefore, the effective heat carried away by the steel strip is the difference in between the heat stored and wall losses.

Steel Strip $\quad: \quad \sqrt{3} \times V \times I \times \operatorname{Cos} \emptyset \times \eta-$ Wall Losses 


\subsection{Load Factor and Efficiencies}

\section{Load Factor}

Load factor for the burners are determined from this study. It helps the user to differentiate between the actual operating capacity and rated capacity. The ratio of these two capacities is denoted as load factor.

Load Factor = Actual operating capacity / (No. of Burners $\mathrm{x}$ Rated capacity $\mathrm{x}$ efficiency)

Actual Operating Capacity $=$ Calculated Total heat in zone

The study also determines efficiencies associated with process and components. Efficiencies like system efficiency and combustion efficiency are determined.

\section{System efficiency}

The main purpose of the furnace system is to heat the steel strip. Therefore the system efficiency is the ratio between the heat added to the steel strip to the total heat input.

System Efficiency $=$ Heat added to the steel strip/ Total calculated heat

\section{Combustion efficiency}

Large value for excess air for combustion of natural gas reduces the combustion efficiency. For most applications, exhaust gas oxygen levels are about $2 \%$ and corresponding excess air levels of about $10 \%$ are optimum. The combustion efficiency is displayed in the results section of the module. The screenshot of determination of combustion efficiency is shown in appendix.

\subsection{Conclusion}

1) A systematic study of the equipment in the galvanizing facilities is conducted. 2) Major energy consuming equipment (furnace) is identified and focus is drawn over collecting data pertaining to the furnace. 3) Variables affecting energy consumption are identified and measured. 4) Preliminary analysis is conducted in Excel ${ }^{\mathrm{TM}}$ and formulas are developed for calculating heat losses, and 5) As discussed in Section 3.8, the efficiency of the system and the load factor of the burners are established. 


\section{CHAPTER 4}

\section{DESIGN AND DEVELOPMENT OF MODEL}

\subsection{Purpose of Modeling}

This chapter deals with the development of a computer-based model using Microsoft Excel ${ }^{\mathrm{TM}}$ referred to as the Enhanced Galvanizing Profiler Decision Support System (E-GEPDSS). It is used to establish baseline energy levels for galvanizing operations. This model can also be used to analyze the effect of different products and process parameters on the system. The model incorporates different spreadsheets for Inputs, References, Results and Analysis. It also contains a reference spreadsheet, which has the properties of different fuels along with the decomposition of those fuels, and compounds that give their standard heat of formation and Molecular weights. The objective of this model is to exactly track the heat input given to the system that helps in determining the energy assessment potential and energy efficiency index for a particular facility by developing their energy baseline.

Following are some of the major purposes of building the E-GEPDSS model:

- to enable the user to input data regarding the energy usage in galvanizing operations to perform system energy analysis;

- to estimate actual energy consumption by various elements of the annealing and galvanneal furnace from the real-time data collection, such as temperatures, and flow measurements;

- to establish the energy baseline by tracking the nonessential energy consumption for the galvanizing process;

- to ease the user in studying the effect of process parameters on energy by executing the model for varying process and product parameters-sensitivity analysis;

\subsection{E-GEPDSS Model Development}

The model has two excel spreadsheets named as "Heat Balance" and "Heat Losses". The user is supposed to fill all the required information in these spreadsheets in order to get proper results. The model is designed in such a way that the user can get the results immediately after entering 
all the necessary data required for calculation. The cells that are not colored are for the user to input the details. The cells that contains formula or reference are marked blue to let the user know that these cells are locked and cannot be modified. Once the user gives the model the required inputs, it will automatically calculate the results with the formulas fed in the respective cells and display the answer in the cells that are colored green.

The "Heat Balance" spreadsheet calculates the mass and heat balance for all the zones in the furnace. This spreadsheet takes the flow of natural gas and air as an input and calculates the amount of charge reacted and products produced during combustion. It also calculates the amount of heat carried away by products of combustion through the stack. The balancing of the products should be done manually and the values have to be entered in the model. The basic combustion reaction for complete combustion is.

$$
\mathrm{CH}_{4}+\mathrm{O}_{2}+\mathrm{N}_{2} \rightarrow \mathrm{CO}_{2}+\mathrm{H}_{2} \mathrm{O}+\mathrm{N}_{2}+\mathrm{O}_{2}
$$

If there are different products of combustion that the user would like to consider, then the user has to manually add the product or reactant and do a mass balance with the equation and give the input to the model. The screenshot of the spreadsheet is shown in Figure 4.1.

\begin{tabular}{|c|c|c|c|c|c|c|}
\hline Zone 1 & & & & & & \\
\hline & Line Speed - & Density - lb/ft3 & Width - $\mathrm{ft}$ & Gauge - $\mathrm{ft}$ & lbssimin & Total Charge Input - lbs/hr \\
\hline Steel Strip (Fe and C) & 423 & \begin{tabular}{|l|}
490 \\
\end{tabular} & 4.3 & 0.00208 & $1,853.82$ & $111,229.37$ \\
\hline$\%$ of $\mathrm{C}$ in the Steel Strip - \% & 0.03 & & & & & \\
\hline & $\mathrm{ft} 3 / \mathrm{hr}$ & Density - lb/ft3 & Mass flow - lbs/hr & & & Air \\
\hline Natural Gas & $4,500.00$ & 0.044 & 198.00 & & $\mathrm{O}_{2}$ & 0.2 \\
\hline Airr - $(21 \% 02 \& 79 \% \mathrm{~N} 2)$ & $47,853.00$ & 0.075 & $3,588.98$ & & $\mathrm{~N}_{2}$ & 0.7 \\
\hline $\mathrm{O}_{2}$ mass flow & & & 754.00 & & & \\
\hline $\mathrm{N}_{2}$ mass flow & & & 2836.00 & & & \\
\hline Reactants & $\mathrm{kg}$-moles hr & & & Products & & \\
\hline $\mathrm{Fe}$ - Charge & 905 & & & $\mathrm{CO}_{2}$ & 5.63 & \\
\hline C-Charge & 1.26 & & & $\mathrm{H}_{2} \mathrm{O}$ & 11.26 & 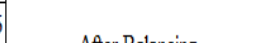 \\
\hline Natural Gas - $\mathrm{CH}_{4}$ & 5.63 & & & $\mathrm{O}_{2}$ & 1.46 & After Balancing \\
\hline $\mathrm{O}_{2}$ & 12.72 & & & $\mathrm{~N}_{2}$ & 47.87 & \\
\hline $\mathrm{N}_{2}$ & 47.87 & & & & & \\
\hline
\end{tabular}

Figure 4.1 Mass Balance of Reactants and Products of Combustion

The "Heat Losses" spreadsheet has different cells designated for entering the zone details of the furnace system, area details of different components of the system, and stack analysis. The user 
has to input the values for each of the input parameters in their respective cells on the input sheet. The model is capable of analyzing up to seven zones. When there is a need to input more than seven zones, the user can combine details of two or more zones which are similar and consolidate to a single zone.

The first section in the "Heat Losses" Spreadsheet is zone inputs. In this section, the user is supposed to enter the dimensions of the zone, number of heating elements in the zone, zone temperatures, and the rated capacity of the heating element. The user also has an option to select the type of fuel from the drop down menu and choose the respective fuel that is being used in the system. The type of fuel that is most commonly used is the natural gas hence, natural gas heating is considered in this study. The utilization factor of the system should be given as 1 ; if the system operates continuously else, it is calculated by dividing the operating hours of the system by the total hours in a year. The screenshot of input section is shown in Figure 4.2.

\begin{tabular}{|l|c|c|}
\hline \multicolumn{1}{|c|}{ INPUT ZONE DETAILS } & Units & Details \\
\hline Name of the Furnace & Annealing & \\
\hline Number of Zones & 7 & \\
\hline Zones & & Zonel \\
\hline Type of Heating & & Gas \\
\hline Fuel Used & & Natural Gas \\
\hline No. of Burners/Grid & no units & 32 \\
\hline Rated Capacity of the Heating Element & MMBtuhr & 0.255 \\
\hline Utilization factor of the system & & 1 \\
\hline Zone Atmosphere & & Air:NG \\
\hline Zone Temperature & $\mathrm{F}$ & 1689 \\
\hline Ambient Temperature & $\mathrm{F}$ & 95 \\
\hline Length of the Zone & $\mathrm{ft}$ & 45 \\
\hline Width of the Zone & $\mathrm{ft}$ & 9 \\
\hline Height of the Zone & $\mathrm{ft}$ & 9 \\
\hline Area of the Zone & $\mathrm{ft}$ & 1782.00 \\
\hline
\end{tabular}

\section{Figure 4.2 Input Sheet for Zone Details}

The next input section in the "Heat Losses" spreadsheet is the area inputs. The area section in the input sheet will be automatically calculated by the model with the dimensional details entered in the input zone section. The model also considers other miscellaneous structures of the system and enables the user to input the area details of those structures. The user approximates the area of the miscellaneous structures to input in the model. The screenshot of area input section is shown in Figure 4.3. 


\begin{tabular}{|c|c|c|}
\hline AREA & & \\
\hline Label & Units & \\
\hline Zones & & Zonel \\
\hline Furnace Zone Temperatures & $\mathrm{F}$ & 1689 \\
\hline Length of the Zones & $\mathrm{ft}$ & 45 \\
\hline Width of the Zones & $\mathrm{ft}$ & 9.00 \\
\hline Height of the Zones & $\mathrm{ft}$ & 9.00 \\
\hline Area of Heat Conduction Through the Sides & $\mathrm{ft}^{2}$ & 972.00 \\
\hline \multicolumn{3}{|l|}{ Area of burner and other heat emitting surfaces } \\
\hline Zones & & Zonel \\
\hline Burner Section Diameter & $\mathrm{ft}$ & 0.600 \\
\hline Height or the length of the Burners & $\mathrm{ft}$ & 0.800 \\
\hline Area of one Burner Section & $\mathrm{ft}^{2}$ & 2.074 \\
\hline Number of Burners in the Zone & & 32.000 \\
\hline Total Area occupied by Burners Section & $\mathrm{ft}^{2}$ & 66.359 \\
\hline Total area of cylindrical surfaces (Pipes and other cylindrical surfaces) & $\mathrm{ft}^{2}$ & 55 \\
\hline Total surface area of Rectangular surfaces & $\mathrm{ft}^{2}$ & 0 \\
\hline Total surface area of Square surfaces & $\mathrm{ft}^{2}$ & 0 \\
\hline Total Area of the burners and other surfaces & $\mathrm{ft}^{2}$ & 121 \\
\hline
\end{tabular}

\section{Figure 4.3 Input Sheet for entering Area of Heat Emitting Surfaces}

The final input section in the "Heat Losses" spreadsheet is the stack analysis. The stack input section will allow the user to input details on the flow rate of natural gas and air that is fed into the system. The user will also have to enter the details of the oxygen percentage in the stack and the stack temperature in each zone. These inputs will be used as references to calculate the combustion efficiency in the zones. The screenshot of stack analysis section is shown in Figure 4.4 .

\begin{tabular}{|l|c|c|}
\hline \multicolumn{1}{|c|}{ STACK ANALYSIS } & \\
\hline \multicolumn{1}{|c|}{ Inputs } & Units & \\
\hline Input cfm of Natural gas & & Zone 1 \\
\hline Input cfm of Air & $\mathrm{ft}^{3} / \mathrm{hr}$ & 4500 \\
\hline Percentage of Oxygen in stack & $\mathrm{ft}^{3} / \mathrm{hr}$ & 47853 \\
\hline Excess air & $\%$ & 2.2 \\
\hline Stoichiometric + Excess air & $\%$ & 12 \\
\hline $16 \mathrm{lb}$ of air to burn $1 \mathrm{lb}$ of NG $=16^{*}(1+$ excessair)/ Total Air Supplied & $\mathrm{lb} / \mathrm{lb}$ of fuel & 1.12 \\
\hline Mass of flue gas & $\mathrm{lb} / \mathrm{lb}$ of fuel & 17.87 \\
\hline Density of air & $\mathrm{lb} / \mathrm{ft}^{3}$ & 18.87 \\
\hline Density of Natural gas & $\mathrm{lb} / \mathrm{ft}^{3}$ & 0.075 \\
\hline mass rate of air & $\mathrm{lbs} / \mathrm{hr}$ & 0.044 \\
\hline mass rate of natural gas & $\mathrm{lbs} / \mathrm{hr}$ & 3589 \\
\hline Total mass rate of the mixture & $\mathrm{lbs} / \mathrm{hr}$ & 198 \\
\hline Specific Heat Capacity of flue gas & $\mathrm{Btu} / \mathrm{b} \cdot \mathrm{F}$ & 3787 \\
\hline Stack Temperature & $\mathrm{F}$ & 0.30 \\
\hline Combustion air Temperature & $\mathrm{F}$ & 950 \\
\hline
\end{tabular}

Figure 4.4 Input Sheet for Stack Analysis 
After entering all the data in the input sheet, the user should scroll down the sheet to go to the losses section as shown in Figure 4.5 to 4.10. As shown in the figures the output section gives the values for various heat losses in terms of MMBtu/hr of fuel. The losses are the outputs for the model and are calculated once the user enters the required information. The various losses as discussed above are conduction, radiation, convection, opening loss, water cooling loss, and phase change loss.

\begin{tabular}{|c|c|c|}
\hline RADIATION - OTHER SURFACES & & \\
\hline Farenheit To Rankine & Farenheit & Rankine \\
\hline Zones & & Zone1 \\
\hline Ambient & 95 & 555.00 \\
\hline Burner and other surfaces & & 850.00 \\
\hline Label & Units & \\
\hline Zones & & Zone1 \\
\hline Surface Material & & Steel \\
\hline Emissivity of the other surfaces & & 0.8 \\
\hline Average Outer Surface Temperature of the Burner and other surfaces & $\mathrm{F}$ & 390 \\
\hline Ambient Temperature & $\mathrm{F}$ & 95 \\
\hline Stephen Boltzmann Constant & $\mathrm{Btu} /\left(\mathrm{h} \cdot \mathrm{ft}^{2} \cdot{ }^{\circ} \mathrm{R}^{4}\right) \times 10-8$ & 0.1714 \\
\hline Burner and other surface area & $\mathrm{ft}^{2}$ & 121 \\
\hline Heat Radiated through the burner and other surface & MMBtu/hr & 0.07 \\
\hline Total Heat Radiated & MMBtu/hr & 0.07 \\
\hline
\end{tabular}

Figure 4.5 Radiation Heat Loss

\begin{tabular}{|l|c|c|}
\hline \multicolumn{1}{|c|}{ CONVECTION - 0THER SURFACES } & \\
\hline \multicolumn{1}{|c|}{ Label } & Units & \\
\hline Zones & & Zonel \\
\hline Medium & & Air \\
\hline Outer Surface Temperature of the Burner and other surface area & $\mathrm{F}$ & 390 \\
\hline Ambient Temperature & $\mathrm{F}$ & 95 \\
\hline Burner and other surface area & $\mathrm{ft}^{2}$ & 121 \\
\hline Heat Transfer Coefficient for Burner walls and Other surfaces & Btu'hr.f ${ }^{2} . \mathrm{F}$ & 1 \\
\hline & & \\
\hline Heat Convected through the burner and other surface & MMBtuhr & 0.036 \\
\hline & & \\
\hline Total Heat Convected & MMBtu/hr & 0.036 \\
\hline
\end{tabular}

Figure 4.6 Convection Heat Loss 
CONDUCTION - HEAT LOSS THROUGH FURNACE WALLS

\begin{tabular}{|c|c|c|}
\hline Details & Units & \\
\hline Zones & & Zonel \\
\hline Furnace Zone Temperatures & $\mathrm{F}$ & 1689 \\
\hline Length of the Zone & $\mathrm{ft}$ & 45 \\
\hline Width of the Zone & $\mathrm{ft}$ & 9.00 \\
\hline Height of the Zone & $\mathrm{ft}$ & 9.00 \\
\hline Furnace Wall Material & & Steel \\
\hline Thermal Conductivity of Wall Material & Btuhr.ft.F & 24 \\
\hline Thickness of Wall Material & $\mathrm{ft}$ & 0.25 \\
\hline Number of Insulation layers on top & & 2 \\
\hline Temperature on the Top of the Furnace & $\mathrm{F}$ & 290 \\
\hline Insulation Material 1 & & Block Insulation \\
\hline Thermal Conductivity of Material 1 & Btu/hr.ft.F & 0.5 \\
\hline Thickness of Material 1 & $\mathrm{ft}$ & 0.25 \\
\hline Insulation Material 2 & & Arch Brick \\
\hline Thermal Conductivity of Material 2 & Btu/hr.ft.F & 0.5 \\
\hline Thickness of Material 2 & $\mathrm{ft}$ & 0.75 \\
\hline Insulation Material 3 & & $\mathrm{~N} / \mathrm{A}$ \\
\hline Thermal Conductivity of Material 3 & Btu/hr.ft.F & $\mathrm{N} / \mathrm{A}$ \\
\hline Thickness of Material 3 & $\mathrm{ft}$ & $\mathrm{N} / \mathrm{A}$ \\
\hline Surface Area of Heat Conduction Through the Top & $\mathrm{ft}^{2}$ & 405 \\
\hline Number of Insulation layers in the Bottom & & 3 \\
\hline Temperature on the Bottom of the Furnace & $\mathrm{F}$ & 280 \\
\hline Insulation Material 1 & & Block Insulation \\
\hline Thermal Conductivity of Material 1 & Btu/hr.ft.F & 0.5 \\
\hline Thickness of Material 1 & $\mathrm{ft}$ & 0.25 \\
\hline Insulation Material 2 & & Straight Brick \\
\hline Thermal Conductivity of Material 2 & Btu/hr.ft.F & 0.65 \\
\hline Thickness of Material 2 & $\mathrm{ft}$ & 0.5 \\
\hline Insulation Material 3 & & Straight Brick \\
\hline Thermal Conductivity of Material 3 & Btu/hr.ft.F & 0.5 \\
\hline Thickness of Material 3 & $\mathrm{ft}$ & 0.5 \\
\hline Surface Area of Heat Conduction Through the Bottom & $\mathrm{ft}^{2}$ & 405 \\
\hline Number of Insulation layers on the Sides & & 3 \\
\hline Temperature on the Sides of the Furnace & & 300 \\
\hline Insulation Material 1 & & Block Insulation \\
\hline Thermal Conductivity of Material 1 & Btu/hr.ft.F & 0.5 \\
\hline Thickness of Material 1 & $\mathrm{ft}$ & 0.25 \\
\hline Insulation Material 2 & & Straight Brick \\
\hline Thermal Conductivity of Material 2 & Btu/hr.ft.F & 0.5 \\
\hline Thickness of Material 2 & $\mathrm{ft}$ & 0.375 \\
\hline Insulation Material 3 & & Straight Brick \\
\hline Thermal Conductivity of Material 3 & Btu/hr.ft.F & 0.5 \\
\hline Thickness of Material 3 & $\mathrm{ft}$ & 0.375 \\
\hline Surface Area of Heat Conduction Through the Sides & $\mathrm{ft}^{2}$ & 972 \\
\hline Total Surface Area of the Furnace & $\mathrm{ft}^{2}$ & 1782 \\
\hline Heat Conducted through the Top & MMBtu/hr & 0.28 \\
\hline Heat Conducted through the Bottom & MMBtu/hr & 0.25 \\
\hline Heat Conducted through the Sides & MMBtu/hr & 0.67 \\
\hline & & \\
\hline Heat Conducted through the Furnace Walls & MMBtu/hr & 1.20 \\
\hline
\end{tabular}

Figure 4.7 Conduction Heat Loss 


\begin{tabular}{|c|c|c|}
\hline OPENING LOSS & & \\
\hline & Average Temp at opening & 470 \\
\hline & & 930 \\
\hline & Ambient & 75 \\
\hline Label & Units & \\
\hline Zones & & Zone1 \\
\hline Emissivity at the opening & & 0.8 \\
\hline Temperature at the opening & $\mathrm{F}$ & 850 \\
\hline Temperature of the Strip entering & $\mathrm{F}$ & 90 \\
\hline Ambient Temperature & $\mathrm{F}$ & 75 \\
\hline Stephen Boltzmann Constant & $\mathrm{Btu} / \mathrm{hr} \cdot \mathrm{ft}^{2} \mathrm{~F}$ & 0.1714 \\
\hline Area of Opening & $\mathrm{ft}^{2}$ & 3 \\
\hline Heat Lost through Opening & MMBtu/hr & $2.74 \mathrm{E}-03$ \\
\hline
\end{tabular}

Figure 4.8 Opening Loss

\begin{tabular}{|c|c|c|}
\hline WATER COOLING - TRANSFER ROLLS & & \\
\hline Label & Units & Values \\
\hline Zones & & Zone1 \\
\hline Type of rolls & Steel & Steel \\
\hline Water Flow & gallons/min & 5.72 \\
\hline Specific heat capacity of water & Btu/lb.F & 0.998 \\
\hline Water in Temperature & $\mathrm{F}$ & 65.00 \\
\hline Water out Temperature & $\mathrm{F}$ & 150.00 \\
\hline Water Cooling Loss & MMBtu/hr & 0.24 \\
\hline
\end{tabular}

Figure 4.9 Water Cooling Loss

\begin{tabular}{|l|c|c|}
\hline \multicolumn{1}{|c|}{ PHASE CHANGE } & \\
\cline { 1 - 2 } Label & Units & \\
\hline Zones & & Zonel \\
\hline Phase change occuring zone $(\mathrm{Y}$ or $\mathrm{N})$ & & $\mathrm{N}$ \\
\hline Heat of reaction (Exothermic or Endothermic) & & \\
\hline & & 0 \\
\hline Heat Loss due to phase changes in the zone & MMBtu/hr & 0 \\
\hline
\end{tabular}

Figure 4.10 Phase Change Heat Loss 
The model calculates the different losses associated with the system and gives the result as shown in the above screenshots. The user at this point has to switch over to the "Heat Balance" spreadsheet and input the values for heat losses in the sensible heat of products section as shown in Figure 4.12. The user has to convert the losses units from MMBtu/hr (US units) to MCal/hr (SI units) to input in this section. The change in units is used in the model as the traditional formulas used to calculate the enthalpy change is given in SI units. Once the user inputs the values in $\mathrm{MCal} / \mathrm{hr}$ the model will automatically calculate the values in US units. The unaccounted losses are the difference between the heat input (sensible heat of reactants) and the other calculated losses in the sensible heat of products section. The model is developed in a way that the total heat input equals the total heat output as shown in Figure 4.11 and 4.12.

\begin{tabular}{|c|c|c|c|c|c|c|}
\hline Sensible heat of Reactants & & & & & & \\
\hline & & & & & & \\
\hline Charge & kg-moleshrh & Temperature C & Temperature(K) & $\Delta \mathrm{H}($ Mcal/kg-mole & . Icalhr & MNBtuhr \\
\hline $\mathrm{Fe}$ & 905 & 148 & 421 & 0.87 & 789.13 & 3.08 \\
\hline $\mathrm{C}$ & 1.26 & 148 & 421 & 0.34 & 0.43 & 0.00 \\
\hline & & & & & & \\
\hline Blast & & & & & & \\
\hline $\mathrm{CH}_{4}$ & 5.63 & 25 & 298 & 0.00 & 0.00 & 0.00 \\
\hline $\mathrm{O}_{2}$ & 12.72 & 150 & 423 & 0.81 & 10.24 & 0.04 \\
\hline $\mathrm{N}_{2}$ & 47.87 & 150 & 423 & 0.88 & 42.00 & 0.16 \\
\hline & & & & & & \\
\hline & & & & & & \\
\hline Heat of Formation & & & & & & \\
\hline $\mathrm{CO}_{2}$ & 5.63 & & & 94.05 & 529.50 & 2.07 \\
\hline $\mathrm{H}_{2} 0$ & 11.26 & & & 60.00 & 675.60 & 2.63 \\
\hline & & & & & & \\
\hline & & & & & & \\
\hline & & & & & & \\
\hline & & & & & & \\
\hline & & & & & & \\
\hline & & & & & & \\
\hline & & & & & & \\
\hline
\end{tabular}

Figure 4.11 Sensible Heat of Reactants (Heat Input) 


\begin{tabular}{|c|c|c|c|c|c|c|}
\hline Sensible Heat of Products & & & & & & \\
\hline Charge & $\mathrm{kg}$-moles/hr & Temperature C & Temperature(K) & $\Delta \mathrm{H}(\mathrm{Mcal} / \mathrm{kg}$-mole & Mcal/hr & MMBtu/hr \\
\hline $\mathrm{Fe}$ & 905 & 235 & 508 & 1.45 & 1314.12 & 5.13 \\
\hline $\mathrm{C}$ & 1.26 & 235 & 508 & 0.66 & 0.83 & 0.00 \\
\hline \multicolumn{7}{|l|}{ Stack Gases } \\
\hline $\mathrm{CO}_{2}$ & 5.63 & 450 & 723 & 4.27 & 24.02 & 0.09 \\
\hline $\mathrm{H}_{2} \mathrm{O}$ & 11.26 & 450 & 723 & 3.63 & 40.85 & 0.16 \\
\hline $\mathrm{N}_{2}$ & 47.87 & 450 & 723 & 3.05 & 146.04 & 0.57 \\
\hline $\mathrm{O}_{2}$ & 1.46 & 450 & 723 & 3.13 & 4.56 & 0.02 \\
\hline \multicolumn{7}{|l|}{ Heat of Decomposition } \\
\hline $\mathrm{CH}_{4}$ & 5.63 & & & 17.89 & 100.72 & 0.39 \\
\hline \multicolumn{7}{|l|}{ Heat losses } \\
\hline Conduction Loss & & & & & 308.64 & 1.20 \\
\hline Radiation Loss & & & & & 18.23 & 0.07 \\
\hline Convection Loss & & & & & 9.18 & 0.04 \\
\hline Opening Loss & & & & & 0.0073 & 0.00 \\
\hline Water Cooling Loss & & & & & 62.33 & 0.24 \\
\hline Unaccounted Loss & & & & & 17.37 & 0.07 \\
\hline & & & & & & \\
\hline Total Heat Output & & & & & $2,046.91$ & 7.98 \\
\hline
\end{tabular}

Figure 4.12 Sensible Heat of Products (Heat Output)

The "Heat Losses" spreadsheet has totally three modules incorporated in it. The worksheets are 1) Losses and Results, 2) Cooling sections, and 3) References. The losses and results module contains all the losses as discussed earlier. After entering all the necessary information needed by the model, the model calculates the losses and consolidates in the Results section of the Losses and Results module.

The results section contains reference from other modules and sheets. The values are pulled by the model and displayed in this section. The results section also estimates the load factor of the burners in different zones. The snapshot of the results section is shown in Figure 4.13. 


\begin{tabular}{|c|c|c|c|c|c|c|c|c|}
\hline & & \multicolumn{7}{|c|}{ HAIIIGSSCCTIOI } \\
\hline Heat & Tits & Zonel & Lone? & lones & lonet & Lone: & lone6 & Loule? \\
\hline Ippotflempy & & 606 & 6 & Gis & Gis & 68 & 6 & 63 \\
\hline 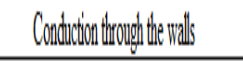 & MBBth & 1.10 & 120 & 1.9 & 1.11 & 1.11 & 1.19 & 1.11 \\
\hline Radidonficum sorderes & MBdult & 0.07 & 008 & 0.18 & 2.18 & 0.07 & 0.01 & 0.07 \\
\hline 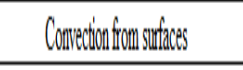 & MBBth & O.A & 0.1 & D.1. & D.A & ONA & 0.3 & D.S. \\
\hline Deving & MBBth & OMOM" & OOM & 0.0 & 1.00 & 0.00 & o. & 10.0 \\
\hline Trat Coulhg & MBBth & 0.4 & 024 & 0.4 & 0.4 & 0.4 & 0.4 & 0.5 \\
\hline Prarechang Heat & MBBth & 0.00 & OOM & 0.0 & 0.0 & 0.0 & o.l. & 10.0 \\
\hline 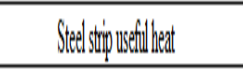 & MBBth & 2015 & 300 & 2.43 & 2.45 & 261 & 24 & 261 \\
\hline Saakhoss & MBBthr & 0.4 & 10. & 199 & 199 & 1.00 & 094 & 1.99 \\
\hline lancounded hases & MBBth & 0.0 & OOP & 0.14 & 0.15 & ODO & 0.11 & 0.12 \\
\hline 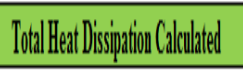 & 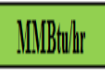 & 4.5. & 5.69 & intis & 3.16 & 3.65 & 5.15 & 3.66 \\
\hline Ratel lapactryotitue buners & WIIBBulir & 6.4 & 7.80 & 1017 & 6.63 & 585 & 388 & 6.96 \\
\hline Laal Fatoro ód Buners & & 1.65 & 0.73 & 0.69 & 0.8 & 0.0 & 0.86 & 1.66 \\
\hline
\end{tabular}

Figure 4.13 Heat Balance Results

The next module in the "Heat Losses" spreadsheet is the cooling section. The model calculates the amount of heat that is being released by the steel strip in the cooling section. The heat released by the steel strip in the cooling section is considered as the amount of work done by the cooling section. The model also accommodates jet cooling section which is present in the same module. The jet cooling section is same as the cooling section except the steel strip looses significant amount of heat when compared to the cooling section. The type of cooling does not affect the model, as the model is currently designed to estimate the work done by the cooling section by tracking the strip temperature at the entry and exit. A snapshot of cooling section is shown in Figure 4.14. The final reference module has a list of references that the model pulls out for calculation. The reference module also helps the user to refer for values if there is a change in condition. Figure 4.15 represents the inputs for induction heating. The induction heating section in the model takes into account the line current and voltage that is being supplied to the induction coils present inside the furnace. 


\begin{tabular}{|c|c|c|}
\hline Cooling Section & & \\
\hline Inputs & & English unit \\
\hline Type of Cooling & & Controlled Radiative Cooling \\
\hline \multicolumn{3}{|l|}{ Number of cooling sections } \\
\hline Speed & $\mathrm{ft} / \mathrm{min}$ & \\
\hline Zone Temperature & $\mathrm{F}$ & \\
\hline Density of Steel & $\mathrm{lb} / \mathrm{ft}^{3}$ & \\
\hline Width of the Strip & $\mathrm{ft}$ & \\
\hline Gauge (thickness) & $\mathrm{ft}$ & \\
\hline Temperature of the Strip at entry & degree $F$ & \\
\hline Temperature of the strip at exit & degree $\mathrm{F}$ & \\
\hline Specific Heat Capacity of the Steel Sheet & Btu/lb.F & \\
\hline Heat loss from steel strip & MMBtu/hr & \\
\hline
\end{tabular}

Figure 4.14 Cooling section

\begin{tabular}{l|c|c|}
\multicolumn{1}{l|}{ INDUCTION HEATING } & \multicolumn{1}{l|}{} \\
\hline Line to Line Voltage Measured & 480 & Volts \\
\hline & & \\
\hline Line Current & 240 & Amps \\
\hline & & \\
\hline Power Factor & 0.6 & \\
\hline & & \\
\hline Efficiency of the Induction Heating & 0.9 & \\
\hline Heat Storage & & \\
\hline
\end{tabular}

Figure 4.15 Induction Heating 


\subsection{Advantages and Limitations of modeling}

Advantages

- The model developed is a quick and reliable method to identify the areas of improvement without doing a lot of hand calculations.

- The model helps the user in identifying the potential areas of improvement by enabling the user to test the effect of process and product parameters on the efficiency of the system.

Limitations

- The model developed is restricted to seven zones and if the user wishes to input the details for more than seven zones he can do so by consolidating two similar zones as one zone.

- The results generated using this model may not be accurate but can be used as an indicator for the areas of potential improvement.

\subsection{Conclusion}

This chapter deals with a systematic approach to help establish an energy baseline through the development of a user-friendly, interactive model named as E-GEPDSS. It talks about the architecture of the model and various input and output modules. These modules provide information pertaining to the energy consumed by various elements of the furnace.

The developed E-GEPDSS model will help the galvanizers to run their furnaces as efficient as possible by identify key parameters that are sensitive to energy. The user can vary the input parameters to the E-GEPDSS model and study its effect on energy basis. It also helps the user in providing the results for varying product and process parameters. 


\section{CHAPTER 5}

\section{MODEL EXECUTION, ANALYSIS AND RESULTS}

\subsection{Model Execution}

This chapter deals with the execution of E-GEPDSS model by using real-time data from one of the facilities visited during the conduct of this research. The goal here is to present the data collected from the site visits and demonstrate its use in the model inputs section.

\subsection{Model Inputs:}

The data collection has been done through plant visit. Extensive details on product, process, and system parameters were collected during the plant visits. The following sections utilize data on product, process, and system parameters to illustrate the workings of heat balance models. However, the models can be applied to variety of parameters as considered and reported earlier. It should be noted that not all losses will be applicable to specific manufacturing conditions.

Since all the losses and their formulas were discussed in detail in the previous section, this section will exclusively focus on the calculations and the values for outputs in table format. The details of the two facilities will be discussed as Facility A and Facility B. The heat balance calculations are detailed for Facility A and the results are shown for Facility B in the results section.

\subsubsection{Facility A:}

The product parameters (US Units):

Product: Carbon Steel

Strip width: $4.3 \mathrm{ft}$

Strip gauge: $0.00208 \mathrm{ft}$

Line speed: $423 \mathrm{ft} / \mathrm{min}$

The model was populated with data collected from the host facility A. This facility uses unit values. Therefore, the data was populated using the US unit spreadsheet. The heat balance results were obtained from the model and screenshots are provided in the section below. 


\subsubsection{Process Parameters:}

Table 5.1: Furnace Parameters

\begin{tabular}{|c|c|c|}
\hline Inputs & Values & Units \\
\hline \multicolumn{3}{|l|}{ Furnace Details } \\
\hline Type of section considered & Radiant tube & \\
\hline Number of Zones & 7 & \\
\hline \multicolumn{3}{|l|}{ Type of Heating } \\
\hline Zone 1 - Zone 7 & Gas Heating & \\
\hline Type of fuel used & Natural Gas & \\
\hline \multicolumn{3}{|l|}{ Burner Details } \\
\hline Zone 1 & 32 & \\
\hline Zone 2 & 36 & \\
\hline Zone 3 , Zone 4 & 34 & \\
\hline Zone 5, Zone6 \& Zone 7 & 30 & \\
\hline \multicolumn{3}{|l|}{ Zone Temperatures } \\
\hline Zone 1 & 1689 & ${ }^{\circ} \mathrm{F}$ \\
\hline Zone 2 & 1701 & ${ }^{\circ} \mathrm{F}$ \\
\hline Zone 3 & 1680 & ${ }^{\circ} \mathrm{F}$ \\
\hline Zone 4 & 1719 & ${ }^{o} \mathrm{~F}$ \\
\hline Zone 5 & 1722 & ${ }^{\circ} \mathrm{F}$ \\
\hline Zone 6 & 1690 & ${ }^{\circ} \mathrm{F}$ \\
\hline Zone 7 & 1720 & ${ }^{\mathrm{o}} \mathrm{F}$ \\
\hline Ambient Temperature & 95 & ${ }^{\circ} \mathrm{F}$ \\
\hline \multicolumn{3}{|l|}{ Dimensions of the Zones (Zones 1 - 7) } \\
\hline Length of zones & 45 & feet \\
\hline Width of zones & 9 & feet \\
\hline Height of zones & 9 & feet \\
\hline
\end{tabular}

The heat absorbed by various elements in the furnace is discussed in the order as it was discussed in the previous section. 


\subsection{Heat Losses}

This section details the methods and results for heat loss through various furnace components. Calculations to show the heat balance aspects for the product, process, and system parameters. All the calculations shown in this section is formulated for zone 1 and the values for the rest of the zones will be tabulated.

\subsubsection{Heat Conducted Through the Walls}

A: 405 sq.ft

Tp: $1689 \mathrm{~F}$

Tw: $290 \mathrm{~F}$

tp: $0.25 \mathrm{ft}$

$\mathrm{t} 1: 0.25 \mathrm{ft}$

$\mathrm{t} 2: 0.75 \mathrm{ft}$

kp: 24 Btu/hr.ft.F

k1: 0.5 Btu/hr.ft.F

k2: 0.5 Btu/hr.ft.F

Table 5.2: Conduction Heat Loss

\begin{tabular}{|l|c|c|c|c|c|c|c|}
\hline & Zone 1 & Zone 2 & Zone 3 & Zone 4 & Zone 5 & Zone 6 & Zone 7 \\
\hline Top of the furnace & & & & & & & \\
\hline $\mathrm{T}_{\mathrm{w}}-$ Top $\left({ }^{\circ} \mathrm{F}\right)$ & 290 & 300 & 290 & 320 & 320 & 300 & 300 \\
\hline Insulation Material 1 & \multicolumn{7}{|c|}{ Block Insulation } \\
\hline Thickness of Insulation (ft) & 0.25 & 0.25 & 0.25 & 0.25 & 0.25 & 0.25 & 0.25 \\
\hline Insulation Material 2 & \multicolumn{7}{|c|}{ Arch Brick } \\
\hline Thickness of Insulation (ft) & 0.75 & 0.75 & 0.75 & 0.75 & 0.75 & 0.75 & 0.75 \\
\hline Bottom of the furnace & & & & & & & \\
\hline $\mathrm{T}_{\mathrm{w}}$ - Bottom $\left({ }^{\circ} \mathrm{F}\right)$ & 280 & 290 & 290 & 300 & 310 & 295 & 300 \\
\hline Insulation Material 1 & \multicolumn{7}{|c|}{ Block Insulation } \\
\hline Thickness of Insulation $(\mathrm{ft})$ & 0.25 & 0.25 & 0.25 & 0.25 & 0.25 & 0.25 & 0.25 \\
\hline Insulation Material 2 \& 3 & \multicolumn{7}{|c|}{ Straight Brick } \\
\hline Thickness of insulation $(\mathrm{ft})$ & 0.5 & 0.5 & 0.5 & 0.5 & 0.5 & 0.5 & 0.5 \\
\hline
\end{tabular}




\begin{tabular}{|l|c|c|c|c|c|c|c|}
\hline & Zone 1 & Zone 2 & Zone 3 & Zone 4 & Zone 5 & Zone 6 & Zone 7 \\
\hline Sides of the furnace & & & & & & & \\
\hline $\mathrm{T}_{\mathrm{w}}$ - Sides ( $\left.{ }^{ } \mathrm{F}\right)$ & 300 & 320 & 310 & 325 & 325 & 315 & 330 \\
\hline Insulation Material 1 & \multicolumn{7}{|c|}{ Block Insulation } \\
\hline Thickness of Insulation (ft) & 0.25 & 0.25 & 0.25 & 0.25 & 0.25 & 0.25 & 0.25 \\
\hline Insulation Material 2 \& 3 & \multicolumn{7}{|c|}{ Straight Brick } \\
\hline Thickness of insulation (ft) & 0.375 & 0.375 & 0.375 & 0.375 & 0.375 & 0.375 & 0.375 \\
\hline
\end{tabular}

An example calculation for the heat conducted through the top of the furnace for zone 1 is calculated as,

$$
\begin{aligned}
Q & =A\left(T_{p}-T_{w}\right) /\left(\frac{t_{p}}{k_{p}}+\frac{t_{1}}{k_{1}}+\frac{t_{2}}{k_{2}}\right) \\
Q & =405(1689-290) /\left(\frac{0.25}{24}+\frac{0.25}{0.5}+\frac{0.75}{0.5}\right) \\
& =281,829 \mathrm{Btu} / \mathrm{hr}=0.28 \mathrm{MMBtu} / \mathrm{hr}
\end{aligned}
$$

Similarly the heat conducted through the furnace walls (Zone 1 - Zone 7) are calculated and the results are shown below:

Heat conducted through the top: $\quad 1.97 \mathrm{MMBtu} / \mathrm{hr}$

Heat conducted through the bottom: $\quad 1.75 \mathrm{MMBtu} / \mathrm{hr}$

Heat conducted through the sides: $\quad$ 4.69 MMBtu/hr

Total Heat conducted through the furnace walls: 8.41 MMBtu/hr

5.3.2. Heat Loss Through other Surfaces (Fins, Burner walls and other typical surfaces emitting heat)

\subsection{2.a Radiation}

$\varepsilon: 0.8$

B: $0.1714 \mathrm{Btu} / \mathrm{hr}-\mathrm{ft}^{2}{ }^{\mathrm{o}} \mathrm{R}^{4}$

A: 121 sq.ft 
Ts: $850 \mathrm{~F}$

Ta: $555 \mathrm{~F}$

Table 5.3: Radiation Heat Loss

\begin{tabular}{|l|c|c|c|c|c|c|c|}
\hline & Zone 1 & Zone 2 & Zone 3 & Zone 4 & Zone 5 & Zone 6 & Zone 7 \\
\hline Area of other surfaces $\left(\mathrm{ft}^{2}\right)$ & 121 & 130 & 126 & 126 & 117 & 117 & 117 \\
\hline Emissivity & 0.8 & 0.8 & 0.8 & 0.8 & 0.8 & 0.8 & 0.8 \\
\hline $\mathrm{T}_{\mathrm{s}}-$ Temperatures $\left({ }^{\mathrm{o}} \mathrm{R}\right)$ & 850 & 860 & 855 & 860 & 855 & 850 & 860 \\
\hline & & & & & & & \\
\hline Results & & & & & & & \\
\hline Total heat radiated $(\mathbf{M M B t u} / \mathbf{h r})$ & $\mathbf{0 . 0 7} *$ & $\mathbf{0 . 0 8}$ & $\mathbf{0 . 0 8}$ & $\mathbf{0 . 0 8}$ & $\mathbf{0 . 0 7}$ & $\mathbf{0 . 0 7}$ & $\mathbf{0 . 0 7}$ \\
\hline
\end{tabular}

*Value calculated as an example below

An example calculation for the heat radiating from other surfaces of zone 1 is calculated as,

$$
\begin{aligned}
Q & =\varepsilon B A\left(T_{s}^{4}-T_{a}^{4}\right) \\
Q & =0.8 \times 0.1714 \times 10^{\wedge-8} \times 121 \times\left(850^{4}-555^{4}\right) \\
& =71,077 \mathrm{Btu} / \mathrm{hr}=0.07 \mathrm{MMBtu} / \mathrm{hr}
\end{aligned}
$$

Similarly the heat radiated through the surfaces (Zone 1 - Zone 7) are calculated and the results are shown in table:

Total heat radiated from the surfaces $=(0.07+0.08+0.08+0.08+0.07+0.07+0.07) \mathrm{MMBtu} / \mathrm{hr}$

$$
=0.52 \mathrm{MMBtu} / \mathrm{hr}
$$

\subsection{2.b Convection}

h: $1 \mathrm{Btu} / \mathrm{hr} . \mathrm{ft}^{2} . \mathrm{F}$
A: 121 sq.ft
$\mathrm{T}_{\mathrm{z}}: 390 \mathrm{~F}$
$\mathrm{T}_{\mathrm{s}}: 95 \mathrm{~F}$ 
Table 5.4: Convection Heat Loss

\begin{tabular}{|l|c|c|c|c|c|c|c|}
\hline & Zone 1 & Zone 2 & Zone 3 & Zone 4 & Zone 5 & Zone 6 & Zone 7 \\
\hline Area of other surfaces $\left(\mathrm{ft}^{2}\right)$ & 121 & 130 & 126 & 126 & 117 & 117 & 117 \\
\hline $\mathrm{T}_{\mathrm{z}}$ - Temperatures $\left({ }^{\circ} \mathrm{F}\right)$ & 390 & 400 & 395 & 400 & 395 & 390 & 400 \\
\hline Heat transfer coefficient $\left(\mathrm{Btu} / \mathrm{hr}^{2} \mathrm{ft}^{2} . \mathrm{F}\right)$ & 1 & 1 & 1 & 1 & 1 & 1 & 1 \\
\hline & & & & & & & \\
\hline Results & & & & & & & \\
\hline Total heat convected $(\mathbf{M M B t u} / \mathbf{h r})$ & $\mathbf{0 . 0 3 6} *$ & $\mathbf{0 . 0 4 0}$ & $\mathbf{0 . 0 3 8}$ & $\mathbf{0 . 0 3 8}$ & $\mathbf{0 . 0 3 5}$ & $\mathbf{0 . 0 3 5}$ & $\mathbf{0 . 0 3 6}$ \\
\hline
\end{tabular}

*Value calculated as an example below

An example calculation for the heat convecting from other surfaces of zone 1 is shown here.

$$
\begin{aligned}
Q & =h A\left(T_{z}-T_{a}\right) \\
Q & =1 \times 121 \times(390-95) \\
& =35,695 \mathrm{Btu} / \mathrm{hr}=0.036 \mathrm{MMBtu} / \mathrm{hr}
\end{aligned}
$$

Similarly the convected heat through the surfaces ( Zone 1 - Zone 7) are calculated and the results are shown in table:

Total heat convected from all surfaces $=(0.036+0.040+0.038+0.038+0.035+0.035+0.036)$

$$
=0.257 \mathrm{MMBtu} / \mathrm{hr}
$$

\subsubsection{Heat carried away by steel strip}

Line speed $=423 \mathrm{ft} / \mathrm{min}$

Density of steel $=490 \mathrm{lbs} / \mathrm{ft}^{3}$

Strip width $=4.3 \mathrm{ft}$

Strip thickness $=0.00208 \mathrm{ft}$

Strip entry temperature in zone $1=300^{\circ} \mathrm{F}=421^{0} \mathrm{~K}$

Strip exit temperature at zone $1=455^{\circ} \mathrm{F}=508^{0} \mathrm{~K}$

Mass flow rate of strip $=423 \times 490 \times 4.3 \times 0.00208 \times 60$

$=111,229 \mathrm{lbs} / \mathrm{hr}$

Carbon steel: $0.03 \% \mathrm{C}$,

Amount of carbon: $0.03 \times 111,229=33.37$ 
Amount of Fe: $111,229-33.37=111,196$

Amount of $\mathrm{Fe}=111,196 \frac{\mathrm{lbs}}{\mathrm{hr}} \times \frac{1 \mathrm{lb} \mathrm{mol}}{55.85 \mathrm{lbs}} \times \frac{1 \mathrm{~kg}}{2.2 \mathrm{lbs}}=905 \frac{\mathrm{kg} \cdot \mathrm{mol}}{\mathrm{hr}}$

Amount of $\mathrm{C}=33.37 \frac{\mathrm{lbs}}{\mathrm{hr}} \times \frac{1 \mathrm{lb} \mathrm{mol}}{12 \mathrm{lbs}} \times \frac{1 \mathrm{~kg}}{2.2 \mathrm{lbs}}=1.26 \frac{\mathrm{kg} \cdot \mathrm{mol}}{\mathrm{hr}}$

Sensible heat of $\mathrm{Fe}$ at $421^{\circ} \mathrm{K}$ :

$\mathrm{H}_{421}-\mathrm{H}_{298}=\frac{3.37 \times 421+0.00355 \times 421^{2}-0.0000043 \times 421^{-1}-1176}{1000}=0.87 \frac{\mathrm{Mcal}}{\mathrm{kg} \cdot \mathrm{mol}}$

Potential heat of Fe at $421^{0} \mathrm{~K}=0.87 \times 905$

$$
=789.13 \mathrm{Mcal} / \mathrm{hr}
$$

Sensible heat of $\mathrm{Fe}$ at $508^{0} \mathrm{~K}$ :

$$
\begin{aligned}
\mathrm{H}_{508}-\mathrm{H}_{298} & =\frac{3.37 \times 508+0.00355 \times 508^{2}-0.0000043 \times 508^{-1}-1176}{1000} \\
& =1.45 \frac{\mathrm{Mcal}}{\mathrm{kg} \cdot \mathrm{mol}}
\end{aligned}
$$

Potential heat of $\mathrm{Fe}$ at $739^{0} \mathrm{~K}=1.45 \times 905$

$$
=1314.12 \mathrm{Mcal} / \mathrm{hr}
$$

Potential heat gain of $\mathrm{Fe}=1314.12-789.13$

$=524.99 \mathrm{Mcal} / \mathrm{hr}$

$=2.05 \mathrm{MMBtu} / \mathrm{hr}$

The amount of $\mathrm{C}$ in the strip is negligible since the concentration is only $0.03 \%$, hence its is not included in calculation.

Therefore heat absorption of steel strip from zone $1=2.05 \frac{\mathrm{MMBtu}}{\mathrm{hr}}$

Similarly the heat absorbed by the steel strip ( Zone 1 - Zone 7) are calculated and the results are shown below:

Total heat carried away by steel strip $=(2.05+2.99+2.43+2.45+2.61+2.42+2.61)$

$$
=17.56 \mathrm{MMBtu} / \mathrm{hr}
$$




\subsubsection{Stack Loss}

Natural Gas flow in zone $1=4,500 \mathrm{ft}^{3} / \mathrm{hr}$

Air Flow in zone $1=47,853 \mathrm{ft}^{3} / \mathrm{hr}$

Density of natural gas $=0.044 \mathrm{lbs} / \mathrm{ft}^{3}$

Density of air $=0.075 \mathrm{lbs} / \mathrm{ft}^{3}$

Mass flow rate of natural gas $=$ Density $\times$ Volume $=4,500 \times 0.044=198 \mathrm{lbs} / \mathrm{hr}$

Mass flow rate of air $=$ Density $\times$ Volume $=47,853 \times 0.075=3588.98 \mathrm{lbs} / \mathrm{hr}$

Amount of $\mathrm{CH}_{4}=198 \frac{\mathrm{lbs}}{\mathrm{hr}} \times \frac{1 \mathrm{lb} \mathrm{mol}}{16 \mathrm{lbs}} \times \frac{1 \mathrm{~kg}}{2.2 \mathrm{lbs}}=5.63 \frac{\mathrm{kg} \cdot \mathrm{mol}}{\mathrm{hr}}$

Amount of $\mathrm{O}_{2}=47,853 \frac{\mathrm{ft} 3}{\mathrm{hr}} \times \frac{1 \mathrm{lb} \mathrm{mol} \mathrm{air}}{359 \mathrm{ft} 3 \mathrm{air}} \times \frac{0.21 \mathrm{moles} \mathrm{O} 2}{\text { mole air }} \times \frac{1 \mathrm{~kg}}{2.2 \mathrm{lbs}}=12.72 \frac{\mathrm{kg} \cdot \mathrm{mol}}{\mathrm{hr}}$

Amount of $\mathrm{N}_{2}=47,853 \frac{\mathrm{ft} 3}{\mathrm{hr}} \times \frac{1 \mathrm{lb} \mathrm{mol} \mathrm{air}}{359 \mathrm{ft} 3 \text { air }} \times \frac{0.79 \mathrm{moles} \mathrm{N} 2}{\text { mole air }} \times \frac{1 \mathrm{~kg}}{2.2 \mathrm{lbs}}=47.87 \frac{\mathrm{kg} \cdot \mathrm{mol}}{\mathrm{hr}}$

Therefore the balanced equation is:

$$
5.63 \mathrm{CH}_{4}+12.72 \mathrm{O}_{2}+47.87 \mathrm{~N}_{2} \rightarrow 5.63 \mathrm{CO}_{2}+11.26 \mathrm{H}_{2} \mathrm{O}+47.87 \mathrm{~N}_{2}+1.46 \mathrm{O}_{2}
$$

The moles of combustion products are obtained by balancing the equation

Stack temperature $=842 \mathrm{~F}=450 \mathrm{C}=723 \mathrm{~K}$

Sensible heat of $\mathrm{CO}_{2}$ at $723^{\circ} \mathrm{K}$ :

$$
\begin{aligned}
\mathrm{H}_{723}-\mathrm{H}_{298} & =\frac{10.55 \times 723+0.00108 \times 723^{2}-0.0000204 \times 723^{-1}-3926}{1000} \\
& =4.27 \frac{\mathrm{Mcal}}{\mathrm{kg} \cdot \mathrm{mol}}
\end{aligned}
$$

Potential heat of $\mathrm{CO}_{2}$ at $723{ }^{0} \mathrm{~K}=4.27 \times 5.63$

$$
=24.02 \mathrm{Mcal} / \mathrm{hr}
$$


Sensible heat of $\mathrm{H}_{2} \mathrm{O}$ at $723^{0} \mathrm{~K}$ :

$$
\begin{aligned}
\mathrm{H}_{723}-\mathrm{H}_{298} & =\frac{7.17 \times 723+0.00128 \times 723^{2}-0.0000008 \times 723^{-1}-2225}{1000} \\
& =3.63 \frac{\mathrm{Mcal}}{\mathrm{kg} \cdot \mathrm{mol}}
\end{aligned}
$$

Potential heat of $\mathrm{H}_{2} \mathrm{O}$ at $723^{0} \mathrm{~K}=3.63 \times 11.26$

$$
=40.85 \mathrm{Mcal} / \mathrm{hr}
$$

Sensible heat of $\mathrm{N}_{2}$ at $723^{\circ} \mathrm{K}$ :

$$
\begin{aligned}
\mathrm{H}_{723}-\mathrm{H}_{298} & =\frac{6.66 \times 723+0.00051 \times 723^{2}-2031}{1000} \\
& =3.05 \frac{\mathrm{Mcal}}{\mathrm{kg} \cdot \mathrm{mol}}
\end{aligned}
$$

Potential heat of $\mathrm{N}_{2}$ at $723^{\circ} \mathrm{K}=3.05 \times 47.87$

$$
=146.04 \mathrm{Mcal} / \mathrm{hr}
$$

Sensible heat of $\mathrm{O}_{2}$ at $723^{\circ} \mathrm{K}$ :

$$
\begin{aligned}
\mathrm{H}_{723}-\mathrm{H}_{298} & =\frac{7.16 \times 723+0.0005 \times 723^{2}-0.000004 \times 723^{-1}-2313}{1000} \\
& =3.13 \frac{\mathrm{Mcal}}{\mathrm{kg} \cdot \mathrm{mol}}
\end{aligned}
$$

Potential heat of $\mathrm{O}_{2}$ at $723^{0} \mathrm{~K}=3.13 \times 1.46$

$$
=4.56 \mathrm{Mcal} / \mathrm{hr}
$$

The total amount of heat that goes through the stack from zone 1 is:

$$
\begin{aligned}
& =24.02+40.85+146.04+4.56=215.47 \mathrm{Mcal} / \mathrm{hr} \\
& =0.84 \mathrm{MMBtu} / \mathrm{hr}
\end{aligned}
$$

Similarly the stack heat loss ( Zone 1 - Zone 7) are calculated and the results are shown below:

Total heat carried away by steel strip $=(0.84+1.04+0.93+0.99+1+0.94+0.97)$

$$
\text { = 6.71 MMBtu/hr }
$$




\subsubsection{Water Cooling Heat Loss}

$\mathrm{m}: 5.72$ gallons $/ \mathrm{min}=5.72 \times 8.35 \times 60=2865.72 \mathrm{lbs} / \mathrm{hr}$

$c_{p}: 0.998$ Btu/lb.F

$\mathrm{T}_{\text {exit }}: 150 \mathrm{~F}$

$\mathrm{T}_{\text {entry }}: 65 \mathrm{~F}$

Table 5.5: Water Cooling Loss

\begin{tabular}{|l|c|c|c|c|c|c|c|}
\hline & Zone 1 & Zone 2 & Zone 3 & Zone 4 & Zone 5 & Zone 6 & Zone 7 \\
\hline Type of rolls & Steel & Steel & Steel & Steel & Steel & Steel & Steel \\
\hline Water Flow (gpm) & 5.72 & 5.72 & 5.72 & 5.72 & 5.72 & 5.72 & 5.72 \\
\hline Specific heat capacity of water & 0.998 & 0.998 & 0.998 & 0.998 & 0.998 & 0.998 & 0.998 \\
\hline Water in Temperature (F) & 65 & 65 & 65 & 65 & 65 & 65 & 65 \\
\hline Water out Temperature (F) & 150 & 150 & 150 & 150 & 150 & 150 & 150 \\
\hline & & & & & & & \\
\hline Results & & & & & & & \\
\hline Total water cooling heat loss & $\mathbf{0 . 2 4 *}$ & $\mathbf{0 . 2 4}$ & $\mathbf{0 . 2 4}$ & $\mathbf{0 . 2 4}$ & $\mathbf{0 . 2 4}$ & $\mathbf{0 . 2 4}$ & $\mathbf{0 . 2 4}$ \\
\hline Total* (MMBtu/hr) & \multicolumn{7}{|l|}{$\mathbf{0 . 2 4} \mathbf{7}=\mathbf{1 . 6 8}$} \\
\hline
\end{tabular}

*Value calculated as an example below

The total water flow is $(5.72 \times 7)=40$ gallons per min. The flow is divided zone by zone for calculation purpose. The flow is assumed equal through all the zones.

An example calculation for water cooling heat loss for zone 1 is calculated as,

$$
\begin{aligned}
Q & =m c\left(T_{\text {exit }}-T_{\text {entry }}\right) \\
Q & =5.72 \times 8.35 \times 60 \times(150-65) \\
& =243,586 \mathrm{Btu} / \mathrm{hr}=0.24 \mathrm{MMBtu} / \mathrm{hr}
\end{aligned}
$$

Similarly the heat lost due to water cooling (Zone 1 - Zone 7) are calculated and the results are shown in table:

Total water cooling loss $\quad=(0.24+0.24+0.24+0.24+0.24+0.24+0.24) \mathrm{MMBtu} / \mathrm{hr}$

$$
=1.68 \mathrm{MMBtu} / \mathrm{hr}
$$




\subsubsection{Opening Loss}

$\varepsilon: 0.8$

B: $0.1714 \mathrm{Btu} / \mathrm{h}-\mathrm{ft}^{2}-{ }^{\mathrm{o}} \mathrm{R}^{4}$

A: 3 sq.ft

$\mathrm{T}_{\mathrm{s}}: 930 \mathrm{R}$

$\mathrm{T}_{\mathrm{a}}: 555 \mathrm{R}$

Table 5.6: Loss due to Openings

\begin{tabular}{|l|c|}
\hline & Zone 1 \\
\hline Emissivity at the opening & 0.8 \\
\hline Temperature at the opening (F) & 850 \\
\hline Temperature of the Strip entering (F) & 90 \\
\hline Ambient Temperature (F) & 95 \\
\hline Average Temperature at opening (R) & 930 \\
\hline Stephen Boltzmann Constant & 0.1714 \\
\hline Area of Opening & 3 \\
\hline & \\
\hline Results & $\mathbf{0 . 0 0 2 6 9 *}$ \\
\hline Heat loss through opening (MMBtu/hr) & \\
\hline
\end{tabular}

*Value calculated as an example below

The heat loss due to opening is calculated as,

$$
\begin{aligned}
Q & =\varepsilon B A\left(T_{s}^{4}-T_{a}^{4}\right) \\
Q & =0.8 \times 0.1714 \times 10^{\wedge}-8 \times 3 \times\left(930^{4}-470^{4}\right) \\
& =2686.89 \mathrm{Btu} / \mathrm{hr}=\mathbf{0 . 0 0 2 6 9} \mathbf{M M B t u} / \mathbf{h r}
\end{aligned}
$$

The opening loss is present only in the entry section of the furnace, hence the loss is considered only for zone 1 . 


\subsubsection{Cooling and Jet Cooling Sections}

number of sections: 1

Line speed $=423 \mathrm{ft} / \mathrm{min}$

Density of steel $=490 \mathrm{lbs} / \mathrm{ft} 3$

Strip width $=4.3 \mathrm{ft}$

Strip thickness $=0.00208 \mathrm{ft}$

Strip entry temperature in cooling section $=1400^{\circ} \mathrm{F}$

Strip exit temperature at cooling section $=1140^{\circ} \mathrm{F}$

Mass flow rate of strip $=423 \times 490 \times 4.3 \times 0.00208 \times 60$

$=111,229 \mathrm{lbs} / \mathrm{hr}$

The work done by the cooling section is calculated as,

$$
\begin{aligned}
Q & =n m c\left(T_{\text {exit }}-T_{\text {entry }}\right) \\
Q & =1 \times 111,229 \times 0.115 \times(1400-1140) \\
& =3,325,758 \mathrm{Btu} / \mathrm{hr}=\mathbf{3 . 3 2} \mathrm{MMBtu} / \mathbf{h r}
\end{aligned}
$$

Similarly the work done of jet cooling section can be determined by tracking the temperature of the strip at entry and exit of the section.

\subsection{Sensitivity Analysis}

There are many factors that influence the total loss, but major causes for these losses are volume of the zones, insulation material inside the zones, line speed, strip gauge, strip density, and zone 
temperatures. The following section discusses the effect of these parameters over the total heat loss.

Volume of the zones

Table 5.7 Sensitivity for Volume

\begin{tabular}{|c|c|c|c|}
\hline Volume & Scenario1 & Scenario2 & Scenario3 \\
\hline Unit & ft & ft & ft \\
\hline Length & 45 & 50 & 40 \\
\hline Width & 9 & 10 & 8 \\
\hline Height & 9 & 10 & 8 \\
\hline
\end{tabular}

This sensitivity is to see the effect of changing the dimensions of the zones on total heat loss. In this sensitivity analysis, the length, width, and height of the zones have been increased and decreased in Scenario 2 and 3 respectively.

Table 5.8 Effect of Volume on Total Heat Loss

\begin{tabular}{|l|c|c|c|}
\hline \multicolumn{1}{|c|}{ Heat } & Scenario 1 & Scenario 2 & Scenario 3 \\
\hline Steel Strip Heat & 17.56 & 17.56 & 17.56 \\
\hline Stack Loss & 6.710 & 6.710 & 6.710 \\
\hline Conduction throught the walls & 8.413 & 10.387 & 6.648 \\
\hline Radiation through other surfaces & 0.517 & 0.517 & 0.517 \\
\hline Convection through other surfaces & 0.257 & 0.257 & 0.257 \\
\hline Opening Loss & 0.003 & 0.003 & 0.003 \\
\hline Water Cooling Loss & 1.702 & 1.702 & 1.702 \\
\hline Total & $\mathbf{3 5 . 1 6 1}$ & $\mathbf{3 7 . 1 3 5}$ & $\mathbf{3 3 . 3 9 6}$ \\
\hline
\end{tabular}

As shown in table 5.8, increasing or decreasing the volume of the zone changes only the heat conducted through the walls and does not have any effect on other losses. The volume of the zone and total heat loss are directly proportional to each other. As shown in table 4.8, an increase in volume leads to increase in losses and similarly decrease in volume results in less heat loss. Figure 5.1 shows a graphical representation of the effect of volume of the zones on total heat loss. 


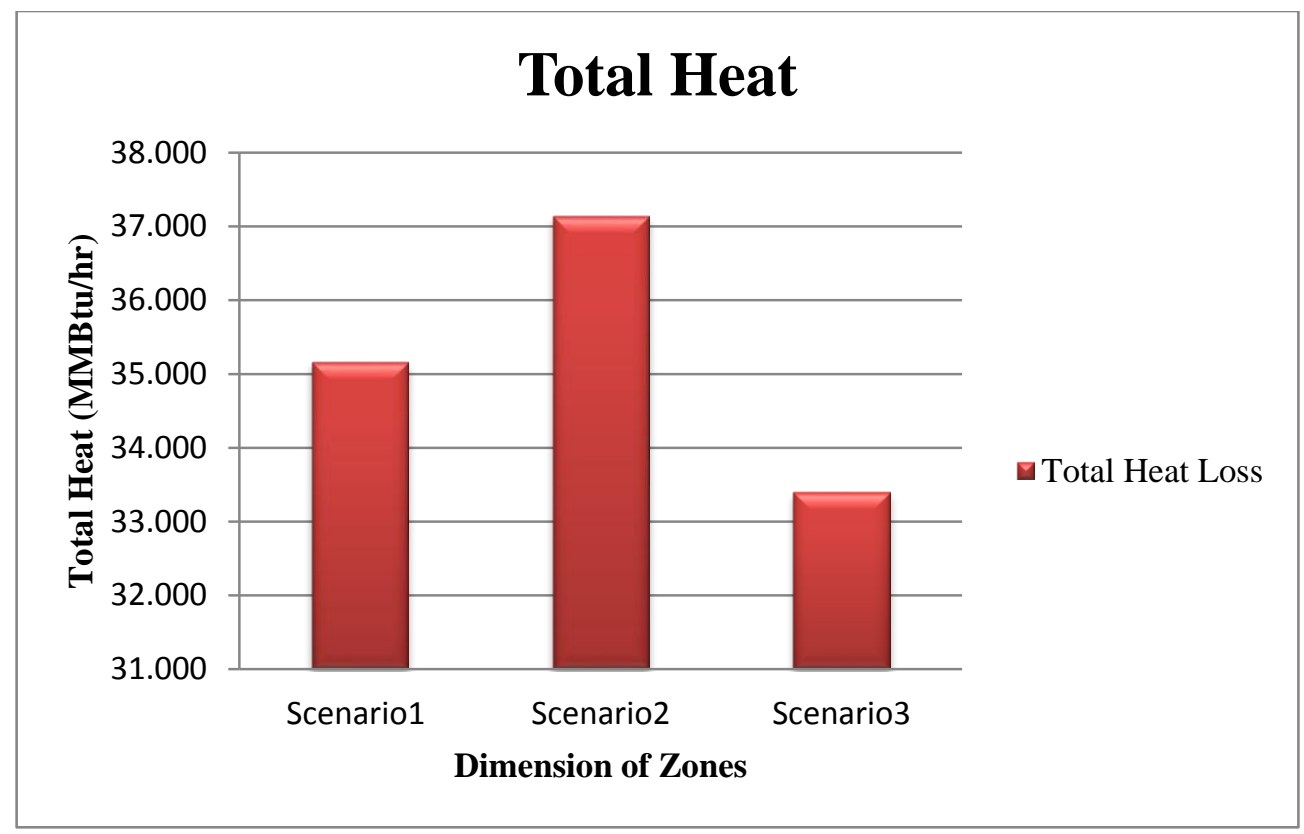

Figure 5.1 Effect of Volume of the Zones on Total Heat

\section{Insulation Material}

Table 5.9 Sensitivity for Insulation Materials

\begin{tabular}{|l|c|c|c|}
\hline Insulation Material & Bricks & Fiber Insulating Board & Fireclay brick \\
\hline & Scenario1 & Scenario2 & Scenario3 \\
\hline Thermal Conductivity & $0.5 \mathrm{Btu} / \mathrm{hr} . \mathrm{ft} . \mathrm{F}$ & $0.027 \mathrm{Btu} / \mathrm{hr} . \mathrm{ft} . \mathrm{F}$ & $0.8 \mathrm{Btu} / \mathrm{hr} . \mathrm{ft} . \mathrm{F}$ \\
\hline
\end{tabular}

This sensitivity is to see the effect of changing the insulation material inside the zones on total heat loss. In this sensitivity analysis, the insulation material used inside the zones have been changed in Scenario 2 and 3 respectively.

Table 5.10 Effect of Insulation Material on Total Heat Loss

\begin{tabular}{|l|c|c|c|}
\hline \multicolumn{1}{|c|}{ Heat } & Scenario1 & Scenario2 & Scenario3 \\
\hline Steel Strip Heat & 17.56 & 17.56 & 17.56 \\
\hline Stack Loss & 6.710 & 6.710 & 6.710 \\
\hline Conduction throught the walls & 8.413 & 0.448 & 13.164 \\
\hline Radiation through other surfaces & 0.517 & 0.517 & 0.517 \\
\hline Convection through other surfaces & 0.257 & 0.257 & 0.257 \\
\hline Opening Loss & 0.003 & 0.003 & 0.003 \\
\hline Water Cooling Loss & 1.702 & 1.702 & 1.702 \\
\hline Total & $\mathbf{3 5 . 1 6 1}$ & $\mathbf{2 7 . 1 9 6}$ & $\mathbf{3 9 . 9 1 2}$ \\
\hline
\end{tabular}


As shown in table 5.10, changing the insulation material from bricks to fiber insulation board decreases the heat loss significantly. The reason for the change in the loss is that the fiber insulation board has a thermal conductivity of $0.027 \mathrm{Btu} / \mathrm{hr} . \mathrm{ft} . \mathrm{F}$ which is less when compared to the thermal conductivity of bricks. Similarly, a change in bricks to fireclay bricks will increase the heat loss as shown in table 5.8 due to the increase in thermal conductivity. Therefore, thermal conductivity and total heat loss are directly proportional to each other. Figure 5.2 shows a graphical representation of the effect of insulation material on total heat loss.

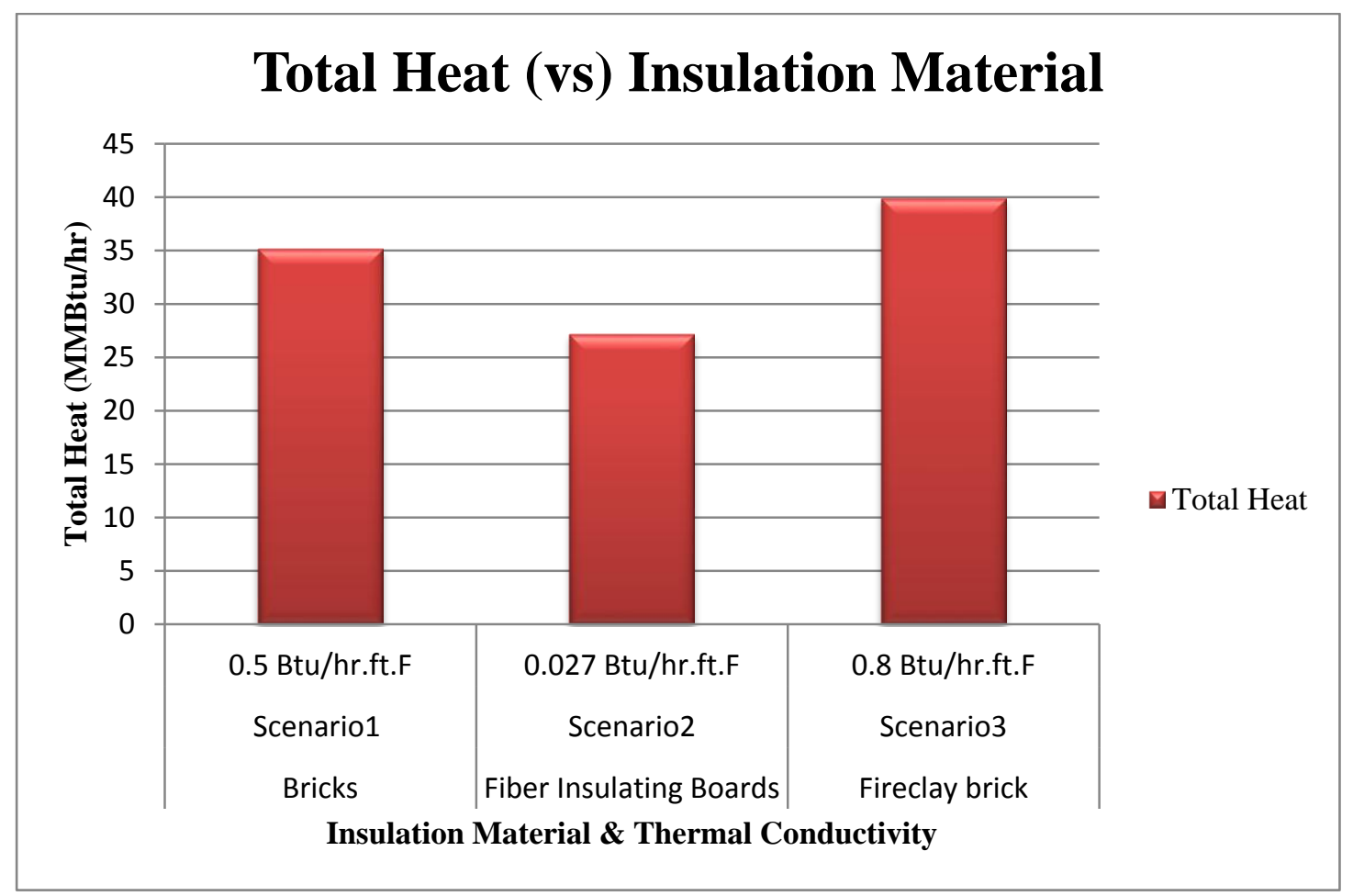

Figure 5.2 Effect of Insulation Material on Total Heat Loss

\section{Line Speed}

Table 5.11 Sensitivity for Line Speed

\begin{tabular}{|c|c|c|c|}
\hline Line Speed & Scenario 1 & Scenario 2 & Scenario 3 \\
\hline Speed & $423 \mathrm{ft} / \mathrm{min}$ & $400 \mathrm{ft} / \mathrm{min}$ & $450 \mathrm{ft} / \mathrm{min}$ \\
\hline
\end{tabular}

This sensitivity is to see the effect of changing the line speed of the steel strip entering on total heat loss. In this sensitivity analysis, the line speed of steel strip entering the furnace have been decreased and increased in Scenario 2 and 3 respectively. 
Table 5.12 Effect of Line Speed on Total Heat Loss

\begin{tabular}{|l|c|c|c|}
\hline \multicolumn{1}{|c|}{ Heat } & Scenario 1 & Scenario 2 & Scenario 3 \\
\hline Steel Strip Heat & 17.56 & 16.61 & 18.69 \\
\hline Stack Loss & 6.710 & 6.710 & 6.710 \\
\hline Conduction throught the walls & 8.413 & 8.413 & 8.413 \\
\hline Radiation through other surfaces & 0.517 & 0.517 & 0.517 \\
\hline Convection through other surfaces & 0.257 & 0.257 & 0.257 \\
\hline Opening Loss & 0.003 & 0.003 & 0.003 \\
\hline Water Cooling Loss & 1.702 & 1.702 & 1.702 \\
\hline Total & $\mathbf{3 5 . 1 6 1}$ & $\mathbf{3 4 . 2 1 1}$ & $\mathbf{3 6 . 2 9 1}$ \\
\hline
\end{tabular}

As shown in table 5.12, decreasing the line speed decreases the heat loss due to less amount of pounds per hour of steel entering inside the furnace. Similarly, an increase in line speed results in more heat loss. Therefore, line speed and total heat loss are directly proportional to each other. Figure 5.3 shows a graphical representation of the effect of line speed on total heat loss.

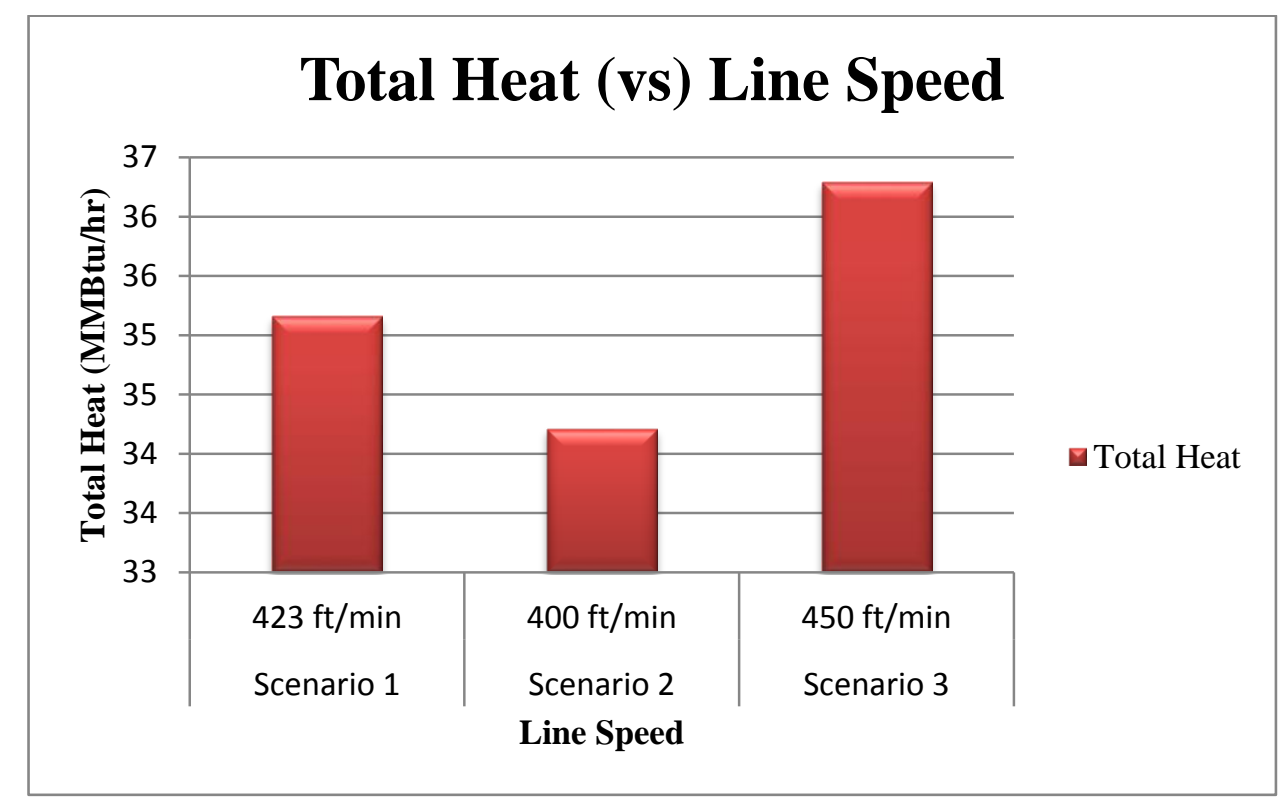

Figure 5.3 Effect of Line Speed on Total Heat Loss

\section{Strip Gage}

Table 5.13 Sensitivity for Strip Gage

\begin{tabular}{|c|c|c|c|}
\hline Strip Gage & Scenario 1 & Scenario 2 & Scenario 3 \\
\hline Gage & $0.00208 \mathrm{ft}$ & $0.0023 \mathrm{ft}$ & $0.00195 \mathrm{ft}$ \\
\hline
\end{tabular}


This sensitivity is to see the effect of changing strip gage on total heat loss. In this sensitivity analysis, the strip thickness of steel strip entering the furnace have been increased and decreased in Scenario 2 and 3 respectively.

Table 5.14 Effect of Strip Gage on Total Heat Loss

\begin{tabular}{|l|c|c|c|}
\hline \multicolumn{1}{|c|}{ Heat } & Scenario 1 & Scenario 2 & Scenario 3 \\
\hline Steel Strip Heat & 17.56 & 19.43 & 16.47 \\
\hline Stack Loss & 6.710 & 6.710 & 6.710 \\
\hline Conduction throught the walls & 8.413 & 8.413 & 8.413 \\
\hline \multicolumn{1}{|c|}{ Heat } & Scenario 1 & Scenario 2 & Scenario 3 \\
\hline Radiation through other surfaces & 0.517 & 0.517 & 0.517 \\
\hline Convection through other surfaces & 0.257 & 0.257 & 0.257 \\
\hline Opening Loss & 0.003 & 0.003 & 0.003 \\
\hline Water Cooling Loss & 1.702 & 1.702 & 1.702 \\
\hline Total & $\mathbf{3 5 . 1 6 1}$ & $\mathbf{3 7 . 0 3 1}$ & $\mathbf{3 4 . 0 7 1}$ \\
\hline
\end{tabular}

As shown in table 5.14, increasing the thickness of the strip increases the heat loss due to more amount of pounds per hour of steel entering inside the furnace. Similarly, a decrease in thickness results in less heat loss. Therefore, strip gage and total heat loss are directly proportional to each other. Figure 5.4 shows a graphical representation of the effect of strip gage on total heat loss.

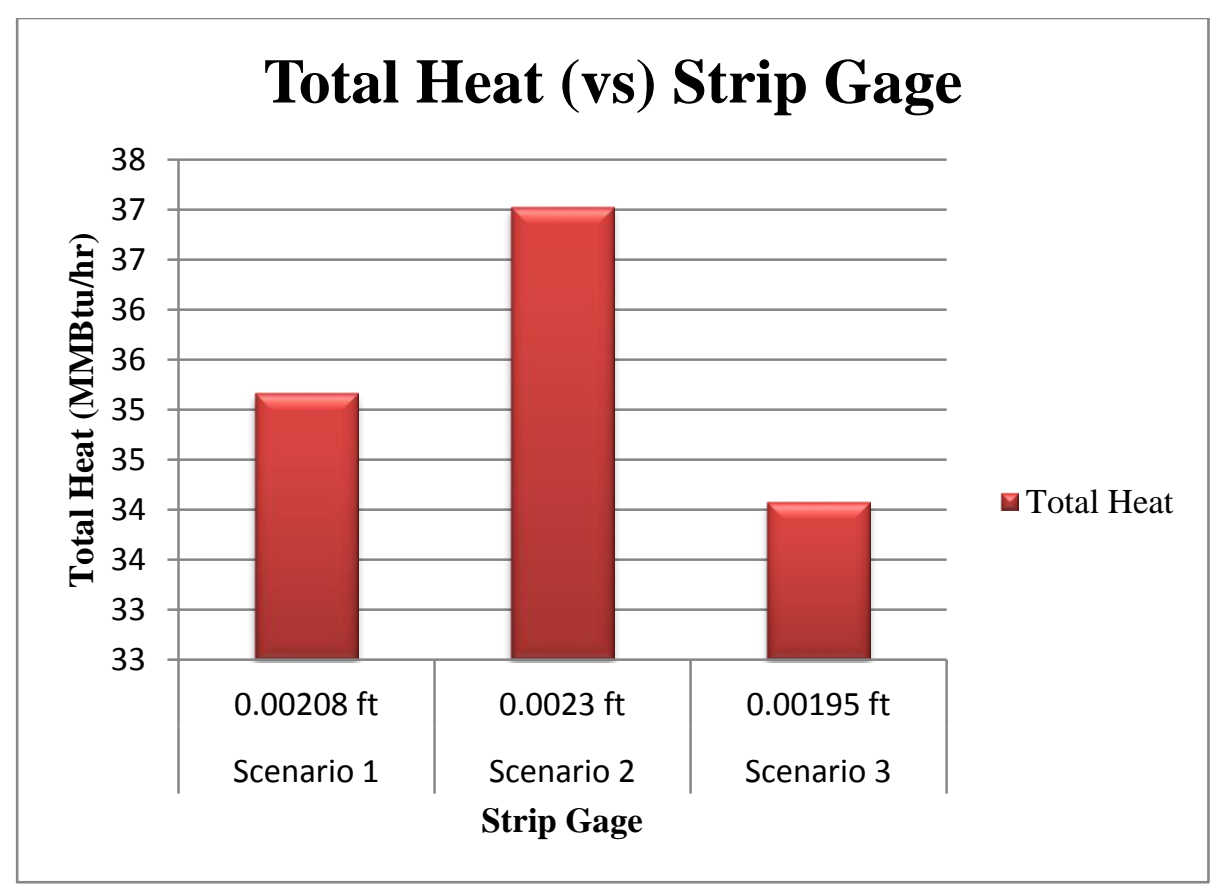

Figure 5.4 Effect of Steel Strip Gage on Total Heat Loss 


\section{Strip Density}

Table 5.15 Sensitivity for Strip Density

\begin{tabular}{|c|c|c|c|}
\hline Strip Density & Scenario 1 & Scenario 2 & Scenario 3 \\
\hline Density & $490 \mathrm{lb} / \mathrm{ft}^{3}$ & $450 \mathrm{lb} / \mathrm{ft}^{3}$ & $540 \mathrm{lb} / \mathrm{ft}^{3}$ \\
\hline
\end{tabular}

This sensitivity is to see the effect of changing strip density on total heat loss. In this sensitivity analysis, the strip thickness of steel strip entering the furnace have been decreased and increased in Scenario 2 and 3 respectively.

Table 5.16 Effect of Strip Density on Total Heat Loss

\begin{tabular}{|l|c|c|c|}
\hline \multicolumn{1}{|c|}{ Heat } & Scenario 1 & Scenario 2 & Scenario 3 \\
\hline Steel Strip Heat & 17.56 & 16.13 & 19.36 \\
\hline Stack Loss & 6.710 & 6.710 & 6.710 \\
\hline Conduction throught the walls & 8.413 & 8.413 & 8.413 \\
\hline Radiation through other surfaces & 0.517 & 0.517 & 0.517 \\
\hline Convection through other surfaces & 0.257 & 0.257 & 0.257 \\
\hline Opening Loss & 0.003 & 0.003 & 0.003 \\
\hline Water Cooling Loss & 1.702 & 1.702 & 1.702 \\
\hline Total & $\mathbf{3 5 . 1 6 1}$ & $\mathbf{3 3 . 7 3 1}$ & $\mathbf{3 6 . 9 6 1}$ \\
\hline
\end{tabular}

As shown in table 5.16, increasing the density of the strip increases the heat loss due to the mass of the strip being high. Similarly, a decrease in density results in less heat loss. Therefore, strip density and total heat loss are directly proportional to each other. Figure 5.5 shows a graphical representation of the effect of strip density on total heat loss.

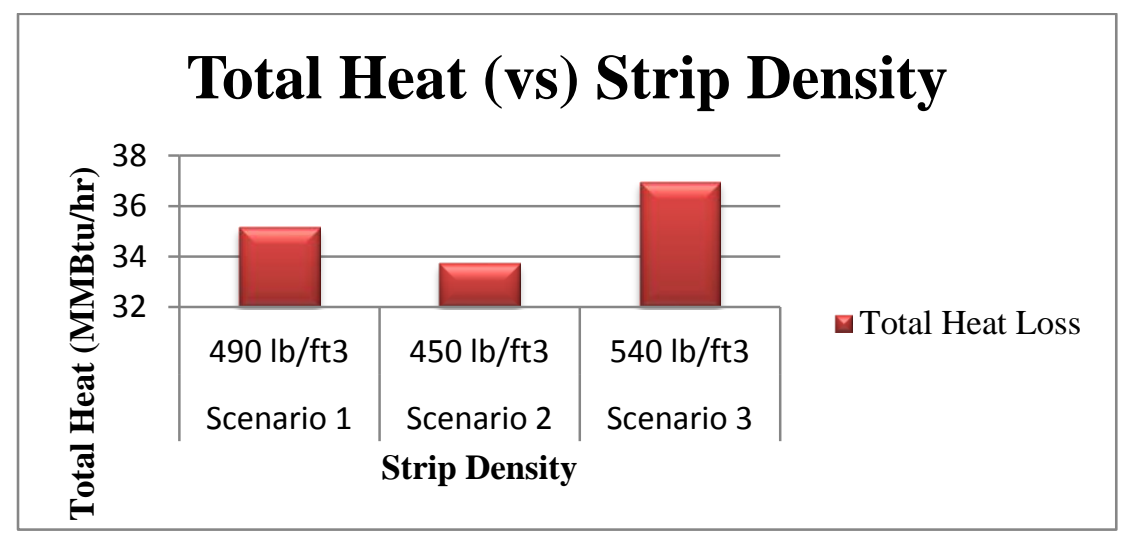

Figure 5.5 Effect of Strip Density on Total Heat Loss 
Furnace Temperature

Table 5.17 Sensitivity for Furnace Temperature

\begin{tabular}{|c|c|c|c|}
\hline Average Zone Temperature & Scenario 1 & Scenario 2 & Scenario 3 \\
\hline Temperature & $1700 \mathrm{~F}$ & $1850 \mathrm{~F}$ & $1450 \mathrm{~F}$ \\
\hline
\end{tabular}

This sensitivity is to see the effect of changing the zone temperature on total heat loss. In this sensitivity analysis, the average temperature maintained inside the zones have been increased and decreased in Scenario 2 and 3 respectively.

Table 5.18 Effect of Average Zone Temperature on Total Heat Loss

\begin{tabular}{|l|c|c|c|}
\hline \multicolumn{1}{|c|}{ Heat } & Scenario 1 & Scenario 2 & Scenario 3 \\
\hline Steel Strip Heat & 17.56 & 17.56 & 17.56 \\
\hline Stack Loss & 6.710 & 6.710 & 6.710 \\
\hline Conduction throught the walls & 8.413 & 9.309 & 6.890 \\
\hline Radiation through other surfaces & 0.517 & 0.517 & 0.517 \\
\hline Convection through other surfaces & 0.257 & 0.257 & 0.257 \\
\hline Opening Loss & 0.003 & 0.003 & 0.003 \\
\hline Water Cooling Loss & 1.702 & 1.702 & 1.702 \\
\hline Total & $\mathbf{3 5 . 1 6 1}$ & $\mathbf{3 6 . 0 5 8}$ & $\mathbf{3 3 . 6 3 8}$ \\
\hline
\end{tabular}

As shown in table 5.18, increasing the average temperature inside the zones increases the heat loss due to high heat escaping from the furnace by conduction, convection and radiation.. Similarly, a decrease in density results in less heat loss. Therefore, zone temperature and total heat loss are directly proportional to each other. Figure 5.6 shows a graphical representation of the effect of strip density on total heat loss.

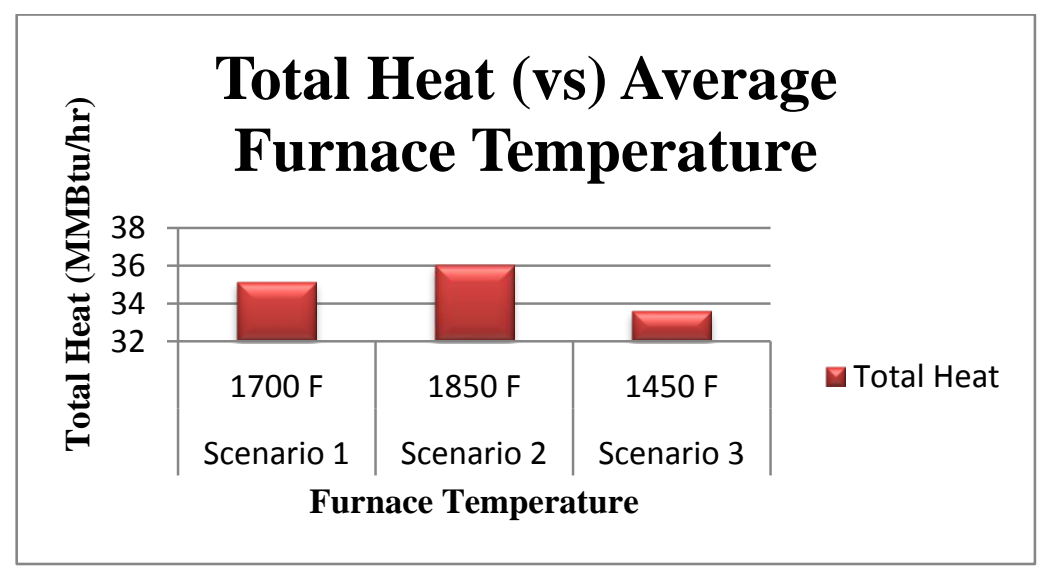

Figure 5.6 Effect of Average Furnace Temperature on Total Heat Loss 


\subsection{Results and Discussion}

The model has been populated with the data collected in the host facility and results were obtained. The calculations on different losses and heat inputs were discussed in section 5.3. This section exclusively deals with providing snapshots of the results obtained from both "Heat Losses" and "Heat Input" spreadsheets for the whole furnace (Zone 1 - Zone 7).

Inputs: "Heat Losses" Spreadsheet, Module 1 - Losses, Zone Details

\begin{tabular}{|c|c|c|c|c|c|c|c|c|}
\hline INPUTS & & & & & & & & \\
\hline & & & & & & & & \\
\hline INPUT ZONE DETAILS & Units & Details & & & & & & \\
\hline Name of the Furnace & Annealing & & & & & & & \\
\hline Number of Zones & 7 & \multicolumn{7}{|c|}{ HEATING SECTION } \\
\hline Zones & & Zonel & Zone2 & Zone3 & Zone4 & Zone5 & Zone6 & Zone7 \\
\hline Type of Heating & & Gas & Gas & Gas & Gas & Gas & Gas & Gas \\
\hline Fuel Used & & Natural Gas & Natural Gas & Natural Gas & Natural Gas & Natural Gas & Natural Gas & Natural Gas \\
\hline No. of Burners/Grid & no units & 32 & 36 & 34 & 34 & 30 & 30 & 30 \\
\hline Rated Capacity of the Heating Element & MMBtuhr & 0.255 & 0.255 & 0.255 & 0.2295 & 0.2295 & 0.2295 & 0.270 \\
\hline Efficiency of Heating Element & & 0.85 & 0.85 & 0.85 & 0.85 & 0.85 & 0.85 & 0.850 \\
\hline Utilization factor of the system & & 1 & 1 & 1 & 1 & 1 & 1 & 1 \\
\hline Zone Atmosphere & & Air: NG & Air:NG & Air, NG & Air:NG & Air:NG & Air: NG & Air: $\mathrm{NG}$ \\
\hline Zone Temperature & $\mathrm{F}$ & 1689 & 1701 & 1680 & 1719 & 1722 & 1690 & 1720 \\
\hline Ambient Temperature & $\mathrm{F}$ & 95 & 95 & 95 & 95 & 95 & 95 & 95 \\
\hline Length of the Zone & $\mathrm{At}$ & 45 & 45 & 45 & 45 & 45 & 45 & 45 \\
\hline Width of the Zone & $\mathrm{ft}$ & 9 & 9 & 9 & 9 & 9 & 9 & 9 \\
\hline Height of the Zone & $\mathrm{ft}$ & 9 & 9 & 9 & 9 & 9 & 9 & 9 \\
\hline Area of the Zone & $\mathrm{ft}^{2}$ & 1782.00 & 1782.00 & 1782.00 & 1782.00 & 1782.00 & 1782.00 & 1782.00 \\
\hline
\end{tabular}

Figure 5.7 Input - Zone Details

Inputs: "Heat Losses" Spreadsheet, Module 1 - Losses, Area

\begin{tabular}{|c|c|c|c|c|c|c|c|c|}
\hline \multicolumn{9}{|l|}{ AREA } \\
\hline Label & Units & & & & \multicolumn{4}{|c|}{ HEATING SECTION } \\
\hline Zones & & Zonel & Zone2 & Zone3 & Zone4 & Zone 5 & Zone 6 & Zone 7 \\
\hline Furnace Zone Temperatures & $\mathrm{F}$ & 1689 & 1701 & 1680 & 1719 & 1722 & 1690 & 1720 \\
\hline Length of the Zones & $\mathrm{ft}$ & 45 & 45 & 45 & 45 & 45 & 45 & 45 \\
\hline Width of the Zones & $\mathrm{ft}$ & 9.00 & 9.00 & 9.00 & 9.00 & 9.00 & 9.00 & 9.00 \\
\hline Height of the Zones & $\mathrm{ft}$ & 9.00 & 9.00 & 9.00 & 9.00 & 9.00 & 9.00 & 9.00 \\
\hline Area of Heat Conduction Through the Sides & $\mathrm{ft}^{2}$ & 972.00 & 972.00 & 972.00 & 972.00 & 972.00 & 972.00 & 972.00 \\
\hline & & & & & & & & \\
\hline \multicolumn{9}{|l|}{ Area of burner and other heat emitting surfaces } \\
\hline Zones & & Zone1 & Zone 2 & Zone 3 & Zone 4 & Zone 5 & Zone 6 & Zone 7 \\
\hline Burner Section Diameter & $\mathrm{ft}$ & 0.600 & 0.600 & 0.600 & 0.600 & 0.600 & 0.600 & 0.600 \\
\hline Height or the length of the Burners & $\mathrm{ft}$ & 0.800 & 0.800 & 0.800 & 0.800 & 0.800 & 0.800 & 0.800 \\
\hline Area of one Burner Section & $\mathrm{ft}^{2}$ & 2.074 & 2.074 & 2.074 & 2.074 & 2.074 & 2.074 & 2.074 \\
\hline Number of Burners in the Zone & & 32.000 & 36.000 & 34.000 & 34.000 & 30.000 & 30.000 & 30.000 \\
\hline Total Area occupied by Burners Section & $\mathrm{At}^{2}$ & 66.359 & 74.654 & 70.506 & 70.506 & 62.212 & 62.212 & 62.212 \\
\hline Total area of cylindrical surfaces (Pipes and other cylindrical surfaces) & $\mathrm{ft}^{2}$ & 55 & 55 & 55 & 55 & 55 & 55 & 55 \\
\hline Total surface area of Rectangular surfaces & $\mathrm{ft}^{2}$ & 0 & 0 & 0 & 0 & 0 & 0 & 0 \\
\hline Total surface area of Square surfaces & $\mathrm{ft}^{2}$ & 0 & 0 & 0 & 0 & 0 & 0 & 0 \\
\hline Total Area of the burners and other surfaces & $\mathrm{ft}^{2}$ & 121 & 130 & 126 & 126 & 117 & 117 & 117 \\
\hline
\end{tabular}

Figure 5.8 Input - Area Details 
Inputs: "Heat Losses" Spreadsheet, Module 1 - Losses, Stack Analysis

\begin{tabular}{|c|c|c|c|c|c|c|c|c|}
\hline STACK ANALYSIS & & & & & & & & \\
\hline Inputs & Units & \multicolumn{7}{|c|}{ HEATING SECTION } \\
\hline & & Zonel & Zone? & Zone3 & Zonet & Zones & Zone6 & Zone? \\
\hline Input cfm of Natural gas & $\mathrm{f}^{3} / \mathrm{hr}$ & 4500 & 5600 & 5000 & 5100 & 5200 & 5000 & 5200 \\
\hline Input cin of Air & $\mathrm{f}^{3} / \mathrm{hr}$ & 47853 & 57500 & 53000 & 53500 & 54000 & 53000 & 53500 \\
\hline Percentlage of Oxygen in stack & $\%$ & 2.2 & 1.62 & 2.17 & 1.98 & 1.82 & 2.17 & 1.66 \\
\hline Excess ail & $\%$ & 12 & 8 & 12 & 10 & 9 & 12 & 9 \\
\hline Stoichiometric + Excess aif & & 1.12 & 1.08 & 1.12 & 1.10 & 1.09 & 1.12 & 1.09 \\
\hline 16 b of air to bum 1 b of $N G=16^{*}(1$ excessair) $/$ Total Air Surplied & Ibllb of fuel & 17.87 & 17.34 & 17.84 & 17.67 & 17.52 & 17.84 & 17.37 \\
\hline Mass of flue gas & billo of fiel & 18.87 & 18.34 & 18.84 & 18.67 & $18.5 ?$ & 18.84 & 18.37 \\
\hline Density of air & $\mathrm{bbtt}^{3}$ & 0.075 & & & & & & \\
\hline Density of Natural gas & $10 \mathrm{ft}^{3}$ & 0.044 & & & & & & \\
\hline mass rate of air & Ibshr & 3589 & 4313 & 3975 & 4013 & 4050 & 3975 & 4013 \\
\hline mass rate of natral gas & lloshir & 198 & 246 & 220 & 224 & 229 & 220 & 229 \\
\hline Total mass atat of the mixture & lbshir & 3787 & 4559 & 4195 & 4237 & 4279 & 4195 & 4241 \\
\hline Specific Heat Capacity of flue gas & Butllb.F & 0.30 & 0.30 & 0.30 & 0.30 & 0.30 & 0.30 & 0.30 \\
\hline Stack Temperature & $\mathrm{F}$ & 950 & 965 & 850 & 888 & 865 & 850 & 925 \\
\hline Combustion air Temperature & $\mathrm{F}$ & 300 & 300 & 300 & 300 & 300 & 300 & 300 \\
\hline
\end{tabular}

\section{Figure 5.9 Input - Stack Analysis}

Figure 5.7 - 5.9 represents the schematic of input section in the "Heat Losses" spreadsheet. The data collected by the user on the furnace should be entered in these sections. The values to calculate different losses are pulled from these sections by the model. As shown in Figure 5.7, the furnace in the host facility has seven zones maintained at different temperatures. The dimensions of the zone are equal and ratings on the burners differ zone by zone. Figure 5.8 displays the area calculated for the zones and miscellaneous surfaces. Stack analysis helps the user in identifying the amount of oxygen present in the stack, and the air in excess used for combustion.

Figure 5.10 shows the schematic of radiation loss. Radiation loss is significant when the surface temperatures are high. It was observed that the miscellaneous surfaces of the furnace were at high temperatures in the host facility and radiate significant amount of heat to atmosphere. As shown in Figure 5.10 the average surface temperature is around $400^{\circ} \mathrm{F}$. Emissivity is a key parameter in radiation. An emissivity factor of 0.8 is taken in this study as these surfaces are steel surfaces. Emissivity differs for different metals and materials. The user should be precise in finding out the emissivity of the metal or material used. 
Outputs: "Heat Losses" Spreadsheet, Module 1 - Losses, Radiation

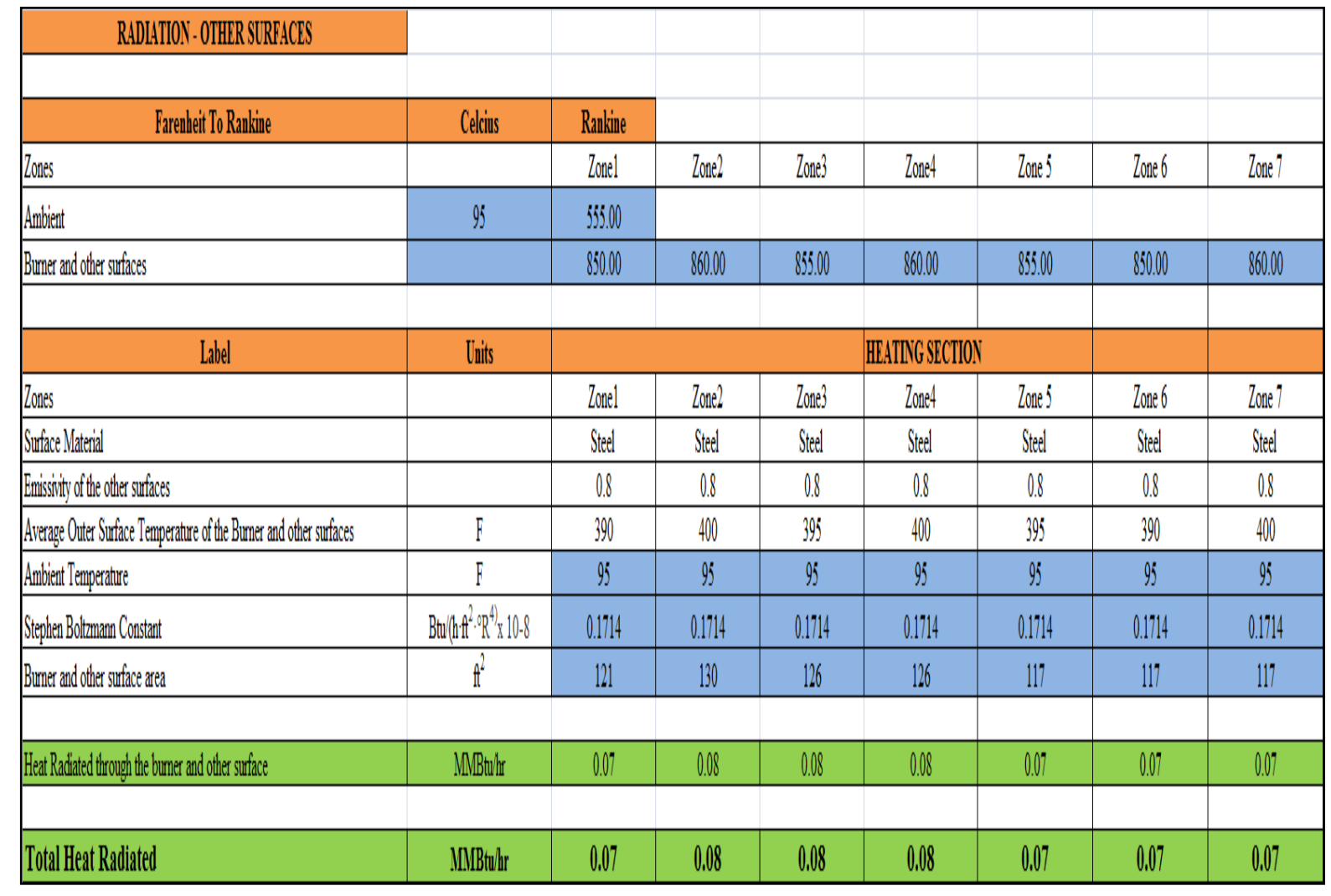

Figure 5.10 Output - Radiation Loss

A schematic representation of conduction loss is shown in Figure 5.11. Insulation materials used inside the furnace plays a key role in conduction heat loss. The model takes up to 3 insulation layers The user has to input the type of material used, its thermal conductivity, and thickness of the layers. Conduction through the walls is highly influenced by the type of insulation material used inside the furnace. The insulation material used in the host facility is bricks and block insulation. There are two layers of insulation on top and three on the bottom and sides of the furnace. The thickness of each layer is around $0.25 \mathrm{ft}$ to $0.75 \mathrm{ft}$. The surface area of heat conduction through the top, bottom and sides are calculated by the model with the dimension details entered in the input zone section. Infrared temperature gun was used to observe the temperature on the surfaces of furnace. The temperature difference with the thickness, area, and thermal conductivity determines the heat conducted through the walls. 
Outputs: "Heat Losses" Spreadsheet, Module 1 - Losses, Conduction

\begin{tabular}{|c|c|c|c|c|c|c|c|c|}
\hline OUTPUTS - LOSSES & & & & & & & & \\
\hline \multicolumn{9}{|c|}{ CONDUCTION - HEAT LOSS THROUGH FURNACE WALLS } \\
\hline 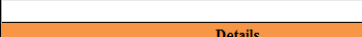 & & & & & \multirow{2}{*}{\multicolumn{4}{|c|}{ HEATING SECTION }} \\
\hline 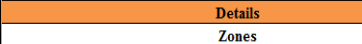 & Units & Zonel & Zone2 & Zone3 & $\begin{array}{l}\text { HEATING SECTIO } \\
\text { Zone4 }\end{array}$ & Zone5 & & \\
\hline Furnace Zone Temperatures & $\mathrm{F}$ & 1689 & 1701 & 1680 & 1719 & 1722 & 1690 & 1720 \\
\hline Length of the Zone & $\mathrm{ft}$ & 45 & 45 & 45 & 45 & 45 & 45 & 45 \\
\hline Width of the Zone & $\mathrm{ft}$ & 9.00 & 9.00 & 9.00 & 9.00 & 9.00 & 9.00 & 9.00 \\
\hline Height of the Zone & $\mathrm{ft}$ & 9.00 & 9.00 & 9.00 & 9.00 & 9.00 & 9.00 & 9.00 \\
\hline Furnace Wall Material & & Steel & Steel & Steel & Steel & Steel & Steel & Steel \\
\hline Thermal Conductivity of Wall Material & Btuhrfft.F & 24 & 24 & 24 & 24 & 24 & 24 & 24 \\
\hline Thickness of Wall Material & $\mathrm{ft}$ & 0.25 & 0.25 & 0.25 & 0.25 & 0.25 & 0.25 & 0.25 \\
\hline Number of Insulation layers on top & & 2 & 2 & 2 & 2 & 2 & 2 & 2 \\
\hline Temperature on the Top of the Furnace & $\mathrm{F}$ & 290 & 300 & 290 & 320 & 320 & 300 & 300 \\
\hline Insulation Material 1 & & Block Insulation & Block Insulation & Block Insulation & Block Insulation & Block Insulation & Block Insulation & Block Insulation \\
\hline Thermal Conductivity of Material 1 & Btuhr.ft.F & 0.5 & 0.5 & 0.5 & 0.5 & 0.5 & 0.5 & 0.5 \\
\hline Thickness of Material 1 & $\mathrm{ft}$ & 0.25 & 0.25 & 0.25 & 0.25 & 0.25 & 0.25 & 0.25 \\
\hline Insulation Material 2 & & Arch Brick & Arch Brick & Arch Brick & Arch Brick & Arch Brick & Arch Brick & Arch Brick \\
\hline Thermal Conductivity of Material 2 & Btuhr.ft.F & 0.5 & 0.5 & 0.5 & 0.5 & 0.5 & 0.5 & 0.5 \\
\hline Thickness of Material 2 & $\mathrm{ft}$ & 0.75 & 0.75 & 0.75 & 0.75 & 0.75 & 0.75 & 0.75 \\
\hline Insulation Material 3 & & $\mathrm{~N} / \mathrm{A}$ & $\mathrm{N} / \mathrm{A}$ & N/A & $\mathrm{N} / \mathrm{A}$ & $\mathrm{N} / \mathrm{A}$ & $\mathrm{N} / \mathrm{A}$ & $\mathrm{N} / \mathrm{A}$ \\
\hline Thermal Conductivity of Material 3 & Btuhr.ft.F & $\mathrm{N} / \mathrm{A}$ & $\mathrm{N} / \mathrm{A}$ & $\mathrm{N} / \mathrm{A}$ & $\mathrm{N} / \mathrm{A}$ & $\mathrm{N} / \mathrm{A}$ & $\mathrm{N} / \mathrm{A}$ & $\mathrm{N} / \mathrm{A}$ \\
\hline Thickness of Material 3 & $\mathrm{ft}$ & $\mathrm{N} / \mathrm{A}$ & $\mathrm{N} / \mathrm{A}$ & $\mathrm{N} / \mathrm{A}$ & $\mathrm{N} / \mathrm{A}$ & $\mathrm{N} / \mathrm{A}$ & $\mathrm{N} / \mathrm{A}$ & $\mathrm{N} / \mathrm{A}$ \\
\hline Surface Area of Heat Conduction Through the Top & $\mathrm{ft}^{2}$ & 405 & 405 & 405 & 405 & 405 & 405 & 405 \\
\hline Number of Insulation layers in the Bottom & & 3 & 3 & 3 & 3 & 3 & 3 & 3 \\
\hline Temperature on the Bottom of the Furnace & $\mathrm{F}$ & 280 & 290 & 290 & 300 & 310 & 295 & 300 \\
\hline Insulation Material 1 & & Block Insulation & Block Insulation & Block Insulation & Block Insulation & Block Insulation & Block Insulation & Block Insulation \\
\hline Thermal Conductivity of Material 1 & Btuhrfft.F & 0.5 & 0.5 & 0.5 & 0.5 & 0.5 & 0.5 & 0.5 \\
\hline Thickness of Material 1 & $\mathrm{ft}$ & 0.25 & 0.25 & 0.25 & 0.25 & 0.25 & 0.25 & 0.25 \\
\hline Insulation Material 2 & & Straight Brick & Straight Brick & Straight Brick & Straight Brick & Straight Brick & Straight Brick & Straight Brick \\
\hline Thermal Conductivity of Material 2 & Btuhr.ff.F & 0.65 & 0.65 & 0.65 & 0.65 & 0.65 & 0.65 & 0.65 \\
\hline Thickness of Material 2 & $\mathrm{ft}$ & 0.5 & 0.5 & 0.5 & 0.5 & 0.5 & 0.5 & 0.5 \\
\hline $\begin{array}{l}\text { Insulation Material } 3 \\
\end{array}$ & & Straight Brick & Straight Brick & Straight Brick & Straight Brick & Straight Brick & Straight Brick & Straight Brick \\
\hline Thermal Conductivity of Material 3 & Btuhr.ft.F & 0.5 & 0.5 & 0.5 & 0.5 & 0.5 & 0.5 & 0.5 \\
\hline Thickness of Material 3 & $\mathrm{ft}$ & 0.5 & 0.5 & 0.5 & 0.5 & 0.5 & 0.5 & 0.5 \\
\hline Surface Area of Heat Conduction Through the Bottom & $\mathrm{ft}^{2}$ & 405 & 405 & 405 & 405 & 405 & 405 & 405 \\
\hline Number of Insulation layers on the Sides & & 3 & 3 & 3 & 3 & 3 & 3 & 3 \\
\hline Temperature on the Sides of the Furnace & & 300 & 320 & 310 & 325 & 325 & 315 & 330 \\
\hline Insulation Material 1 & & Block Insulation & Block Insulation & Block Insulation & Block Insulation & Block Insulation & Block Insulation & Block Insulation \\
\hline Thermal Conductivity of Material 1 & Btuhhrff.F & 0.5 & 0.5 & 0.5 & 0.5 & 0.5 & 0.5 & 0.5 \\
\hline Thickness of Material 1 & $\mathrm{ft}$ & 0.25 & 0.25 & 0.25 & 0.25 & 0.25 & 0.25 & 0.25 \\
\hline Insulation Material 2 & & Straight Brick & Straight Brick & Straight Brick & Straight Brick & Straight Brick & Straight Brick & Straight Brick \\
\hline Thermal Conductivity of Material 2 & Btuhrfft.F & 0.5 & 0.5 & 0.5 & 0.5 & 0.5 & 0.5 & 0.5 \\
\hline Thickness of Material 2 & $\mathrm{ft}$ & 0.375 & 0.375 & 0.375 & 0.375 & 0.375 & 0.375 & 0.375 \\
\hline Insulation Material 3 & & Straight Brick & Straight Brick & Straight Brick & Straight Brick & Straight Brick & Straight Brick & Straight Brick \\
\hline Thermal Conductivity of Material 3 & Btuhr.ft.F & 0.5 & 0.5 & 0.5 & 0.5 & 0.5 & 0.5 & 0.5 \\
\hline Thickness of Material 3 & $\mathrm{ft}$ & 0.375 & 0.375 & 0.375 & 0.375 & 0.375 & 0.375 & 0.375 \\
\hline Surface Area of Heat Conduction Through the Sides & $\mathrm{ft}^{2}$ & 972 & 972 & 972 & 972 & 972 & 972 & 972 \\
\hline Total Surface Area of the Funace & $\mathrm{ft}^{2}$ & 1782 & 1782 & 1782 & 1782 & 1782 & 1782 & 1782 \\
\hline Heat Conducted through the Top & MMBtuhr & 0.28 & 0.28 & 0.28 & 0.28 & 0.28 & 0.28 & 0.29 \\
\hline & & & & & & & & \\
\hline Heat Conducted through the Bottom & MMBtuhr & 0.25 & 0.25 & 0.25 & 0.25 & 0.25 & 0.25 & 0.25 \\
\hline Heat Conducted through the Sides & MMBtuhr & 0.67 & 0.67 & 0.66 & 0.67 & 0.68 & 0.66 & 0.67 \\
\hline & & & & & & & & \\
\hline Heat Conducted through the Furnace Walls & MMBtu/hr & 1.20 & 1.20 & 1.19 & 1.21 & 1.21 & 1.19 & 1.21 \\
\hline
\end{tabular}

Figure 5.11 Output - Conduction Loss

Figure 5.12 displays the convection loss in the model. The convection loss is similar to radiation loss except heat transfer coefficient is used in place of emissivity and Stephen Boltzmann constant. Heat transfer coefficient is taken as 1 in this study as the type of convection is natural convection. Natural convection is a mechanism, or type of heat transport, in which the fluid motion is not generated by any external source (like a pump, fan, suction device, etc.) but only by density differences in the fluid occurring due to temperature gradients. 
Outputs: "Heat Losses" Spreadsheet, Module 1 - Losses, Convection

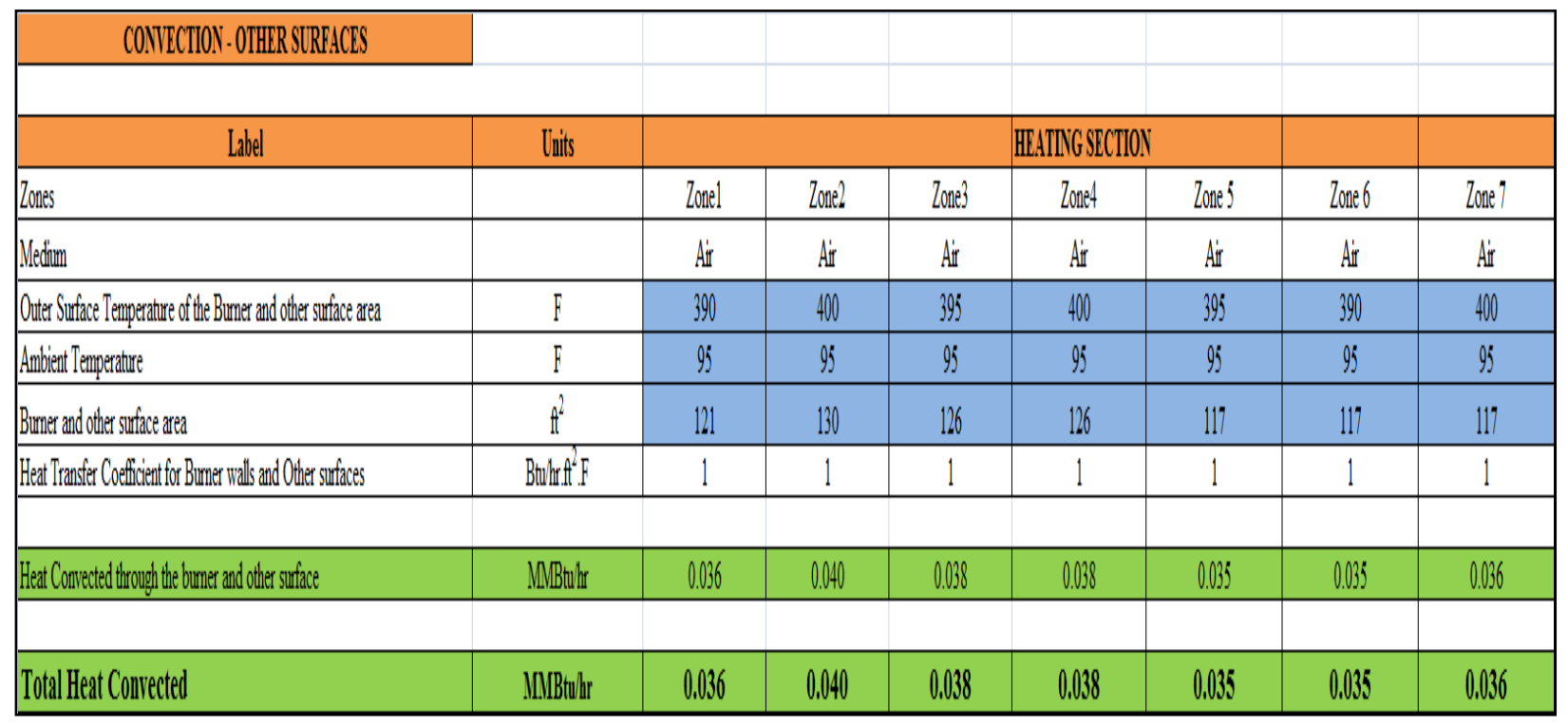

Figure 5.12 Output - Convection Loss

A schematic representation of opening loss is shown in Figure 5.13. The furnace in the host facility had a small opening of about $3 \mathrm{ft} 2$ to accommodate steel strip to enter. Any opening in the furnace is considered as radiation loss. The temperature is taken as the average of the temperature at the opening and the temperature of the steel strip entering. Emissivity is taken as the average of the emissivity of the furnace wall surface and steel trip. Opening loss is comparatively smaller than other losses as there are not much openings in the furnace. Presence of too many openings will result in infiltration of air inside the furnace.

Figure 5.14 displays the water cooling loss considered in the model. The transfer rolls used to move the steel strip inside the furnace absorbs significant amount of heat. The rolls used in the host facility are steel rolls and are integrated with a common water-cooled hydraulic drawbar to ensure straight consistent transfer to downstream head hardening equipment. Water cooling is not needed when ceramic rolls are used as ceramics resist high temperatures. Water flow for the transfer rolls is measured as 40 gallons/min and is divided equally for seven zones for calculation purpose. The water in temperature and water out temperature is also noted to observe the amount of heat being absorbed by the water. 
Outputs: "Heat Losses" Spreadsheet, Module 1 - Losses, Opening Loss

\begin{tabular}{|c|c|c|c|c|c|c|c|c|}
\hline \multicolumn{9}{|c|}{ OPENIIGLOSS } \\
\hline & Areagere Temp topening & 470 & 0 & 0 & 0 & 0 & 0 & 0 \\
\hline & & 930 & 460 & 460 & 460 & 460 & 460 & 460) \\
\hline & Ambiant & 95 & 355 & & & & & \\
\hline Label & Luits & & & & HEATIG SECTI & & & \\
\hline Zones & & Zonel & 20nel2 & Lone3 & Lonet & Zones & Zone6 6 & Zonet 7 \\
\hline 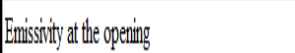 & & 0.8 & & & & & & \\
\hline Temperatre at at e pening & F & 80 & & & & & & \\
\hline Tempentare of the Stip pitring & F & 90 & & & & & & \\
\hline Amblient lemperatrive & $\mathrm{F}$ & 95 & & & & & & \\
\hline Stephen Bothman Constartit & Bthlunt $\mathrm{F}$ & 0.1714 & & & & & & \\
\hline Arearfopemy & $A^{2}$ & 3 & & & & & & \\
\hline & & & & & & & & \\
\hline Heat Lost through Opening & l.INBthlr & $2.69 \mathrm{E}-13$ & $0.00 E+00$ & $0.00 E+00$ & $0.00 E+00$ & $0.00 E+00$ & $0.00 E+00$ & $0.00 E+00$ \\
\hline
\end{tabular}

Figure 5.13 Output - Opening Loss

Outputs: "Heat Losses" Spreadsheet, Module 1 - Losses, Water Cooling Loss

\begin{tabular}{|c|c|c|c|c|c|c|c|c|}
\hline 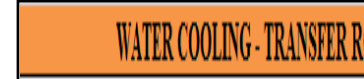 & & & & & & & & \\
\hline Latel & [ulls & Valless & & & & & & \\
\hline Lones & & Lonel & Lomel & Zanes & lonist & Zones & lowero & Lani" \\
\hline Typotidls & Stet & Steted & Steted & feted & fited & Steted & Steted & Sted \\
\hline 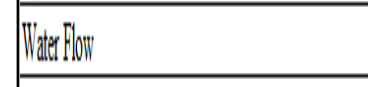 & gallowinim & 311 & $\$ 11$ & 311 & $3 \%$ & 311 & $3 \%$ & $5 \%$ \\
\hline 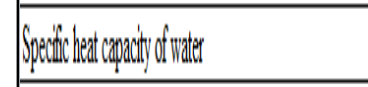 & Bubllif & 0998 & 0988 & 0.98 & 0998 & 1998 & 0998 & 0988 \\
\hline 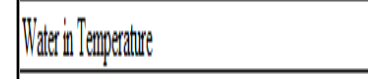 & 1 & 6000 & 60010 & 6000 & 6000 & 600 & 650 & 6:00 \\
\hline That on lempenture & $\mathrm{I}$ & 100.0 & 100.0 & 150.0.0 & 100.0 & 150.0 & 15000 & 15000 \\
\hline Nater Colimg Loss & 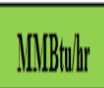 & 0.4 & 0.24 & 0.4 & 0.24 & 0.24 & 0.24 & 0.24 \\
\hline
\end{tabular}

Figure 5.14 Output - Water Cooling Loss 
Input and output - "Heat Balance" Spreadsheet, Module 1 - Zone 1 Heat Balance

\begin{tabular}{|c|c|c|c|c|c|c|c|c|c|c|c|c|c|}
\hline Sensible heat of Reactants & & & & & & & Sensible Heat of Products & & & & & & \\
\hline & & & & & & & & & & & & & \\
\hline Charge & kg-moleshlir & Temperature C & Temperature(K) & $\Delta \mathrm{H}$ (Mcallkg-mole & Mcallhr & MNBtuhr & Charge & kg-moleshr & Temperature C & Temperature( $\mathrm{K})$ & $\Delta \mathrm{H}$ (IIcalkg-mole & Mcalhr & MNBtuhr \\
\hline $\mathrm{Fe}$ & 905 & 148 & 421 & 0.87 & 789.13 & 3.08 & $\mathrm{Fe}$ & 905 & 235 & 508 & 1.45 & 1314.12 & 5.13 \\
\hline $\mathrm{C}$ & 1.26 & 148 & 421 & 0.34 & 0.43 & 0.00 & $\mathrm{C}$ & 1.26 & 235 & 508 & 0.66 & 0.83 & 0.00 \\
\hline & & & & & & & & & & & & & \\
\hline Blast & & & & & & & Stack Gases & & & & & & \\
\hline $\mathrm{CH}_{4}$ & 5.63 & 25 & 298 & 0.00 & 0.00 & 0.00 & $\mathrm{CO}_{2}$ & 5.63 & 450 & 723 & 4.27 & 24.02 & 0.09 \\
\hline $\mathrm{O}_{2}$ & 12.72 & 150 & 423 & 0.81 & 10.24 & 0.04 & $\mathrm{H}_{2} \mathrm{O}$ & 11.26 & 450 & 723 & 3.63 & 40.85 & 0.16 \\
\hline \multirow[t]{2}{*}{$\mathrm{N}_{2}$} & 47.87 & 150 & 423 & 0.88 & 42.00 & 0.16 & $\mathrm{~N}_{2}$ & 47.87 & 450 & 723 & 3.05 & 146.04 & 0.57 \\
\hline & & & & & & & $\mathrm{O}_{2}$ & 1.46 & 450 & 723 & 3.13 & 4.56 & 0.02 \\
\hline & & & & & & & & & & & & & \\
\hline Heat of Formation & & & & & & & Heat of Decomposition & & & & & & \\
\hline $\mathrm{CO}_{2}$ & 5.63 & & & 94.05 & 529.50 & 2.07 & $\mathrm{CH}_{4}$ & 5.63 & & & 17.89 & 100.72 & 0.39 \\
\hline \multirow[t]{9}{*}{$\mathrm{H}_{2} \mathrm{O}$} & 11.26 & & & 60.00 & 675.60 & 2.63 & & & & & & & \\
\hline & & & & & & & Heat losses & & & & & & \\
\hline & & & & & & & Conduction Loss & & & & & 308.64 & 1.20 \\
\hline & & & & & & & Radiation Loss & & & & & 18.23 & 0.07 \\
\hline & & & & & & & Convection Loss & & & & & 9.18 & 0.04 \\
\hline & & & & & & & Opening Loss & & & & & 0.0073 & 0.00 \\
\hline & & & & & & & Water Cooling Loss & & & & & 62.33 & 0.24 \\
\hline & & & & & & & Unaccounted Loss & & & & & 17.37 & 0.07 \\
\hline & & & & & & & & & & & & & \\
\hline Total Heat Input & & & & & $2,046.91$ & 7.98 & Total Heat Output & & & & & $2,046.91$ & 7.98 \\
\hline
\end{tabular}

Figure 5.15 Heat Balance - Zone 1

The heat balance for zone 1 is shown in Figure 5.15. The steel sheet enters the zone at $300^{\circ} \mathrm{F}\left(148^{\circ} \mathrm{C}\right)$ and leaves at $455^{\circ} \mathrm{F}\left(235^{\circ} \mathrm{C}\right)$. The heat absorbed by the steel strip in zone 1 is $2.05 \mathrm{MMBtu} / \mathrm{hr}$. The heat carried away by the combustion products or stack loss is 0.84 $\mathrm{MMBtu} / \mathrm{hr}$ and rest of the losses accounts for 1.62 MMBtu/hr. 
Input and output - "Heat Balance" Spreadsheet, Module 2 - Zone 2 Heat Balance

\begin{tabular}{|c|c|c|c|c|c|c|c|c|c|c|c|c|c|}
\hline Sensible heat of Reactants & & & & & & & Sensible Heat of Products & & & & & & \\
\hline & & & & $\mathrm{aT}+\mathrm{bT}^{2}+\mathrm{CT}^{-1}+\mathrm{d}$ & & & & & & & $\mathrm{aT}+\mathrm{bT}^{2}+\mathrm{CT}^{-1}+\mathrm{d}$ & & \\
\hline Charge & kg-moles/hr & Temperature & CTemperature(K) & $\Delta \mathrm{H}$ (Mcalkg-mole & Mcallhr & MMBtu/hr & Charge & $\mathrm{kg}$-moles/h & urTemperature $\subseteq$ & बTemperature(K) & (5) $\mathrm{H}$ (Mcalkg-mol & Mcal/hr & MMBtulhr \\
\hline $\mathrm{Fe}$ & 905 & 235 & 508 & 1.45 & 1314.12 & 5.13 & $\mathrm{Fe}$ & 905 & 350 & 623 & 2.30 & 2082.71 & 8.12 \\
\hline $\mathrm{C}$ & 1.26 & 235 & 508 & 0.66 & 0.83 & 0.00 & $\mathrm{C}$ & 1.26 & 350 & 623 & 1.12 & 1.41 & 0.01 \\
\hline & & & & & & & & & & & & & \\
\hline Blast & & & & & & & Stack Gases & & & & & & \\
\hline $\mathrm{CH}_{4}$ & 7.00 & 25 & 298 & 0.00 & 0.00 & 0.00 & $\mathrm{CO}_{2}$ & 7.00 & 460 & 733 & 4.39 & 30.71 & 0.12 \\
\hline $\mathrm{O}_{2}$ & 15.29 & 150 & 423 & 0.81 & 12.31 & 0.05 & $\mathrm{H}_{2} \mathrm{O}$ & 14 & 460 & 733 & 3.72 & 52.06 & 0.20 \\
\hline $\mathrm{N}_{2}$ & 57.51 & 150 & 423 & 0.88 & 50.47 & 0.20 & $\mathrm{~N}_{2}$ & 57.51 & 460 & 733 & 3.12 & 179.71 & 0.70 \\
\hline & & & & & & & $\mathrm{O}_{2}$ & 1.29 & 460 & 733 & 3.20 & 4.13 & 0.02 \\
\hline & & & & & & & & & & & & & \\
\hline Heat of Formation & & & & & & & Heat of Decomposition & & & & & & \\
\hline $\mathrm{CO}_{2}$ & 7 & & & 94.05 & 658.35 & 2.57 & $\mathrm{CH}_{4}$ & 5.63 & & & 17.89 & 100.72 & 0.39 \\
\hline $\mathrm{H}_{2} \mathrm{O}$ & 14 & & & 60.00 & 840.00 & 3.28 & & & & & & & \\
\hline & & & & & & & Heat losses & & & & & & \\
\hline & & & & & & & Conduction Loss & & & & & 307.85 & 1.20 \\
\hline & & & & & & & Radiation Loss & & & & & 20.61 & 0.08 \\
\hline & & & & & & & Convection Loss & & & & & 10.14 & 0.04 \\
\hline & & & & & & & Opening Loss & & & & & 0 & 0.00 \\
\hline & & & & & & & Water Cooling Loss & & & & & 62.33 & 0.24 \\
\hline & & & & & & & Unaccounted Loss & & & & & 23.69 & 0.09 \\
\hline & & & & & & & & & & & & & \\
\hline Total Heat Input & & & & & $2,876.08$ & 11.22 & Total Heat Output & & & & & $2,876.08$ & 11.22 \\
\hline
\end{tabular}

Figure 5.16 Heat Balance - Zone 2

The heat balance for zone 2 is shown in Figure 5.16. The steel sheet enters the zone at $455^{\circ} \mathrm{F}\left(235^{\circ} \mathrm{C}\right)$ and leaves at $662^{\circ} \mathrm{F}\left(350^{\circ} \mathrm{C}\right)$. The heat absorbed by the steel strip in zone 1 is $2.99 \mathrm{MMBtu} / \mathrm{hr}$. The heat carried away by the combustion products or stack loss is 1.04 $\mathrm{MMBtu} / \mathrm{hr}$ and rest of the losses accounts for 1.66 MMBtu/hr. 
Input and output - "Heat Balance" Spreadsheet, Module 3 - Zone 3 Heat Balance

\begin{tabular}{|c|c|c|c|c|c|c|c|c|c|c|c|c|c|}
\hline Sensible heat of Reactants & & & & & & & Sensible Heat of Products & & & & & & \\
\hline & & & & $a T+b T^{2}+C T^{-1}+d$ & & & & & & & $a T+b T^{2}+c T^{-1}+d$ & & \\
\hline Charge & kg-moles/ht & Temperature $\mathrm{C}$ & Temperature( $\mathbf{K})$ & AH (Mcallkg-mole & Mcallhr & MNBtuhr & Charge & kg-molesh & IT Temperature $\mathbb{C}$ & @Temperature(K) & $4 \mathrm{H}(\mathrm{Mcal} / \mathrm{kg}-\mathrm{mol}$ & ol Mcalhr & MNBtuhr \\
\hline $\mathrm{Fe}$ & 905 & 350 & 623 & 2.30 & 2082.71 & 8.12 & $\mathrm{Fe}$ & 905 & 435 & 708 & 2.99 & 2705.42 & 10.55 \\
\hline $\mathrm{C}$ & 1.26 & 350 & 623 & 1.12 & 1.41 & 0.01 & $\mathrm{C}$ & 1.26 & 435 & 708 & 1.48 & 1.87 & 0.01 \\
\hline & & & & & & & & & & & & & \\
\hline Blast & & & & & & & Stack Gases & & & & & & \\
\hline $\mathrm{CH}_{4}$ & 6.25 & 25 & 298 & 0.00 & 0.00 & 0.00 & $\mathrm{CO}_{2}$ & 6.25 & 450 & 723 & 4.27 & 26.66 & 0.10 \\
\hline $\mathrm{O}_{2}$ & 14.09 & 150 & 423 & 0.81 & 11.35 & 0.04 & $\mathrm{H}_{2} \mathrm{O}$ & 12.5 & 450 & 723 & 3.63 & 45.35 & 0.18 \\
\hline $\mathrm{N}_{2}$ & 53.01 & 150 & 423 & 0.88 & 46.52 & 0.18 & $\mathrm{~N}_{2}$ & 53.01 & 450 & 723 & 3.05 & 161.72 & 0.63 \\
\hline & & & & & & & $\mathrm{O}_{2}$ & 1.59 & 450 & 723 & 3.13 & 4.97 & 0.02 \\
\hline Heat of Formation & & & & & & & & & & & & & \\
\hline & & & & & & & Heat of Decomposition & & & & & & \\
\hline $\mathrm{CO}_{2}$ & 6.25 & & & 94.05 & 587.81 & 2.29 & $\mathrm{CH}_{4}$ & 5.63 & & & 17.89 & 100.72 & 0.39 \\
\hline $\mathrm{H}_{2} \mathrm{O}$ & 12.5 & & & 60.00 & 750.00 & 2.93 & & & & & & & \\
\hline & & & & & & & Heat losses & & & & & & \\
\hline & & & & & & & Conduction Loss & & & & & 304.95 & 1.19 \\
\hline & & & & & & & Radiation Loss & & & & & 19.40 & 0.08 \\
\hline & & & & & & & Convection Loss & & & & & 9.65 & 0.04 \\
\hline & & & & & & & Opening Loss & & & & & 0 & 0.00 \\
\hline & & & & & & & Water Cooling Loss & & & & & 62.33 & 0.24 \\
\hline & & & & & & & Unaccounted Loss & & & & & 36.75 & 0.14 \\
\hline & & & & & & & & & & & & & \\
\hline Total Heat Input & & & & & $3,479.80$ & 13.57 & Total Heat Output & & & & & $3,479.80$ & 13.57 \\
\hline
\end{tabular}

Figure 5.17 Heat Balance - Zone 3

The heat balance for zone 3 is shown in Figure 5.17. The steel sheet enters the zone at $662^{\circ} \mathrm{F}\left(350^{\circ} \mathrm{C}\right)$ and leaves at $815^{\circ} \mathrm{F}\left(435^{\circ} \mathrm{C}\right)$. The heat absorbed by the steel strip in zone 1 is $2.43 \mathrm{MMBtu} / \mathrm{hr}$. The heat carried away by the combustion products or stack loss is 0.93 $\mathrm{MMBtu} / \mathrm{hr}$ and rest of the losses accounts for 1.69 MMBtu/hr. 
Input and output - "Heat Balance" Spreadsheet, Module 4 - Zone 4 Heat Balance

\begin{tabular}{|c|c|c|c|c|c|c|c|c|c|c|c|c|c|}
\hline Sensible heat of Reactants & & & & & & & Sensible Heat of Products & & & & & & \\
\hline & & & & $\mathrm{aT}+\mathrm{b} \mathrm{T}^{2}+\mathrm{CT}^{-1}+\mathrm{d}$ & & & & & & & $a T+b T^{2}+C T^{-1}+d$ & & \\
\hline Charge & kg-moleshr & Temperature $\mathrm{C}$ & Temperature(K) & $\Delta \mathrm{H}$ (Mcalkg-mole & Mcalhr & MINBtuhr & Charge & kg-molesh & mperature \&: & Temperature(K). & $\mid \mathrm{H}$ (Mcallkg-mo & Mcallhr . & MiNBtuhr \\
\hline $\mathrm{Fe}$ & 905 & 435 & \begin{tabular}{|l|}
708 \\
\end{tabular} & 2.99 & 2705.42 & 10.55 & $\mathrm{Fe}$ & 905 & 515 & 788 & 3.68 & 33339.90 & 13.00 \\
\hline C & 1.26 & 435 & 708 & 1.48 & 1.87 & 0.01 & C & 1.26 & 515 & 788 & 1.84 & 2.33 & 0.01 \\
\hline & & & & & & & & & & & & & \\
\hline Blast & & & & & & & Stack Gases & & & & & & \\
\hline $\mathrm{CH}_{4}$ & 6.38 & 25 & 298 & 0.00 & 0.00 & 0.00 & $\mathrm{CO}_{2}$ & 6.38 & 470 & 743 & 4.51 & 28.77 & 0.11 \\
\hline $\mathrm{O}_{2}$ & 14.23 & 150 & 423 & 0.81 & 11.45 & 0.04 & $\mathrm{H}_{2} \mathrm{O}$ & 12.76 & 470 & 743 & 3.81 & 48.60 & 0.19 \\
\hline $\mathrm{N}_{2}$ & 53.51 & 150 & 423 & 0.88 & 46.95 & 0.18 & $\mathrm{~N}_{2}$ & 53.51 & 470 & 743 & 3.20 & 171.17 & 0.67 \\
\hline & & & & & & & $\mathrm{O}_{2}$ & 1.47 & 470 & 743 & 3.28 & 4.83 & 0.02 \\
\hline Heat of Formation & & & & & & & & & & & & & \\
\hline & & & & & & & Heat of Decomposition & & & & & & \\
\hline $\mathrm{CO}_{2}$ & 6.38 & & & 94.05 & 600.04 & 2.34 & $\mathrm{CH}_{4}$ & 5.63 & & & 17.89 & 100.72 & 0.39 \\
\hline $\mathrm{H}_{2} \mathrm{O}$ & 12.76 & & & 60.00 & 765.60 & 2.99 & & & & & & & \\
\hline & & & & & & & Heat losses & & & & & & \\
\hline & & & & & & & Conduction Loss & & & & & 309.72 & 1.21 \\
\hline & & & & & & & Radiation Loss & & & & & 19.95 & 0.08 \\
\hline & & & & & & & Convection Loss & & & & & 9.81 & 0.04 \\
\hline & & & & & & & Opening Loss & & & & & 0 & 0.00 \\
\hline & & & & & & & Water Cooling Loss & & & & & 62.33 & 0.24 \\
\hline & & & & & & & Unaccounted Loss & & & & & 39.21 & 0.15 \\
\hline & & & & & & & & & & & & & \\
\hline Total Heat Input & & & & & $4,131.34$ & 16.11 & Total Heat Output & & & & & $4,131.34$ & 16.11 \\
\hline
\end{tabular}

Figure 5.18 Heat Balance - Zone 4

The heat balance for zone 4 is shown in Figure 5.18. The steel sheet enters the zone at $815^{\circ} \mathrm{F}\left(435^{\circ} \mathrm{C}\right)$ and leaves at $959^{\circ} \mathrm{F}\left(515^{\circ} \mathrm{C}\right)$. The heat absorbed by the steel strip in zone 1 is $2.45 \mathrm{MMBtu} / \mathrm{hr}$. The heat carried away by the combustion products or stack loss is 0.99 $\mathrm{MMBtu} / \mathrm{hr}$ and rest of the losses accounts for $1.72 \mathrm{MMBtu} / \mathrm{hr}$. 
Input and output - "Heat Balance" Spreadsheet, Module 5 - Zone 5 Heat Balance

\begin{tabular}{|c|c|c|c|c|c|c|c|c|c|c|c|c|c|}
\hline Sensible heat of Reactants & & & & & & & Sensible Heat of Products & & & & & & \\
\hline & & & & $a T^{2}+b T^{2}+C T^{-1}+d$ & & & & & & & $\mathrm{a} T+\mathrm{b}^{2}+\mathrm{C} \mathrm{CT}^{-1}+\mathrm{d}$ & & \\
\hline Charge & kg-molesh & Temperature $\mathrm{C}$ & Temperature(K) & $\mathrm{H}$ (Mcallkg-mo & Mcallhr & MMBtuhr & Charge & kg-molesh & Temperature $\mathbb{C}$. & Temperature( $\mathrm{K})$ & ) $\mathrm{H}$ (Mcal kg-mo & ol Mcallhr & MNBBtuhr \\
\hline $\mathrm{Fe}$ & 905 & 515 & 788 & 3.68 & 3333.90 & 13.00 & $\mathrm{Fe}$ & 905 & 595 & 868 & 4.42 & 4003.50 & 15.61 \\
\hline $\mathrm{C}$ & 1.26 & 515 & 788 & 1.84 & 2.33 & 0.01 & C & 1.26 & 595 & 868 & 2.21 & 2.79 & 0.01 \\
\hline & & & & & & & & & & & & & \\
\hline Blast & & & & & & & Stack Gases & & & & & & \\
\hline $\mathrm{CH}_{4}$ & 6.50 & 25 & 298 & 0.00 & 0.00 & 0.00 & $\mathrm{CO}_{2}$ & 6.50 & 470 & 743 & 4.51 & 29.31 & 0.11 \\
\hline $\mathrm{O}_{2}$ & 14.36 & 150 & 423 & 0.81 & 11.56 & 0.05 & $\mathrm{H}_{2} \mathrm{O}$ & 13 & 470 & 743 & 3.81 & 49.52 & 0.19 \\
\hline $\mathrm{N}_{2}$ & 54.01 & 150 & 423 & 0.88 & 47.39 & 0.18 & $\mathrm{~N}_{2}$ & 54.01 & 470 & 743 & 3.20 & 172.77 & 0.67 \\
\hline & & & & & & & $\mathrm{O}_{2}$ & 1.36 & 470 & 743 & 3.28 & 4.46 & 0.02 \\
\hline Heat of Formation & & & & & & & & & & & & & \\
\hline & & & & & & & Heat of Decomposition & & & & & & \\
\hline $\mathrm{CO}_{2}$ & 6.5 & & & 94.05 & 611.33 & 2.38 & $\mathrm{CH}_{4}$ & 5.63 & & & 17.89 & 100.72 & 0.39 \\
\hline $\mathrm{H}_{2} \mathrm{O}$ & 13 & & & 60.00 & 780.00 & 3.04 & & & & & & & \\
\hline & & & & & & & \begin{tabular}{|c|} 
Heat losses \\
\end{tabular} & & & & & & \\
\hline & & & & & & & Conduction Loss & & & & & 309.92 & 1.21 \\
\hline & & & & & & & Radiation Loss & & & & & 18.11 & 0.07 \\
\hline & & & & & & & Convection Loss & & & & & 9.02 & 0.04 \\
\hline & & & & & & & Opening Loss & & & & & 0 & 0.00 \\
\hline & & & & & & & Water Cooling Loss & & & & & 62.33 & 0.24 \\
\hline & & & & & & & Unaccounted Loss & & & & & 24.04 & 0.09 \\
\hline & & & & & & & & & & & & & \\
\hline Total Heat Input & & & & & $4,786.50$ & 18.67 & Total Heat Output & & & & & $4,786.50$ & 18.67 \\
\hline
\end{tabular}

\section{Figure 5.19 Heat Balance - Zone 5}

The heat balance for zone 5 is shown in Figure 5.19. The steel sheet enters the zone at $959^{\circ} \mathrm{F}\left(515^{\circ} \mathrm{C}\right)$ and leaves at $1103^{\circ} \mathrm{F}\left(595^{\circ} \mathrm{C}\right)$. The heat absorbed by the steel strip in zone 1 is $2.61 \mathrm{MMBtu} / \mathrm{hr}$. The heat carried away by the combustion products or stack loss is 1 $\mathrm{MMBtu} / \mathrm{hr}$ and rest of the losses accounts for $1.65 \mathrm{MMBtu} / \mathrm{hr}$. 
Input and output - "Heat Balance" Spreadsheet, Module 6 - Zone 6 Heat Balance

\begin{tabular}{|c|c|c|c|c|c|c|c|c|c|c|c|c|c|}
\hline Sensible heat of Reactants & & & & & & & Sensible Heat of Products & & & & & & \\
\hline & & & & $a T+b T^{2}+C T^{-1}+d$ & & & & & & & $\mathrm{aT}+\mathrm{b} \mathrm{T}^{2}+\mathrm{CT} \mathrm{T}^{-1}+\mathrm{d}$ & & \\
\hline Charge & kg-moles/hr & Temperature $\mathrm{C}$ & Temperature(K) & $\Delta \mathrm{H}(\mathrm{Mcalkg}-\mathrm{mol}$ & Mcallhr 1 & MinBtuhr & Charge & kg-moles/hr & InTemperature c & Temperature(K) & $4 \mathrm{H}(\mathrm{Mcal} / \mathrm{kg}-\mathrm{mol}$ & Mcalhr & MIMBtuhr \\
\hline $\mathrm{Fe}$ & 905 & 595 & 868 & 4.42 & 4003.50 & 15.61 & $\mathrm{Fe}$ & 905 & 665 & 938 & 5.11 & 4623.14 & 18.03 \\
\hline $\mathrm{C}$ & 1.26 & 595 & 868 & 2.21 & 2.79 & 0.01 & $\mathrm{C}$ & 1.26 & 665 & 938 & 2.55 & 3.22 & 0.01 \\
\hline Blast & & & & & & & Stack Gases & & & & & & \\
\hline $\mathrm{CH}_{4}$ & 6.25 & 25 & 298 & 0.00 & 0.00 & 0.00 & $\mathrm{CO}_{2}$ & 6.25 & 455 & 728 & 4.33 & 27.04 & 0.11 \\
\hline $\mathrm{O}_{2}$ & 14.09 & 150 & 423 & 0.81 & 11.35 & 0.04 & $\mathrm{H}_{2} \mathrm{O}$ & 12.5 & 455 & 728 & 3.67 & 45.91 & 0.18 \\
\hline \multirow[t]{2}{*}{$\mathrm{N}_{2}$} & 53.01 & 150 & 423 & 0.88 & 46.52 & 0.18 & $\mathrm{~N}_{2}$ & 53.01 & 455 & 728 & 3.09 & 163.68 & 0.64 \\
\hline & & & & & & & $\mathrm{O}_{2}$ & 1.59 & 455 & 728 & 3.16 & 5.03 & 0.02 \\
\hline \multicolumn{14}{|l|}{ Heat of Formation } \\
\hline & & & & & & & Heat of Decomposition & & & & & & \\
\hline $\mathrm{CO}_{2}$ & 6.25 & & & 94.05 & 587.81 & 2.29 & $\mathrm{CH}_{4}$ & 5.63 & & & 17.89 & 100.72 & 0.39 \\
\hline \multirow[t]{9}{*}{$\mathrm{H}_{2} \mathrm{O}$} & 12.5 & & & 60.00 & 750.00 & 2.93 & & & & & & & \\
\hline & & & & & & & \begin{tabular}{|c|} 
Heat losses \\
\end{tabular} & & & & & & \\
\hline & & & & & & & Conduction Loss & & & & & 305.80 & 1.19 \\
\hline & & & & & & & \begin{tabular}{|l|} 
Radiation Loss \\
\end{tabular} & & & & & 17.60 & 0.07 \\
\hline & & & & & & & Convection Loss & & & & & 8.87 & 0.03 \\
\hline & & & & & & & Opening Loss & & & & & 0 & 0.00 \\
\hline & & & & & & & Water Cooling Loss & & & & & 62.33 & 0.24 \\
\hline & & & & & & & Unaccounted Loss & & & & & 38.62 & 0.15 \\
\hline & & & & & & & & & & & & & \\
\hline Total Heat Input & & & & & $5,401.97$ & 21.07 & Total Heat Output & & & & & $5,401.97$ & 21.07 \\
\hline
\end{tabular}

Figure 5.20 Heat Balance - Zone 6

The heat balance for zone 6 is shown in Figure 5.20. The steel sheet enters the zone at $1103^{\circ} \mathrm{F}\left(595^{\circ} \mathrm{C}\right)$ and leaves at $1229^{\circ} \mathrm{F}\left(665^{\circ} \mathrm{C}\right)$. The heat absorbed by the steel strip in zone 1 is $2.42 \mathrm{MMBtu} / \mathrm{hr}$. The heat carried away by the combustion products or stack loss is $0.94 \mathrm{MMBtu} / \mathrm{hr}$ and rest of the losses accounts for 1.69 MMBtu/hr. 
Input and output - "Heat Balance" Spreadsheet, Module 7 - Zone 7 Heat Balance

\begin{tabular}{|c|c|c|c|c|c|c|c|c|c|c|c|c|c|}
\hline Sensible heat of Reactants & & & & & & & Sensible Heat of Products & & & & & & \\
\hline & & & & $a T+b T^{2}+C T^{-1}+d$ & & & & & & & $a T+b T^{2}+C T^{-1}+d$ & & \\
\hline Charge & kg-molesh & Temperature $\mathrm{C}$ & Temperature( $(\mathrm{K})$ & HH (Mcallkg-mol & Mcallhr & INMBtuhr & Charge & kg-molesh & emperature $S$ & (Temperature $(\mathrm{K})$ & $\mid \mathrm{H}$ (Mcallkg-mol & ol Mcallhr & IINBtuhr \\
\hline $\mathrm{Fe}$ & 905 & 665 & 938 & 5.11 & 4623.14 & 18.03 & $\mathrm{Fe}$ & 905 & 737 & 1010 & 5.85 & 5293.33 & 20.64 \\
\hline C & 1.26 & 665 & 938 & 2.55 & 3.22 & 0.01 & C & 1.26 & 737 & 1010 & 2.90 & 3.66 & 0.01 \\
\hline & & & & & & & & & & & & & \\
\hline Blast & & & & & & & Stack Gases & & & & & & \\
\hline $\mathrm{CH}_{4}$ & 6.50 & 25 & 298 & 0.00 & 0.00 & 0.00 & $\mathrm{CO}_{2}$ & 6.50 & 460 & 733 & 4.39 & 28.52 & 0.11 \\
\hline $\mathrm{O}_{2}$ & 14.23 & 150 & 423 & 0.81 & 11.45 & 0.04 & $\mathrm{H}_{2} \mathrm{O}$ & 13 & 460 & 733 & 3.72 & 48.34 & 0.19 \\
\hline $\mathrm{N}_{2}$ & 53.51 & 150 & 423 & 0.88 & 46.95 & 0.18 & $\mathrm{~N}_{2}$ & 53.51 & 460 & 733 & 3.12 & 167.21 & 0.65 \\
\hline & & & & & & & $\mathrm{O}_{2}$ & 1.23 & 460 & 733 & 3.20 & 3.94 & 0.02 \\
\hline Heat of Formation & & & & & & & & & & & & & \\
\hline & & & & & & & Heat of Decomposition & & & & & & \\
\hline $\mathrm{CO}_{2}$ & 6.5 & & & 94.05 & 611.33 & 2.38 & $\mathrm{CH}_{4}$ & 5.63 & & & 17.89 & 100.72 & 0.39 \\
\hline $\mathrm{H}_{2} \mathrm{O}$ & 13 & & & 60.00 & 780.00 & 3.04 & & & & & & & \\
\hline & & & & & & & \begin{tabular}{|l} 
Heat losses \\
\end{tabular} & & & & & & \\
\hline & & & & & & & \begin{tabular}{|l} 
Conduction Loss \\
\end{tabular} & & & & & 310.35 & 1.21 \\
\hline & & & & & & & Radiation Loss & & & & & 18.63 & 0.07 \\
\hline & & & & & & & Convection Loss & & & & & 9.16 & 0.04 \\
\hline & & & & & & & Opening Loss & & & & & 0 & 0.00 \\
\hline & & & & & & & Water Cooling Loss & & & & & 62.33 & 0.24 \\
\hline & & & & & & & Unaccounted Loss & & & & & 29.91 & 0.12 \\
\hline & & & & & & & & & & & & & \\
\hline Total Heat Input & & & & & $6,076.09$ & 23.70 & Total Heat Output & & & & & $6,076.09$ & 23.70 \\
\hline
\end{tabular}

Figure 5.21 Heat Balance - Zone 7

The heat balance for zone 7 is shown in Figure 5.21. The steel sheet enters the zone at $1229^{\circ} \mathrm{F}\left(665^{\circ} \mathrm{C}\right)$ and leaves at $1360^{\circ} \mathrm{F}\left(737^{\circ} \mathrm{C}\right)$. The heat absorbed by the steel strip in zone 1 is $2.61 \mathrm{MMBtu} / \mathrm{hr}$. The heat carried away by the combustion products or stack loss is $0.97 \mathrm{MMBtu} / \mathrm{hr}$ and rest of the losses accounts for $1.68 \mathrm{MMBtu} / \mathrm{hr}$. 
Summary - "Heat Losses", Module 1 - Summary for total heat losses

\begin{tabular}{|c|c|c|c|c|c|c|c|c|c|c|}
\hline RESULTS & & & & & & & & & & \\
\hline \multicolumn{11}{|l|}{ TOTAL CALCULATED HEAT } \\
\hline & & & & & & & & & & \\
\hline & & \multicolumn{5}{|c|}{ HEATING SECTION } & & & & \\
\hline Heat & Units & Zonel & Zone? & Zone3 & Zonet & Zone 5 & Zone 6 & Zone 7 & Total-Losses & Loss \% \\
\hline Type of Heating & & Gas & Gas & Gas & Gas & Gas & Gas & Gas & & \\
\hline Conduction through the walls & MMBtuhr & 1.20 & 1.20 & 1.19 & 1.21 & 1.21 & 1.19 & 1.21 & 8.41 & $23.38 \%$ \\
\hline Radiation from suffaces & MMBtuhr & 0.07 & 0.08 & 0.08 & 0.08 & 0.07 & 0.07 & 0.07 & 0.52 & $1.44 \%$ \\
\hline Convection from suffaces & MVBuhhr & 0.04 & 0.04 & 0.04 & 0.04 & 0.04 & 0.03 & 0.04 & 0.26 & $0.71 \%$ \\
\hline Opering & MMBtuhr & 0.0027 & 0.00 & 0.00 & 0.00 & 0.00 & 0.00 & 0.00 & 0.00 & $0.01 \%$ \\
\hline Water Cooling & MMBtuhr & 0.24 & 0.24 & 0.24 & 0.24 & 0.24 & 0.24 & 0.24 & 1.70 & $4.73 \%$ \\
\hline Phase Change Heat & MVBtuhr & 0.00 & 0.00 & 0.00 & 0.00 & 0.00 & 0.00 & 0.00 & 0.00 & $0.00 \%$ \\
\hline Steel strip usefil heat & MMBtuhr & 2.05 & 3.00 & 2.43 & 2.45 & 2.61 & 2.42 & 2.61 & 17.57 & $48.82 \%$ \\
\hline Stack Loss & MMBuhrir & 0.84 & 1.04 & 0.93 & 0.99 & 1.00 & 0.94 & 0.97 & 6.71 & $18.64 \%$ \\
\hline Unaccounted Losses & MMBtuhr & 0.07 & 0.09 & 0.14 & 0.15 & 0.09 & 0.15 & 0.12 & 0.82 & $2.27 \%$ \\
\hline Total Heat Dissipation Calculated & MINBtuhr & 4.51 & 5.69 & 5.05 & 5.16 & 5.26 & 5.05 & 5.26 & 35.98 & $100.00 \%$ \\
\hline Rated Capacity of the burners & MNBtulhr & 6.94 & 7.80 & 7.37 & 6.63 & 5.85 & 5.85 & 6.89 & & \\
\hline & & & & & & & & & & \\
\hline Load Factor of Burners & & 0.65 & 0.73 & 0.69 & 0.78 & 0.90 & 0.86 & 0.76 & & \\
\hline
\end{tabular}

\section{Figure 5.22 Summary of Total Heat Loss}

The losses are summarized in the results section as shown in Figure 5.22. The losses are identified zone by zone and the consolidated loss accounts for $100 \%$. The total loss in each zone has been identified and the load factor of the zones is estimated by dividing the total zone loss by the rated capacity of the burner with efficiency of the burner included. 


\subsection{Conclusion}

\section{Pie chart - Loss Percentage}

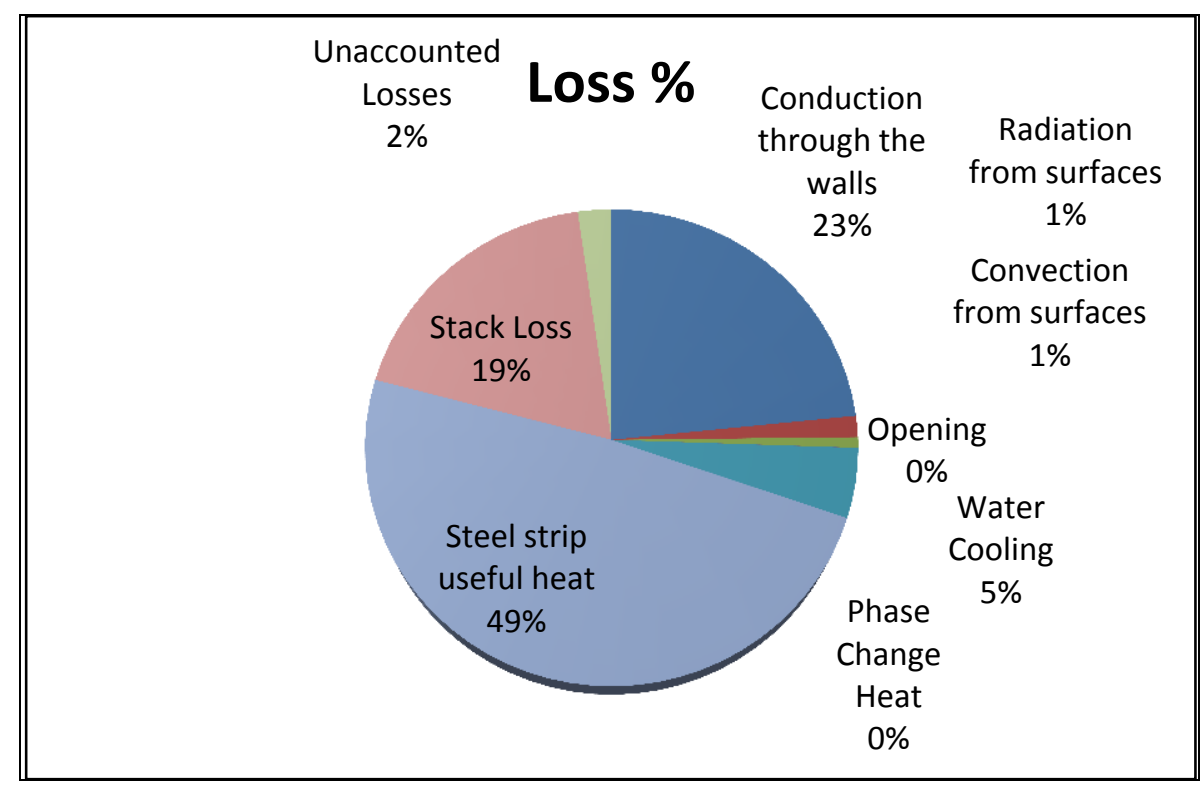

Figure 5.23 Losses in Percentage

Three Galvanizing facilities were visited for research and analysis purposes. Data collected from facility 2 was used to determine the energy baseline and useful heat determination in the industry. The model consolidates the percentage of heat transferred in a furnace in a pie chart. As seen in Figure 5.23, the heat carried away by the steel strip results for $49 \%$, i.e. the useful heat that is transferred to the steel strip is $49 \%$ of the total heat supplied to the furnace. The remaining $51 \%$ accounts for losses. Therefore the furnace is only $50 \%$ efficient. Conduction loss accounts for $23 \%$ of the total heat supplied to the furnace due to high temperatures maintained inside the furnace. The factors that influence these losses are insulation materials and their thickness. The stack loss is significant as it accounts for $19 \%$ of the total heat supplied to the furnace. The factors that influence stack loss is due to excess air that is combusted along with the fuel. This excess air and the products of combustion carries significant amount of heat through the stack. Water cooling losses results for $5 \%$ of the total heat supplied and these losses are significant due to the cooling water picking up heat when passing through the hot rolls inside the furnace. Radiation loss is influenced by the emissivity of the radiating surface and convection loss by the heat transfer coefficient. These losses are minor due to the area of the heat emitting surfaces and 
their temperatures. Phase change loss occurs only when the steel strip is heated to high temperatures and when there is a drastic change in its phase.

The nonessential energy consumption was determined by the model. Important factors influencing the nonessential energy consumption were discussed, and factors contributing to the establishment of energy baseline were analyzed. Thus, the concept of energy efficiency measures will play an important role in utilizing the heat wisely.

\subsection{Facility B}

The model was also populated with data collected from other host facility B. This facility uses metric unit values. Therefore, the data was populated using the metric unit spreadsheet. The heat balance results were obtained from the model and screenshots are provided in the section below.

The Product and Process Parameters (Metric Units)

Product: Carbon Steel

Strip width: $1.225 \mathrm{~m}$

Strip gauge: $0.0048 \mathrm{~m}$

Line speed: $125 \mathrm{~m} / \mathrm{min}$

\begin{tabular}{|c|c|c|c|c|c|}
\hline INPUT ZONE DETAILS & Units & Details & & & \\
\hline Name of the Furnace & Annealing & & & & \\
\hline Number of Zones & 4 & & & & \\
\hline Zones & & Zonel & Zone2 & Zone3 & Zone4 \\
\hline Type of Heating & & Gas & Gas & Gas & Electric \\
\hline Fuel Used & & LPG & LPG & LPG & Electricity \\
\hline No. of Burners/Grid & no units & 8 & 8 & 8 & 36 \\
\hline Rated Capacity of the Heating Element & $\mathrm{GJ} / \mathrm{hr} / \mathrm{kW}$ & 1.41 & 1.64 & 2.11 & 220 \\
\hline Efficiency of Heating Element & & 0.8 & 0.8 & 0.8 & 0.95 \\
\hline Utilization factor of the system & & 1 & 1 & 1 & 1 \\
\hline Zone Atmosphere & & Air:LPG & Air $:$ LPG & Air,LPG & \\
\hline Zone Temperature & $\mathrm{C}$ & 1215 & 1246 & 1295 & 868 \\
\hline Ambient Temperature & $\mathrm{C}$ & 35 & 35 & 35 & 35 \\
\hline Length of the Zone & $\mathrm{m}$ & 5.625 & 5.625 & 5.625 & 25.18 \\
\hline Width of the Zone & $\mathrm{m}$ & 2.16 & 2.16 & 2.16 & 2.16 \\
\hline Height of the Zone & $\mathrm{m}$ & 1.55 & 1.55 & 1.55 & 1.55 \\
\hline Area of the Zone & $\mathrm{m}^{2}$ & 48.43 & 48.43 & 48.43 & 193.53 \\
\hline
\end{tabular}

Figure 5.24 Product and Process Parameters

Figure 5.24 shows the product and process parameters which include the furnace dimensions, temperatures, burner ratings etc. 


\begin{tabular}{|c|c|c|c|c|c|}
\hline OUTPUTS - LOSSES & & & & & \\
\hline \multicolumn{6}{|l|}{ RADIATION } \\
\hline \multirow[t]{2}{*}{ Farenheit To Rankine } & Farenheit & Rankine & & & \\
\hline & & Zone 1 & Zone 2 & Zone 3 & Zone 4 \\
\hline Ambient & 35 & 308.15 & & & \\
\hline Top - Furnace & 160 & 433.15 & 438.15 & 453.15 & 418.15 \\
\hline Bottom - Furnace & 120 & 393.15 & 393.15 & 408.15 & 418.15 \\
\hline Sides - Furnace & 230 & 503.15 & 503.15 & 543.15 & 473.15 \\
\hline Burner & 280 & 553.15 & 558.15 & 563.15 & 416.15 \\
\hline \multicolumn{6}{|l|}{ Gas Heating } \\
\hline \multirow[t]{2}{*}{ Inputs } & Units & \multicolumn{3}{|c|}{ HEATING SECTION } & \\
\hline & & \begin{tabular}{|l|} 
Zone 1 \\
\end{tabular} & Zone 2 & Zone 3 & Zone 4 \\
\hline Furnace Material & & Steel & Steel & Steel & Steel \\
\hline Emissivity of the Wall Material & & 0.8 & 0.8 & 0.8 & 0.8 \\
\hline Emissivity of the other surfaces & & 0.8 & 0.8 & 0.8 & 0.8 \\
\hline Top Surface Temperature of Furnace Walls & $\mathrm{C}$ & 160 & 165 & 180 & 145 \\
\hline Bottom Surface Temperature of Furnace Walls & $\mathrm{C}$ & 120 & 120 & 135 & 145 \\
\hline Sides Surface Temperature of the Furnace Walls & $\mathrm{C}$ & 230 & 230 & 270 & 200 \\
\hline Outer Surface Temperature of the other surfaces & $\mathrm{C}$ & 280 & 285 & 290 & 143 \\
\hline Ambient Temperature & $\mathrm{C}$ & 35 & 35 & 35 & 35 \\
\hline Stephen Boltzmann Constant & $\mathrm{W} / \mathrm{m} 2{ }^{\circ} \mathrm{K} 4 * \mathrm{E}-8$ & 5.67 & 5.67 & 5.67 & 5.67 \\
\hline Top Surface Area of the Furnace Walls & $\mathrm{m}^{2}$ & 12.15 & 12.15 & 12.15 & 54.3888 \\
\hline Bottom Surface Area of the Furnace Walls & $\mathrm{m}^{2}$ & 12.15 & 12.15 & 12.15 & 54.3888 \\
\hline Side Surface Area of the Furnace Walls & $\mathrm{m}^{2}$ & 30.996 & 30.996 & 30.996 & 115.4736 \\
\hline Burner and other surface area & $\mathrm{m}^{2}$ & 38 & 38 & 38 & 12 \\
\hline Heat Radiated from the Top & $\mathrm{GJ} / \mathrm{hr} / \mathrm{kW}$ & 0.052 & 0.055 & 0.066 & 53.179 \\
\hline Heat Radiated from the Bottom & $\mathrm{GJ} / \mathrm{hr} / \mathrm{kW}$ & 0.030 & 0.030 & 0.037 & 53.179 \\
\hline Heat Radiated from the Sides & $\mathrm{GJ} / \mathrm{hr} / \mathrm{kW}$ & 0.279 & 0.279 & 0.395 & 215.285 \\
\hline Heat Radiated through the other surfaces & $\mathrm{GJ} / \mathrm{hr} / \mathrm{kW}$ & 0.525 & 0.546 & 0.568 & 11.417 \\
\hline Total Heat Radiated & $\mathrm{GJ} / \mathrm{hr} / \mathbf{k W}$ & 0.885 & 0.910 & 1.066 & 333.060 \\
\hline & & & & & \\
\hline \multicolumn{6}{|l|}{ CONVECTION } \\
\hline \multirow[t]{2}{*}{ Inputs } & Units & \multicolumn{3}{|c|}{ HEATING SECTION } & \\
\hline & & Zone 1 & Zone 2 & Zone 3 & Zone 4 \\
\hline Gaseous content of the Furnace & & $\mathrm{H} 2, \mathrm{~N} 2, \mathrm{O} 2$ & $\mathrm{H} 2, \mathrm{~N} 2, \mathrm{O} 2$ & $\mathrm{H} 2, \mathrm{~N} 2, \mathrm{O} 2$ & $\mathrm{H} 2, \mathrm{~N} 2, \mathrm{O} 2$ \\
\hline Top Surface Temperature of Furnace Walls & $\mathrm{C}$ & 160 & 165 & 180 & 145 \\
\hline Bottom Surface Temperature of Furnace Walls & $\mathrm{C}$ & 120 & 120 & 135 & 145 \\
\hline Sides Surface Temperature of the Furnace Walls & $\mathrm{C}$ & 230 & 230 & 270 & 200 \\
\hline Outer Surface Temperature of other surfaces & $\mathrm{C}$ & 280 & 285 & 290 & 143 \\
\hline Ambient Temperature & $\mathrm{C}$ & 35 & 35 & 35 & 35 \\
\hline Top Surface Area of the Furnace Walls & $\mathrm{m}^{2}$ & 12.15 & 12.15 & 12.15 & 54.3888 \\
\hline Bottom Surface Area of the Furnace Walls & $\mathrm{m}^{2}$ & 12.15 & 12.15 & 12.15 & 54.3888 \\
\hline Side Surface Area of the Furnace Walls & $\mathrm{m}^{2}$ & 30.996 & 30.996 & 30.996 & 115.4736 \\
\hline Burner and other surface area & $\mathrm{m}^{2}$ & 38 & 38 & 38 & 12 \\
\hline Heat Transfer Coefficient for Furnace walls & $\mathrm{W} / \mathrm{m}^{2} \mathrm{C}$ & 5.68 & 5.68 & 5.68 & 5.68 \\
\hline Heat Transfer Coefficient for Burner walls and Other surfaces & $\mathrm{W} / \mathrm{m}^{2} \mathrm{C}$ & 5.68 & 5.68 & 5.68 & 5.68 \\
\hline Heat Convection from the Top & $\mathrm{GJ} / \mathrm{hr} / \mathrm{kW}$ & 0.031055 & 0.032298 & 0.036024 & 33.982122 \\
\hline Heat Convection from the Bottom & $\mathrm{GJ} / \mathrm{hr} / \mathrm{kW}$ & 0.021118 & 0.021118 & 0.024844 & 33.982122 \\
\hline Heat Convection from the Sides & $\mathrm{GJ} / \mathrm{hr} / \mathrm{kW}$ & 0.123592 & 0.123592 & 0.148944 & 108.221858 \\
\hline Heat Convected through the burner and other surface & $\mathrm{GJ} / \mathrm{hr} / \mathrm{kW}$ & 0.190371 & 0.194256 & 0.198141 & 7.361280 \\
\hline & & & & & \\
\hline Total Heat Convected & $\mathbf{G J} / \mathbf{h r} / \mathbf{k W}$ & 0.366136 & 0.371263 & 0.407954 & 183.547382 \\
\hline
\end{tabular}

Figure 5.25 Heat Loss Calculations 
The heat losses are calculated with the data collected during the plant visit. The heat balance through the walls for this loss is calculated only by radiation and convection not including conduction as facility A since the insulation information on the furnace was not available with the plant personnel. The results show that a loss due to radiation is higher than the loss due to convection. This may be a result of poor insulation inside the furnace. By insulating the furnace with better material or adding another layer of insulation will reduce these losses.

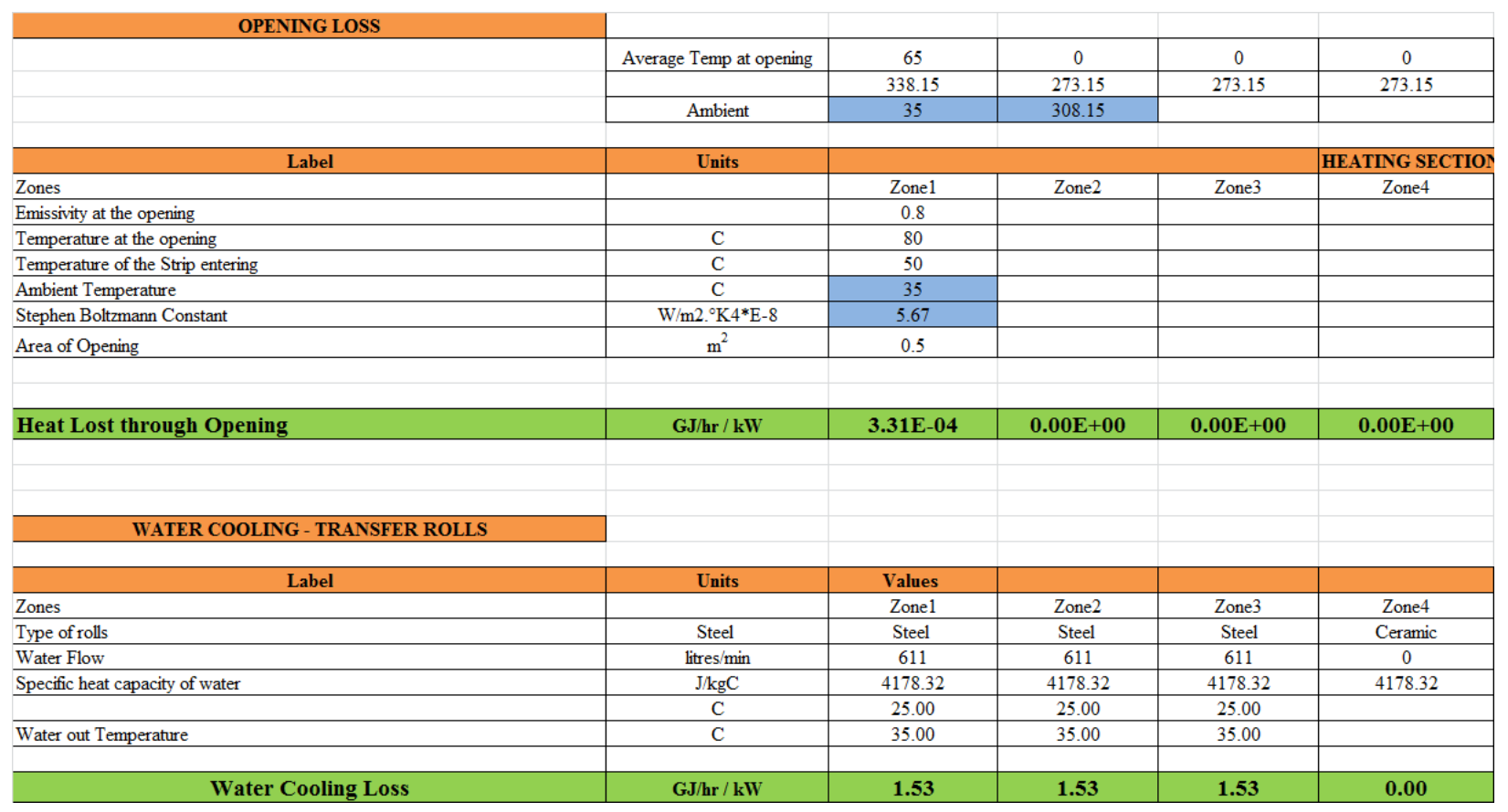

Figure 5.26 Heat Loss Calculations (Cont)

The opening loss is not significant since the opening that was present in the start of the furnace was very small to accommodate steel strip entry. The water cooling loss is observed only in first 3 zones since steel transfer rolls are used. The fourth zone is electric and has ceramic rolls inside them which does not need external water cooling. 


\begin{tabular}{|c|c|c|c|c|c|}
\hline RESULTS & & & & & \\
\hline \multicolumn{6}{|l|}{ TOTAL CALCULATED HEAT } \\
\hline & HEATING SECTION & & & & \\
\hline Heat & Units & Zonel & Zone2 & Zone3 & Zone4 \\
\hline Type of Heating & & Gas & Gas & Gas & Electric \\
\hline Radiation & $\mathrm{GJ} / \mathrm{hr} / \mathrm{kW}$ & 0.89 & 0.91 & 1.07 & 333.06 \\
\hline Convection & $\mathrm{GJ} / \mathrm{hr} / \mathrm{kW}$ & 0.37 & 0.37 & 0.41 & 183.55 \\
\hline Opening & $\mathrm{GJ} / \mathrm{hr} / \mathrm{kW}$ & 0.0003 & 0.00 & 0.00 & 0.00 \\
\hline Water Cooling & $\mathrm{GJ} / \mathrm{hr} / \mathrm{kW}$ & 1.53 & 1.53 & 1.53 & 0.00 \\
\hline Phase Change Heat & $\mathrm{GJ} / \mathrm{hr} / \mathrm{kW}$ & 0.00 & 0.00 & 0.00 & 0.00 \\
\hline Steel strip useful heat & $\mathrm{GJ} / \mathrm{hr} / \mathrm{kW}$ & 3.56 & 3.82 & 6.12 & 1263.36 \\
\hline Stack Loss & $\mathrm{GJ} / \mathrm{hr} / \mathrm{kW}$ & 4.99 & 5.04 & 8.25 & 0.00 \\
\hline Unaccounted Losses & $\mathrm{GJ} / \mathrm{hr} / \mathrm{kW}$ & 0.64 & 0.21 & 0.13 & 5742.99 \\
\hline Total Heat Dissipation Calculated & $\mathbf{G J} / \mathrm{hr} / \mathrm{kW}$ & 11.34 & 11.67 & 17.38 & 1779.96 \\
\hline
\end{tabular}

\section{Figure 5.27 Total Heat Losses (Facility B)}

The total heat loss calculations for facility B is shown in figure 5.27. This shows that the loss due to stack is much higher than the other losses. Proper measures to reduce stack losses will help to reduce the total loss from the system. 


\section{CHAPTER 6}

\section{CONCLUSION AND FUTURE WORK}

\subsection{Conclusion}

Galvanizing facilities are highly energy intensive operation with electrical and fuel energy representing a significant share of their total energy usage. Furnaces are extensively used in galvanizing process. The galvanizing industry conducts a remarkable level of ongoing research and developed a considerable knowledge base and maintains its expertise in steel coating [17]. Production process expertise along with the energy conservation practices can play a significant role in proper usage of energy at galvanizing facilities. Therefore, benchmarking galvanizing energy consumption and understanding the specific energy consumption by various elements are critical.

This research involved the analysis of galvanizing operations focusing on the furnace side of energy consumption. A user-friendly interactive model named E-GEPDSS (Enhanced Galvanizing Energy Profiler Decision Support System) was developed to enable the user to simulate the complete galvanizing process by providing information about the process and product parameters. Upon feeding the model with proper data, it has the capability of developing the heat balance of the furnace for the facility under consideration. The user can easily identify the effect of product and process parameters on energy by utilizing the model. The use of EGEPDSS does not hinder the production process and the user may run the model for different set of operating conditions and observe the results. The results obtained from the analysis will help the user to make energy enhancing decisions.

The furnace operation is identified as one of the energy intensive process in the galvanizing process. A methodology to determine their theoretical and actual energy consumption was presented along with the data collection methods. A complete heat balance for the furnace is modeled according to the data entered for a particular facility. From the energy analysis conducted for the furnace equipment at the host facility, it was found that the useful heat absorbed by the product is only $50 \%$ of the heat supplied to the furnace and rest of heat 
dissipates as losses. Energy Efficiency Measures (EEM) can be adopted and improve the efficiency of the process. Hence, it can be concluded that there is significant potential for energy savings opportunities at the overall facility level.

\section{Energy Efficiency Measures:}

1. From analysis, it was identified that heat loss due to conduction accounts for $23 \%$ of total heat supplied to the furnace. This situation can be enhanced by changing to a better insulation material as discussed in Section 5.4. Better insulation material results in less heat conducted through the furnace and holds large amount of heat inside the furnace which results in heating up the product.

2. The stack loss was another area identified for improvement. Proper amount of air-fuel ratio combustion will result in less heat loss through the stack. The heat through the stack can be recovered by heat exchangers and used to preheat the combustion air increasing combustion efficiency. Regular monitoring and regulating oxygen percentage in the stack will help to enhance the situation.

3. Proper insulation of other miscellaneous surfaces in the furnace will result in less radiation and convection heat loss.

The following research objectives were met and are as follows.

1. Development of an interactive model to estimate the energy baseline for galvanizing process.

2. Enable sensitivity analysis using the model to identify key parameters sensitive to energy.

3. Validate the model for a galvanizing facility.

As a final conclusion, benchmarking of energy levels plays an important role in the determination of energy efficiency measures and has provided ways to improve the process efficiency at the host facility. 


\subsection{Future Work}

An ongoing research is required to make the process more reliable. Any system has to be refined by including minute details that can affect the system output. The development of E-GEPDSS model in this study has given a feasible methodology to help the galvanizers analyze their furnace heat losses and benchmark it for the determination of energy efficiency measures. However, the following work would further improve the appearance, comfort, robustness, and credibility of the E-GEPDSS model.

1. Convert the model from Microsoft Excel to a user-friendly Visual Basic interface.

2. Link the model with GEPDSS to make it a complete package of energy efficiency model for galvanizers.

3. Develop alternate methods to determine the work done in cooling section.

4. Fine- tune the induction heating option in the model.

5. Improvise the model by collecting data in more detail, and verify the model to make it more reliable and universal.

6. Run the model for the data collected on process and product parameters from different galvanizing facilities.

7. Execute the model by varying inputs from the data collected and analyze the output to develop operating strategies for the production process. 


\section{REFERENCES}

1. Bhave, G. S., "Enhancing the Effectiveness of the Utility Energy Supply Chain in Integrated Steel Manufacturing" Masters Thesis, West Virginia University, Morgantown, WV, 2003.

2. "Development of Improved Materials for Continuous Steel Hot-Dipping Processes, Quarterly Report, West Virginia University Research Corporation, 2003.

3. Energy Consumption, Intermediate InfoBook, VA 2008,

http://www.need.org/needpdf/infobook_activities/IntInfo/ConsI.pdf.

4. Energy Use, Website, as on April 2010,

http://www.eia.doe.gov/emeu/mecs/iab/steel/page2d.html.

5. Bailey, R.W.,: in Proc., Second International Conference on Hot Dip Galvanizing, Düsseldorf, Germany, June 30 to July 4, 1952, Zinc Development Association, July 1953, $222-236$

6. Chavan, R. R: "Analysis of Energy Consumption in Continuous Galvanizing Lines", Masters Thesis, West Virginia University, Morgantown, WV, 2006.

7. Tang, N. Y., "Practical Applications of Phase Diagrams in Continuous Galvanizing", Journal of Phase Equilibria and Diffusion, Vol 27, 2006, pp. 462-468.

8. GalInfoNote 5, http://www.steelmillsoftheworld.com/activities/datacenter/G_Note5.pdf.

9. "US Department of Energy" - Energy Efficiency and Renewable Energy - Industrial Technologies Program" Website, as on January 2010,

http://www1.eere.energy.gov/industry/bestpractices/software.html\#phast.

10. Trinks, W., Mawhinney, M. H., Shannon, R. A., Reed, R. J., Garvey, J. R., Industrial Furnaces, 6th ed., John Wiley \& Sons, Hoboken, NJ, 2004.

11. Wu,B., Roesel,T., Elnenaey, A., Johnson, K., Atkinson, M., and Zhou, C.Q., "Numerical simulation of a direct fired preheating furnace", Department of Engineering, Purdue 
University-Calumet, Hammond IN 46323, ArcelorMittal, Global Research and Development, East Chicago, IN 46312.

12. Georgiew, A., Bonnet, U., Milani, A., "Next generation of radiant tubes for vertical galvanising lines", Salzgitter Flachstahl and WS Wärmeprozesstechnik, "Millenium Steel 2008", Pg 223.

13. Milani, A., Wünning, J.G., " Radiant tube technology for strip annealing furnaces", WS Warmeprozesstechnik, Renningen, Germany.

14. "Production of Galvannealed Steel by Induction Heating", The EPRl Center for Materials Production, http://www.p2pays.org/ref/09/08909.pdf.

15. "Annealing Furnace 1968 Model Catalogue, Serial No. 2559, Pg 13 - 15.

16. "Steel Annual Report" Industrial Technologies Program, U.S. Department of Energy Fiscal Year 2003.

17. "International Lead and Zinc Research organization", Website, as on April 2010, http://www.zincworld.org/galvanizing.html

18. Stubbles, J., "Energy Use in the US Steel Industry: An Historical Perspective and Future Oppurtunities", September 2000, pg 7 - 29.

19. Schumacher, K., Sathaye, J., "India's Iron and Steel Industry: Productivity, Energy Efficiency and Carbon Emissions", Environmental Energy Technologies Division, October 1998, pg 1- 11 .

20. "Advanced Melting Technologies:Energy Saving Concepts and Opportunities for the Metal Casting Industry", BCS, Incorporated, "US Department of energy - Energy Efficiency and Renewable Energy - Industrial Technologies program" November 2005.

http://www1.eere.energy.gov/industry/metalcasting/pdfs/advancedmeltingtechnologies.pdf 21. Yoshitani, N., Hasegawa, A., "Model-based control of strip temperature for the heating furnace in continuous annealing", Volume 6, Issue 2, Mar 1998 Page(s):146 - 156.

22. Bang, B., Chen, Z., Xu, L., Wang, J., Zhang, J., Shao, H., "The Modeling and Control of a Reheating Furnace", Proceedings of the American Control Conference, 2002. 
23. Blakley, S. G., Beck, S B M., "Energy consumption and capacity utilization of galvanizing furnaces", Proc. Institution Mechanical Engineers, Vol. 218 Part E, Journal of Process Mechanical Engineering 2004, pg 251-259.

24.Galvanizing, Website, as on January 2010,

http://www.ckit.co.za/secure/conveyor/troughed/corrosion-protection/steel-protection/steelprotection---06-galvanizing-of-sheet-metal.htm.

25. "Coating process and surface treatment", GalvInfoNote 2.7, Galvanizing-The use of chemical fluxes.

http://galvinfo.com/ginotes/GalvInfoNote_2_7.pdf

26. Kreith, F., Mark S. Bohn, " Prinicples of Heat Transfer ", Sixth edition, Asian books private Ltd. 2001.

27. Bejan, A., "Heat Transfer", John Wiley \& Sons Inc, Canada, 1993.

28. Art Galvanizing, Website, as on April 2010,

http://www.artgalvanizing.com/Process.htm

29. Drever International, Website, as on April 2010,

http://www.drever.be/doc.php?nd=111\&amp;tid=11\&amp;site=1\&amp;lg=1

30. Computational Thermodynamics, Website, as on April 2010, http://www.calphad.com/

31. Schuhmann, R., "Metallurgical Engineering", Volume 1, Addison-Wesley publishing Company, Inc, London, England, 1952.

32. Wicks, C. E, Block. F. E, "Thermodynamic properties of 65 elements", Bulletin 605, Bureau of mines, United states government printing office, Washington, 1963.

33. "Creese C. R, "Combustion \& Thermochemistry", "Cupola Handbook", 5th edition, American Foundrymen's Society, Des Plaines, Illinois, 1984.

34. http://www1.eere.energy.gov/industry/resources/ebulletin/volume47.html

35. http://www.omega.com/literature/transactions/volume1/emissivitya.html 


\section{APPENDIX A}

\section{Heat Content Constants for Metals and Gases}

\begin{tabular}{|c|c|c|c|c|c|c|c|c|c|c|}
\hline & \multicolumn{9}{|c|}{ Metals } & \multirow{3}{*}{$\mathrm{C}$} \\
\hline & \multicolumn{5}{|c|}{$\mathrm{Fe}$} & \multicolumn{2}{|c|}{$\mathrm{Al}$} & \multicolumn{2}{|c|}{$\mathrm{Zn}$} & \\
\hline & $0-1033 \mathrm{~K}$ & $\begin{array}{l}1033 \mathrm{~K}- \\
1179 \mathrm{~K}\end{array}$ & $\begin{array}{l}1179 \mathrm{~K}- \\
1674 \mathrm{~K}\end{array}$ & $\begin{array}{l}1674 \mathrm{~K}- \\
1803 \mathrm{~K}\end{array}$ & $>1803 \mathrm{~K}$ & $\begin{array}{c}0- \\
931.7 \mathrm{~K}\end{array}$ & $>931.7 \mathrm{~K}$ & $\begin{array}{c}0- \\
692.7 \mathrm{~K}\end{array}$ & $>692.7 \mathrm{~K}$ & \\
\hline & $\alpha$ & $\beta$ & $\gamma$ & $\delta$ & liq & cryst & liq & cryst & liq & Graphite \\
\hline $\mathrm{a}$ & 3.37 & 10.4 & 4.85 & 10.3 & 10 & 4.94 & 7 & 5.35 & 7.5 & 4.1 \\
\hline $\mathrm{b}$ & 0.00355 & 0 & 0.0015 & 0 & 0 & 0.00148 & 0 & 0.0012 & 0 & 0.00051 \\
\hline $\mathrm{c}$ & -0.0000043 & 0 & 0 & 0 & 0 & 0 & 0 & 0 & 0 & 210000 \\
\hline d & -1176 & -4280 & 390 & -4420 & -180 & -1605 & 330 & -1702 & -850 & -1972 \\
\hline
\end{tabular}

\begin{tabular}{|c|c|c|c|c|c|c|c|c|c|c|c|}
\hline & \multicolumn{11}{|c|}{ Gases } \\
\hline & $\begin{array}{c}\text { Rare } \\
\text { Gases }\end{array}$ & $\mathrm{CO}$ & $\mathrm{CO}_{2}$ & $\mathrm{CH}_{4}$ & $\mathrm{H}_{2}$ & $\mathrm{H}_{2} \mathrm{O}$ & $\mathrm{H}_{2} \mathrm{~S}$ & $\mathrm{~N}_{2}$ & $\mathrm{O}_{2}$ & $\mathrm{SO}_{2}$ & $\mathrm{SO}_{3}$ \\
\hline $\mathrm{a}$ & 4.969 & 6.79 & 10.55 & 5.65 & 6.52 & 7.17 & 7.02 & 6.66 & 7.16 & 10.38 & 13.7 \\
\hline $\mathrm{b}$ & 0 & 0.0005 & 0.00108 & 0.00572 & 0.0004 & 0.00128 & 0.00184 & 0.00051 & 0.0005 & 0.00127 & 0.00321 \\
\hline $\mathrm{c}$ & 0 & 0.0000011 & 0.0000204 & 0.0000046 & $-1.2 \mathrm{E}-06$ & -0.0000008 & 0 & 0 & 0.000004 & 0.0000142 & 0.0000312 \\
\hline d & -1481.6 & -2105 & -3926 & -2347 & -1939 & -2225 & -2257 & -2031 & -2313 & -3683 & -5417 \\
\hline
\end{tabular}




\section{APPENDIX B}

\section{Combustion Efficiency}

\begin{tabular}{|c|c|c|c|c|c|c|c|c|}
\hline COMBLSTION EFFICIENCY & & & & & & & & \\
\hline Combustion Efficiency & Units & Zonel & Zone2 & Zone3 & Zonet & Zones & Zone6 & Zone? \\
\hline$E A=$ excess air $(0=$ stoch, $0.1=$ optimum $)$ & & 0.117 & 0.084 & 0.115 & 0.104 & 0.095 & 0.115 & 0.086 \\
\hline$T_{c a}=$ temperature combustion air before burner $(\mathrm{F})$ & $\mathrm{F}$ & 300 & 300 & 300 & 300 & 300 & 300 & 300 \\
\hline Tex $=$ temperature exhaust gasses $(F)$ & $\mathrm{F}$ & 850 & 860 & 850 & 880 & 880 & 850 & 860 \\
\hline \multicolumn{9}{|l|}{ Constants for natural gas } \\
\hline $\mathrm{LHV}=$ lower heating value (Btullb) & Btullb & 21500 & 21500 & 21500 & 21500 & 21500 & 21500 & 21500 \\
\hline $\mathrm{HHV}=$ higher heating value (Btullb) & Btullb & 23900 & 23900 & 23900 & 23900 & 23900 & 23900 & 23900 \\
\hline$c p p=$ specific heat of products of exhaust (Btullb-F) & Btullb-F & 0.26 & 0.26 & 0.26 & 0.26 & 0.26 & 0.26 & 0.26 \\
\hline Idpp = dew point temp of $\mathrm{H}_{2} \mathrm{O}$ in exhaust $(\mathrm{F})$ & F & 140 & 140 & 140 & 140 & 140 & 140 & 140 \\
\hline Afs = airffuel mass ratio at stochiometric conditions & & 18 & 18 & 18 & 18 & 18 & 18 & 18 \\
\hline \multicolumn{9}{|l|}{ Combustion Efficiency Calculations } \\
\hline hr $=$ heat of reaction $=(\mathbb{f} T$ ex $<140$ then $h r=H H V$ else hr $=\mathrm{LHV})$ & & 21500.00 & 21500.00 & 21500.00 & 21500.00 & 21500.00 & 21500.00 & 21500.00 \\
\hline $\mathrm{Tc}=$ temp combustion $(\mathrm{F})=\mathrm{Tca}_{\mathrm{c}}+\mathrm{hr}[(1+(1+\mathrm{EA})(\mathrm{Afs})) \mathrm{cpp}]$ & & 4191.90 & 4441.85 & 4209.73 & 4286.62 & 4357.38 & 4209.73 & 4425.87 \\
\hline Efficiency $=[1+(1+\mathrm{EA})(\mathrm{AFs})]^{*} \mathrm{c}(\mathrm{pp})^{*}(\mathrm{Tc}-\mathrm{Tex}) \mathrm{HHV}$ & & $77.25 \%$ & $77.80 \%$ & $77.30 \%$ & $76.87 \%$ & $77.10 \%$ & $77.30 \%$ & $77.75 \%$ \\
\hline
\end{tabular}

